Portland State University

PDXScholar

Spring 5-28-2014

\title{
Mediating Academic Success: Race, Class, Gender and Community College Persistence
}

Schaylee Marie Esparza

Portland State University

Follow this and additional works at: https://pdxscholar.library.pdx.edu/open_access_etds

Part of the Sociology Commons

Let us know how access to this document benefits you.

\section{Recommended Citation}

Esparza, Schaylee Marie, "Mediating Academic Success: Race, Class, Gender and Community College Persistence" (2014). Dissertations and Theses. Paper 2019.

https://doi.org/10.15760/etd.2018

This Thesis is brought to you for free and open access. It has been accepted for inclusion in Dissertations and Theses by an authorized administrator of PDXScholar. Please contact us if we can make this document more accessible: pdxscholar@pdx.edu. 
Mediating Academic Success: Race, Class, Gender and Community College Persistence

by

Schaylee Marie Esparza

A thesis submitted in partial fulfillment of the requirements for the degree of

\author{
Master of Arts \\ in \\ Sociology
}
Thesis Committee:
José Padín, Chair
Peter Collier
Maura Kelly

\title{
Portland State University
}

2014 
(C) 2014 Schaylee Marie Esparza 


\begin{abstract}
Over the last forty years, the U.S. community college system has expanded, allowing disadvantaged groups greater access to higher education. With that expansion, a body of research has emerged examining community college students' educational outcomes. However, the research is limited in understanding the academic persistence of low-income students and community college student in particular. The purpose of this comparative, qualitative study is to explore some of the unanswered questions about how low income white and Latino students' experience academic persistence similarly and differently and understand how gender influences the challenges students may face during college.

This study draws from interviews of 22 (11 White/11 Latino/a) low-income community college students at a rural, Hispanic-Serving Institution (HSI) in the West. All students share similar challenges because of their class constraints, but Latino/a students in particular face challenges of racism and discrimination that carried over into their college careers. Faculty and family are the key sources of support for all students, which mediate some of the challenges. Variation is seen between the experiences of males and females, as traditional gender roles are reinforced and maintained in the family. This study offers insights into how structural inequality creates barriers for students from their perspective and gives recommendations for practitioners on how to mediate some of these challenges and increase student persistence.
\end{abstract}




\section{DEDICATION}

This thesis is dedicated to my husband and partner, José Esparza. Without all of your love, sacrifice and advice, this project would not have been possible. Your own story is an inspiration to many others and myself. I also wanted to dedicate this work to the many students, future students and family members that are struggling along the way in obtaining their degree. To those that are living in the shadows or question their place in higher education-your stories are inspiring and valuable. Finally, I dedicate this "book", as my children call it, to Mateo and Noelia. You keep me going and make all of my work meaningful. 


\section{ACKNOWLEDGEMENTS}

I would like to thank a number of individuals that helped with this research project. First of all, I would like to thank Dr. José Padín for his mentorship, guidance and enthusiasm for this project. I also owe my sincere gratitude to those at Small Town Community College. Without their support, guidance and connection to students this would not have been possible. I would especially like to thank those administrators and staff members for their effort in getting the project off the ground and identifying students. I also need to recognize the amazing recruitment efforts of those key individuals in student services for your support and connection to students. I would also like to recognize Christa Zinke for her efforts in traveling back and forth over a tight time frame to gather interviews. Your commitment to this project was enduring. Your work enhanced and strengthened this project. I am indebted to you. I would also like to recognize José Esparza for his recruitment efforts, valuable perspective and endless support of this project and our family. Finally, but most importantly, I would like to thank all those students that participated in this study and shared your stories. I am grateful for your time and feel privileged to share your stories. 


\section{TABLE OF CONTENTS}

Abstract..........................

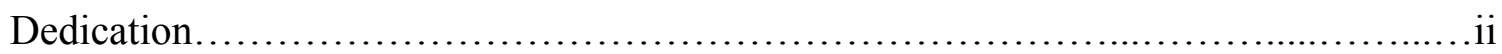

Acknowledgements...........................................................

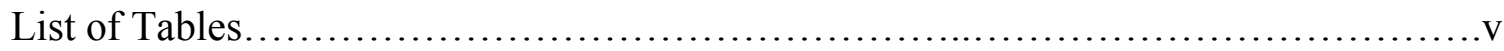

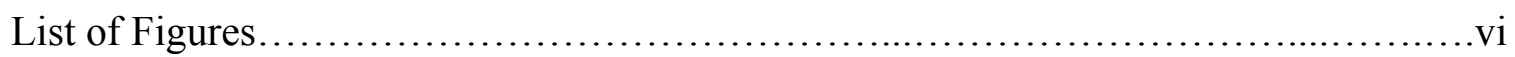

\section{Chapter I}

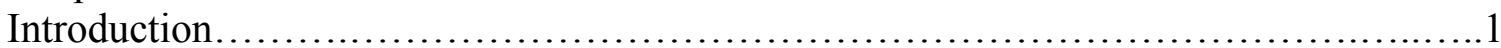

Chapter II

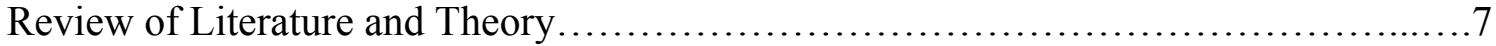

Chapter III

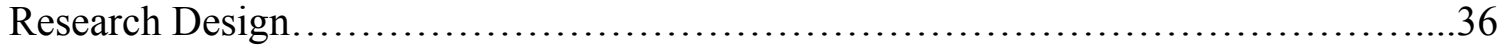

Chapter IV

Common Class Experiences..................................................53

Chapter V

Exploring Racial-Ethnic Differences......................................... 80

Chapter VI

Gendered Experiences of Academic Persistence..................................111

Chapter VII

Discussion and Conclusion................................................... 142

Epilogue............................................................... 165

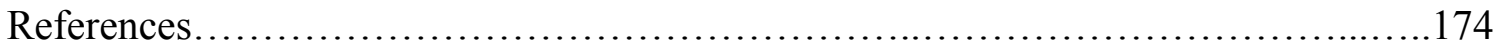

Appendices

A. Interview Protocol................................................. 182

B. Code Book............................................................ 188

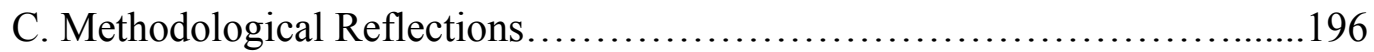




\section{LIST OF TABLES}

Table 1: Codebook Revisions.....................................................49 


\section{LIST OF FIGURES}

Figure 1: Social Reproduction Theory..................................................................12

Figure 2: Influences of Academic Success Among Low-Income Students.......................31

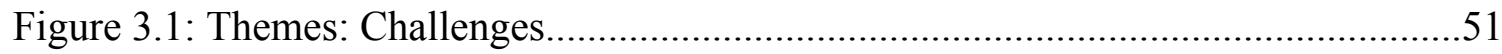

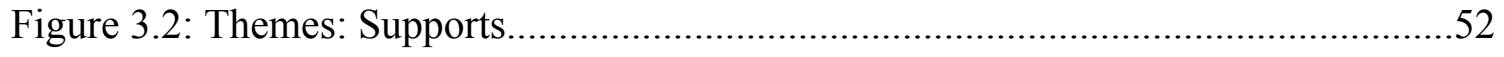

Figure 4: Racial-Ethnic Differences.....................................................................145

Figure 5: Gendered Intersections.....................................................................150 


\section{CHAPTER I: INTRODUCTION}

Over the last forty years, the U.S. community college system has expanded, allowing disadvantaged groups greater access to higher education. With that expansion, a body of research has emerged examining community college students' educational outcomes. However, the research is limited in understanding the academic persistence of low-income students. Low-income students are overrepresented at community colleges and are less likely to complete degrees. Only $23 \%$ complete their degrees, as compared to $53 \%$ of students that earn a degree at 4-year institutions (IPED 2010).

Similarly, Latinos attend community colleges at higher rates than other institutions of higher education. Over $50 \%$ of all Latinos attending post-secondary education are enrolled at community colleges, yet only $10.5 \%$ complete associate degrees (IPED 2010). Additionally, previous research has identified a growing gender gap in college completion. Women earn $58 \%$ of all Bachelor degrees in the United States (Snyder, Dillow, and Hoffman 2008). The statistics for Latinos/as reflect an even greater gender gap. Among Latinos, 61\% of Bachelor's degrees are earned by females (Buchmann, DiPrete, and McDaniel 2008). Latinas are more likely to complete their college degrees within six years, with $50 \%$ of females completing on-time, as compared to $43 \%$ of males completing on-time (Snyder et al. 2008).

Previous quantitative research has identified a significant difference in educational attainment between males and females (Buchmann et al. 2008; Buchmann and DiPrete 2006; Feliciano and Rubén G Rumbaut 2005; Feliciano 2012; Saenz and Ponjuan 2009), but is limited in describing how individual students experience these differences and how they may influence academic success. There is a pressing need to 
further theoretical understanding of the experiences of low-income and Latino students attending community college, considering their high rates of attendance and lack of completion.

Answered and Unanswered Questions About Academic Persistence

Social class is a primary factor negatively influencing the academic persistence of both low income and Latino students (Goldrick-Rab 2006; Porchea JeffRobbins, StevePhelps, Richard P. 2010; Strayhorn 2010; Walpole 2003). Students from lowincome families and parents that have not attended college are less likely to persist. High school academic preparation, including grades, GPA and course taking, is strongly correlated with academic persistence. Those students taking more advanced courses, earning higher grades and maintaining a higher GPA were more likely to persist (BordesEdgar et al. 2011; Porchea JeffRobbins, StevePhelps, Richard P. 2010)

Additionally, students with strong social networks of family, friends, classmates and faculty are more likely to persist (Bordes-Edgar et al. 2011; Espinoza-Herold 2007; Gloria, Castellanos, Lopez, et al. 2005). Past studies have also identified the importance of mentoring on the academic success of low income and Latino students (Crisp and Nora 2010; Porchea JeffRobbins, StevePhelps, Richard P. 2010). Furthermore, previous literature clearly identifies gender and race-ethnic group as strong predictors of success. Females in every race and ethnic group are more likely to persist and earn degrees, though white females are the most likely to persist. Low- income white and Latino males are the most underrepresented groups in college and are the least likely to persist (Barajas and Pierce 2001; Buchmann et al. 2008; Buchmann and DiPrete 2006; Feliciano 2012). 
However, there are some factors that seem to influence academic persistence both positively and negatively. For low-income students it is unclear if work, financial aid awards, grants and students' age positively or negatively influence persistence (Dowd and Coury 2006; Mamiseishvili 2010). For Latino students it is unclear if social class plays as great of role influencing persistence as it does for white students (Strayhorn 2010).

Findings on involvement in organizations and campus climate are also somewhat contradictory for Latinos, suggesting that the type of organization in addition to the campus racial climate may influence their success differently (Crisp and Nora 2010; Hurtado and Carter 1997; Hurtado and Ponjuan 2005). Furthermore, it is unclear as to how family may both act as a support and challenge to Latino students' academic persistence, or if this may be different depending on one's gender (Muñoz and Maldonado 2011; Ojeda, Navarro, and Morales 2011; Saenz and Ponjuan 2009).

The purpose of this study is to explore some of the unanswered questions about how low income white and Latino community college students' experiences of academic persistence at a rural, Hispanic-Serving Institution (HSI) in the West. This site differs in context from previous studies, making it an opportune site to explore how the context may influence academic persistence differently than previous studies. The current body of research has focused on experiences of low-income students at large 4-year institutions. The context of this particular community college may impact student academic experiences differently.

Additionally, previous research on persistence has examined the challenges for Latinos, and for low-income students. There is significant overlap between these two 
categories, but a problem exists in that some "Latino" barriers identified in the literature may in fact be class barriers. Similarly, barriers to persistence found in studies of lowincome students may not operate in the same fashion across ethnic and racial groups. The study will examine the experiences of low-income community college students from two ethnic/racial groups, Whites and Latinos. The secondary purpose of the study is to understand shared class challenges, and the differences that can be properly attributed to ethnicity-race. Finally, this study explores the gendered challenges to academic persistence that may be experienced differently by low income White and Latino students.

For the purpose of this study, academic persistence will be defined as being within one quarter of graduation while in pursuit of an Associate's Transfer Degree. Academic persistence has previously been defined as continued enrollment from one quarter to the next (Sheffield 2011). This definition assumes students' persistence will follow a linear path culminating in degree attainment, when in fact credit threshold is a more predictive measure of graduation (Adelman 1999). This study will examine how students persist despite encountering barriers, and does not assume a linear path to completion. By examining students' experiences of academic persistence and overcoming challenges, the study will contribute theoretical knowledge and has the potential to inform future policy in the community college system.

This qualitative study is designed as a comparative in-depth interview study. Semi-structured interviews provide "deep meaning of experience in the participants' own words" (Marshall and Rossman 2010). A qualitative approach is necessary to explore students' experiences of persistence to uncover deep understanding of the complex 
processes of culture, identity gender. Qualitative methodology will allow for understanding of how the processes manifest themselves in the lives of individual students and yet is flexible enough to allow for the emergence of new meaning and theory. Additionally, a comparative qualitative approach provides a utile design to examine the similarities and differences between racial-ethnic groups and gender. Therefore, the primary research questions for this project are: How do students understand what supports their academic persistence? How do students understand what challenges their academic persistence? How do students' identities influence their understanding of supports and challenges to their academic persistence?

In order to explore the similarities and differences the following research sub-questions guide the study:

1. How are low- income white students' experiences of academic persistence similar to low income Latinos' experiences? How are they different?

1a. Which of these differences are related to low income students' culture? 1b. Which of these differences are related to experiences of prejudice? 1c. Which are the products of other experiences that vary between the groups?

2. How does gender influence the experiences of academic persistence of low income students?

2a. How are low income white male students' experiences similar to low income white females' experiences? How are they different? 
2b. How are low income Latino male students' experiences similar to low income Latina female students' experiences? How are they different?

2c. How are the women's experiences similar and different between these two groups, low income Latinas and low income whites? 


\section{CHAPTER II: REVIEW OF LITERATURE AND THEORY}

This chapter discusses previous literature, outlines the theoretical framework that has developed during this study and describes the empirical model that is used to guide the analysis in the following chapters. Previous studies and models have established the many barriers low-income students face in both college access and completion. The numbers suggest there is a persistent gap in completion between students coming from lower economic statuses, students of color and males (Fry \& Center 2002; NCES 2012; Buchmann \& DiPrete 2008). Most low-income students struggle to complete college, but contrary to larger demographic trends, some students are able to persist through graduation. It is important to understand how students overcome the barriers identified in previous literature to further theoretical understanding and inform practice.

Developing a theoretical frame that is grounded in the empirical world allows for the in-depth analysis of how students encounter these barriers and the mechanisms they employ to overcome them for academic success. Considering previous models and studies, I take a multi-dimensional theoretical approach in building this framework because of the complexity of process and the variance in students' identities. This empirical model is grounded in the following theoretical frameworks: 1) Social Reproduction Theory, 2) Community Cultural Wealth/Critical Race Theory, and 3) Feminist Theory. While this study specifically explores the outcome of persistence, I will review the literature and theorize more generally about academic success, as the final outcome of persistence is degree completion. 


\section{Models of Student Persistence}

Academic persistence is a complex process and varies depending on students' social class, family, pre-college experiences, race-ethnicity, culture, context and gender. Over the past few decades, the majority of studies on student retention, academic persistence, and student social characteristics draw from Tinto's (1987) Student Departure Model. According to Tinto's model, students' social and academic integration contribute to student persistence, since the combination of these factors influences students' goal commitments and institution commitments that ultimately determine dropout decisions. For Tinto, integration occurs through three stages: separation, transmission, and finally incorporation.

In the first stage of separation, students much distance themselves from their past communities and social ties. Students break ties with family, high school associations and their place of previous residence. Students must separate from "past habits and patterns of affiliation" (Tinto 1987: 443). However, students that live at home may not be able to disassociate themselves with past ties, as they are still immersed in their home communities. Tinto suggests that for these students they will be at a disadvantage and will not benefit from the full experience of being a college student and persistence will be more difficult.

In the second stage of transmission students acquire new norms of the college culture. Students are not fully members of this new community and are floating in between the their past associations and their new community. They are in the process of forming new relationships. Tinto (1987) argues that students experience a sense of bewilderment during this stage, as it is a stressful point along the continuum. He argues 
that the stress itself is not a source of departure, but a student's individual response to that stress determines persistence or departure decisions. Some individuals are better able to cope with the stress of change and transition, whereas others will depart. He suggests that students coming from backgrounds that do not match the institution's goals and norms will be at a disadvantage during this stage and are at a greater risk for departure.

Similarly, he suggests that students living at home during this stage will be at a greater risk for departure because they have had less presence on campus, form fewer social bonds and will therefore be less likely to acquire the norms of the institution.

Finally, students that do persist move into the incorporation stage. In this stage, Tinto suggests that students either integrate fully into the institution or risk departure. To a certain extent colleges and universities promote integration through programs, such as orientations, but these are temporary and do not ensure full integration. Students may come into contact with other programs such as student organizations, clubs, fraternities and extracurricular programs. Involvement promotes academic and social connection. If involved in these types of programs, Tinto suggests that incorporation will be encouraged and sustained, leading to persistence. Students that do not incorporate into the institution are more likely to depart because they have not adopted the values and norms of the institution. Again, involvement and connection is dependent upon the individual student's effort to become involved in these types of programs.

However, after receiving criticism in recent years, Tinto's original theoretical framework has been updated to reflect more cultural sensitivity, using words like connection and engagement to replace integration. Guiffrida (2006) asserts that greater cultural sensitivity includes taking into account the norms of more diverse student 
populations. According to Guiffrida (2006), taking cultural norms into account allows researchers to develop a theoretical framework that applies to more diverse student populations. Guiffrida (2006) adapted Tinto's Model of Student Departure (1987) to include students' cultural values and norms as Pre-Entry Attributes. He suggests that students coming from a more collectivist culture, versus an individualist oriented culture, do not separate from their home communities. In fact, the home community and family are important for student persistence. Students with this orientation may need to maintain connection with these ties in order to be academically successful.

Additionally, Guiffrida suggests that students' Motivational Orientation should be considered in Tinto's model. Guiffrida argues that a student's orientation will be influenced by one's culture. Minority students are more likely to adhere to extrinsic motivation, citing students' desire to finish college. White students are more likely to adhere to intrinsic motivation, valuing a commitment to academic involvement and the commitment to the institution (Guiffrida 2006). A student's motivational orientation is influential both at the transition and incorporation stages of Tinto's model.

Contrary to Tinto's stage of separation, Guiffrida (2006) argues that may not need to separate themselves from their past relationships and home communities. In fact, he argues that family and home community relationships may positively influence students' motivational orientation. Students living at home may experience support and accountability from their families and friends even if they do not integrate into the college culture.

Tinto and Guiffrida's Models of Student Departure (2006) may be useful in understanding the departure decisions of college students, but they are limited in 
explaining how students overcome barriers to their success. The educational theories tend to treat students as individual actors, and minimize the influence of structural barriers to persistence. In light of these models, Bourdieu's theory of Social Reproduction (1977) may be more useful framework to understand how students have persisted academically despite the structural barriers to their success.

\section{SOCIAL REPRODUCATION THEORY}

Bourdieu's Social Reproduction Theory (1977) is commonly used in sociology of education particularly when studying social class. Bourdieu refers to the institution of education as the field. The field acts as a structured social space that determines the value of different kinds of resources and "capital" (Thompson 1991). The elite dominate the social structure, allowing those that have power to remain in power and control scare resources. Education is important then for maintaining the social structure and distinction of the classes.

Bourdieu's framework considers the influence of social class, family and precollege contexts in this process, which are not absent of historical and material influences. In order for the system of inequality to be maintained the distribution of power and resources need to be reproduced. This is not done so through force nor coercion, but through socialization of one's habitus. Habitus mediates between the objective structure and internalized disposition to shape students' practice or actions (Harker 1984). In this sense, Bourdieu's framework is useful for examining how students confront the objective barriers to academic success while simultaneously experiencing those barriers as subjective realities. Habitus is not static or fixed, but is a dialectical 
process that constantly adjusts to objective conditions and realities to shape practice (Harker 1984).

Figure 1 Social Reproduction Theory

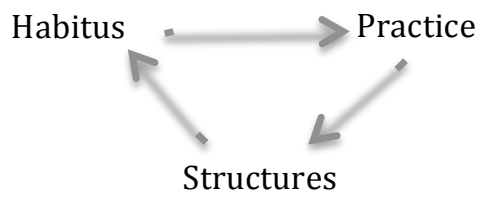

(Harker 1984)

A student's habitus both shapes and is shaped by objective structures (e.g. family, education). Practice depends on how students are socialized to respond to the structures and the capital they have available. Bourdieu's distinction of types of capital is important to note, because students' available capital is dependent upon their social class, family background and pre-college context. Bourdieu identifies four types of capital: economic, symbolic, social and cultural. Economic capital refers to the available physical resources such as income, wealth and assets. Low-income students are objectively limited by their lack of economic capital, which is a significant barrier to college access and completion. Income level is a strong predictor of educational success (Goldrick-Rab 2006; Porchea J.R., Phelps, S., Richard P. 2010; Strayhorn 2010; Walpole 2003). Students' low level of economic capital is limiting before they even enter college. They have less access to high quality schools, advanced coursework and well-prepared staff and teachers, which is correlated with higher academic achievement. The achievement is translated into what Bourdieu describes as, symbolic capital. Symbolic capital is the value exchange all other forms of capital have in the dominant field. For example, student achievement is translated into grades or grade point average. The symbolic capital is validated only in 
the field. Those students that follow the rules and perform accordingly receive greater symbolic capital.

Social capital provides access to resources through social networks and connections. The more social capital one has, the greater the access to valuable resources and information. Previous studies have suggested that low-income students and females in particular may have a greater degree of social capital to navigate the educational context successfully in the form of support from family, friends and faculty (BARAJAS and PIERCE 2001; Bordes-Edgar et al. 2011; Feliciano and Rubén G Rumbaut 2005; Feliciano 2012; Gloria, Castellanos, and Orozco 2005).

Finally, cultural capital refers to the ways of knowing, thinking and acting that are consistent with the dominant culture, particularly in the educational setting. Students coming from working class backgrounds may use different language patterns, have subtle behavioral differences and be limited in their knowledge of the dominant culture. Therefore, their cultural capital has a lower exchange value in the educational setting. Educational actors, such as teachers and instructors, praise and give value to the language and behavior of the dominant class. Annette Lareau thoroughly documents and analyzes these sometimes subtle, yet distinct differences in Unequal Childhoods (2011). Though these differences seem to be materialized at the individual familial level, the impact on working class children's education has a reproductive impact. Working class children receive less academic preparation in the home, less interaction with adults and feel less entitled to advocate for their needs. Lareau does highlight that working class children do have more opportunities to become independent, are taught to respect adults and value hard work, but these are not consistently rewarded in the educational context. Their 
opportunities then are limited in a subjective sense because of the diminished value of their cultural capital, whereas middle and upper middle children's cultural capital is rewarded in the educational setting.

In the following sections I will use the framework of social reproduction theory to discuss in more detail the influences of social class, family background, and pre-college experiences on academic success and how they influence academic success.

\section{Social Class}

Social class barriers to educational success are well documented by previous studies. Students from low-income families are less likely to persist in community college. In addition to family background, students' income level is predictive of persistence. Low-income students are less likely to persist and graduate (D’Amico et al. 2011; Paulsen and St. John 2002). Student income-level represents an objective class reality of students' class background. Students are limited by lack of resources, or economic capital, which prompts the need to work, apply for financial aid, and may reproduce the cycle of unequal academic incomes (Dowd and Coury 2006). The need to pay for tuition or related college expenses increases for low-income students. Students then work part-time or full-time, which has been associated with decreased likelihood of transferring and degree completion (Dougherty and Kinzel 2006; Eddy, Christie and Rao 2006; Lee and Frank 1990; O'Connor and Noga 2009). The need to work draws students' time away from academic work, and therefore less likely to spend time studying, being involved on campus (Walpole 2003). The objective reality of time and income constraints then limits the educational attainment of students.

\section{Family Background}


These class constraints are not simply experienced objectively, but are internalized subjectively in students' habitus through the socialization process. Students learn about what is possible and what constrains their future within the context of the family. Previous research indicates that familial values towards education influence student satisfaction (Dixon Rayle et al 2006). Students from families who highly value education are more likely to have greater levels of self-esteem and self-efficacy while demonstrating significantly lower levels of academic stress, all of which factor into a student's persistence (2006).

Similarly for Latino students, Ojeda, Navarro and Morales's (2011) identified familismo as a mediating variable in predicting persistence. Familismo is defined as strong commitment and obligation to the nuclear and extended family network (Sabogal et al. 1987). In Ojeda et al's (2011) study, they found that familismo mediated parental encouragement and conversations about college. Students were strongly committed to the family, took pride in their role as family member, and found support from their family, which contributed to persistence intentions. Additionally, students who expressed a close relationship with their mothers received more support, which helped them to succeed (Espinoza-Herold 2007). Strayhorn's (2010) study of Latino and African American men confirms these themes, finding that Latino males benefit in greater degree from conversations with parents regarding educational goals.

The empirical data highlights the way in which habitus can positively impact what students see is possible. The role of the family is generally the primary mechanism by which students are socialized. Students first encounter ways of understanding their objective realities through relationships within the family. Not all of these relationships 
remain salient over time, but previous studies suggest that they are important for educational success. Maintaining close relationships with family may be associated with increased levels of social capital necessary for academic success (Barajas and Pierce 2001; Feliciano and Rumbaut 2005; Feliciano 2012). Social support from family, friends and faculty was the greatest predictor among Latinos at universities (Bordes-Edgar et al. 2011; Gloria, Castellanos, and Orozco 2005).

Additionally, students' habitus and cultural capital is shaped by parental educational level. Parents' level of education also has a positive association with education related outcomes like transferring and persistence (Crisp and Nora 2010; Porchea et al 2005). Parents or family members that have attended college increased level of cultural capital that can be passed onto their children. College-educated parents may be more able to pass on the ways of thinking, knowing and being, that are valued in the field of higher education. Students that are the first to attend college in their family may be disadvantaged, as they may lack the habitus and cultural capital necessary to navigate within the unfamiliar context of higher education (Collier and Morgan 2008).

\section{Pre-College Experiences and Academic Preparation}

In addition to the factors mentioned above, there are several additional factors that contribute to student persistence and success, including academic preparation. Students entering college more academically prepared are more likely to persist and transfer than less prepared students enrolled in developmental courses (D'Amico, 2011, Crisp \& Nora 2010; Dougherty and Kienzl 2006; Porchea J.R., Phelps, S., Richard P. 2010). Buchman and DiPrete (2006) also found that women are more likely to be academically prepared 
when entering college compared to their male counterparts, which increases the likelihood of degree completion.

Similarly, Latino students that higher GPA's and grades in high school were more likely to persist and graduate from college (Bordes-Edgar, Arrendondo, Kurpius and Rund 2011). Students that had taken higher-level math courses in high school were also more likely to graduate and transfer (Crisp and Nora 2010). Those students that are able to successfully navigate through the dominant field of education, by taking advanced courses and earning higher grades, are at an advantage in the field of higher education. In each of these studies, social class remains the strongest predictor in addition to preparation. Teachers and educators value and reward the cultural speech, mannerisms and behaviors of middle and upper class students. Therefore, students with higher social class backgrounds have cultural capital that can be translated into symbolic capital that is valued in the educational field (Bourdieu 1984). In short, these students begin their careers in higher education at a different starting point because of their cultural capital, which is translated into academic preparation for college.

\section{RACE AND CULTURE: CRITICAL RACE THEORY (CRT) IN EDUCATION}

Critical Race Theory (CRT) suggests that one's habitus is influenced by one's race, culture and gender. It acknowledges that inequality is experienced on a continuum of these intersecting forms of oppression which act as barriers to educational success (Muñoz and Maldonado 2011; O Villalpando 2004). Despite the many barriers low income and Latino/a students face, some are able to navigate the system and find success. CRT framework examines how culture, race-ethnicity and the context interact to explain how students persist despite their lack of assimilation (Bernal 2002; Muñoz and 
Maldonado 2011). Yosso (2013) asserts that communities of color possess community cultural wealth, which helps them navigate and survive in the dominant structures of society. Communities of color cannot fully assimilate to the dominant culture because skin color has historically been used as a marker of culture. Therefore, they have passed on other forms of capital primarily through the family to ensure survival of future generations. The community wealth is not necessarily of value in the dominant culture, but is necessary to resist the oppressive structures.

\section{Culture as a Resource: Community Cultural Wealth}

Yosso (2013) outlines six types of community cultural wealth: aspirational capital, linguistic capital, familial capital, social capital, navigational capital and resistant capital. Aspirational capital refers to the ability to maintain high hopes and dreams in the face of real obstacles and barriers. Previous studies found the positive impact of college aspirations on degree attainment for Latino/a students. Children whose parents have high expectations are more likely to graduate and attend college (Feliciano and Rubén G Rumbaut 2005; Feliciano 2012; Portes and R G Rumbaut 2001; Strayhorn 2010). Yosso argues that Latinos maintain high aspirations despite having the lowest educational achievement.

These aspirations are cultivated and communicated within the family. Parents share their aspirations and expectations for their children through what Yosso terms, linguistic capital. Linguistic capital refers to the ability of the community to communicate a shared history through storytelling and parables. Additionally, students' bilingual ability helps them develop a cross-cultural understanding and awareness, which aids in the development of academic and cognitive skills. More recent qualitative studies 
have highlighted the ways in which students receive advice and motivation through consejos, dichos and storytelling. Students are able to navigate systems using these "survival skills" or cultural resources passed on through familial relationships (Campa 2010). Espinoza-Herold (2007) found that Latina students receive support from their mothers in the form of dichos or consejos when faced with barriers during college. Nondominant language then acts as a supportive mechanism when confronted with dominant barriers to success.

Familial capital refers to the sense of shared community history, memory and culture. Previous literature finds that Latinos/as have a broad sense of kinship, which helps them maintain ties and connection (Ferrari 2002; Valenzuela and Dornbusch 1994). This type of capital is different from social capital because it is a consciousness of collective orientation. Previous literature uses the term familismo to describe and define this orientation as the cultural value characterized by strong commitment and obligation to both the nuclear and extended family, embodying the ideals of loyalty, responsibility, interdependence, collectivism and reciprocity (Marin \& Marin 1991; Suarez-Orozco \& Suarez-Orozco 1995). Commitment to familismo has been argued to be both a potential barrier and resource to Latinos educational success. Espinoza's (2010) recent study of female doctoral students found that family obligations added to stress and created challenges in meeting competing obligations. She found that Latinas chose to stay close to home in order to fulfill their familial roles and spend more time with family members. Other research suggests that Latinos' high commitment to collectivism may help students navigate and persist in post-secondary education, which is characterized by highly individualistic culture (Hardway and Fuligni 2006). Valenzuela's work suggests 
that familismo cultivates strong social networks and social capital necessary for educational attainment (1990). She argues that cultural identity is essential for academic persistence and success (Valenzuela 1999). The work of Valenzuela provides valuable insight into the ways in which familial culture may act as a resource.

Social capital, similar to Bourdieu's definition, is the network of social relationships in which members share resources and information. The primary mechanism for transmission of the social capital is the family network. The network provides both tangible and emotional support, which helps members deal with adversity and daily challenges (Yosso 2013). According to previous studies, social class and academic preparation may not be as strong of an indicator of academic success for Latino students as other racial and ethnic groups (Hurtado, Silva, Carter and Faye 1997; Strayhorn 2010). In fact, social support may be the strongest indicator of success for Latino/a students (Gloria, Castellanos, Lopez, Rosales 2005).

Translating Cultural Wealth to Navigate Higher Education

Within the context of higher education, individuals as well as the larger cultural community have agency to access resources even though their knowledge of the dominant culture may be limited. Students and communities use their navigational capital to navigate institutions of the dominant culture. In the later sense, navigational capital is dependent upon the social capital of the group or family. Social networks help students to access resources and information, giving them tools to navigate within the institution of higher education. Campa's study highlights this, explaining how students have learned to "play the game" in higher education (2010). They learn how to speak, act and address faculty and staff members at the institution, showing "respeto," while 
learning to be assertive and meeting their needs. They understand the cultural capital needed in the context of the dominant culture, but do not to assimilate.

Instead students maintain their cultural identity while navigating the institution. For students of color, navigational capital is a part of everyday life, experienced over their lifetime as they come into contact with institutions designed for White people (Sólorzano, Octavio Villalpando, and Oseguera 2005). Maintaining in-group ties, and outer group ties within the dominant culture has found to be a strong predictor of academic success for Latinos/as. Those students that did not have strong in group ties were more likely to drop out of school and experience academic failure (Altschul, Oyserman, and Bybee 2008; Portes and R G Rumbaut 2001). The findings were salient even when students experienced racism in their community or on their campus. In fact, students that were involved in organizations such as $\mathrm{MEChA}^{1}$, were more likely to have negative perceptions of the campus racial climate and had greater academic success (Hurtado and Carter 1997).

\section{Campus Context and Culture}

Cultural context of the campus did have an impact, but it was mediated by cultural organizations (Hurtado and Ponjuan 2005). Those students that felt "at home" on campus, or felt that the campus was congruent with their own culture, had a decreased sense of barriers to their academic achievement (Crisp and Nora 2010; Gloria, Castellanos, and Orozco 2005; Gloria, Castellanos, Lopez, et al. 2005). Crisp and Nora's

${ }^{1}$ Movemiento Estudiantile Chicano/a de Azatlan. 
(2010) study on Hispanic Serving Institutions (HSI) ${ }^{2}$ found that Latino students attending HSI's are more likely to graduate and have academic success. It is unclear to whether the context of these institutions is influential or if the density of the Latino/a student population is the causal factor. By maintaining these cultural ties, students are able to navigate the institutional context, whether it is congruent or incongruent with their culture of origin.

Using Cultural Wealth for Resistance

Cultural wealth then acts as a resource when students translate their wealth to navigate the institutional barriers to educational success. The process is dependent upon students' resistance to the structural constraints they face because of their race-ethnicity and culture. Resistant capital is manifested in the oppositional behavior of students, and is the mechanism by which cultural wealth is passed onto the community (Yosso 2013).

Oppositional behavior can take two forms. Students may challenge the dominant structures and their gatekeepers, but perceive the system as illegitimate, resulting in their nonparticipation in the educational system (Obgu 1978). Other students may resist the structures while maintaining the perception that the system is legitimate, while seeking to reform or transform the system to meet the needs of their community (Giroux 1983; Yosso 2013). In both cases students have a nascent collective consciousness of the structural constraints to their success, but their response may vary (Giroux 1983). Cammarota (2004) assert's that it matters if students perceive education as oppressive or as a tool for resistance. Those students that perceive education as necessary for resisting

\footnotetext{
${ }^{2}$ Hispanic Serving Institutions is a Federal designation when an institution's Hispanic population reaches $28 \%$ or more. The designation allows institutions access to funds and grants.
} 
oppression are more likely to succeed, though there is some variation depending on gender.

For Latinos/as, resistant capital is essential to educational success. Recent studies have begun to explore how students resist structures and the behaviors that are associated with effective resistance. Munoz and Maldonado (2012) found that students used familial supports and "safe spaces" on campus where they could express their identities and cultural values that they otherwise concealed. Similarly, Campa's (2010) study of Mexican-American community college students explored how students connected their educational success with a larger purpose of "community uplift" for their family and community. Students learned the codes of power, and the culture of the educational context, but used the new knowledge to contribute to the collective success of their community (Campa 2010). Resistant capital transfers the wealth of the community, not as an individual process, but a collective process whereas cultural knowledge and values are transferred to the community and future generations. Resistance, as opposed to assimilation, to dominant structures is important for Latinos/as' educational success.

\section{GENDER DYNAMICS AND ACADEMIC ACHIEVEMENT}

Previous research has identified a growing gender gap in college completion.

Women earn 58\% of all Bachelor degrees in the United States (Snyder et al. 2008).

Bachmann et al. (2008) assert that shorter completion time is the primary factor explaining the female advantage in higher education. Men were more likely to drop out and take six years or longer. Buchmann and DiPrete (2006) found that low-income men and men without fathers present in the home were least likely to complete college. These 
findings suggest that class, family structure and gender may intersect and influence educational outcomes differently for men and women. (Buchmann and DiPrete 2006).

The statistics for Latinos reflect an even greater gender gap. Among Latinos, 61\% of Bachelor's degrees are earned by females (Buchmann et al. 2008). Latinas are more likely to complete their college degrees within six years, with $50 \%$ of females completing on-time, as compared to $43 \%$ of males completing on-time (Snyder et al. 2008). Studies have suggested that gender roles influence persistence differently for the sexes (Barajas and Pierce 2001;Ojeda, Navarro, and Morales 2011; Saenz and Ponjuan 2009).

\section{Doing Gender}

Previous studies have identified a growing gender gap, but are limited in explaining how gender influences academic achievement. Research has treated the labels of male and female as binary categories that are innately meaningful, when in fact gender is not a stable nor stagnant category, but is an interactional performance of societal expectations that changes over time and according to social context.

It was once believed that gender identity is a salient role maintained throughout the life course (Goffman 1976), through the work of West and Zimmerman (1987), gender can be described as an ongoing process by which gender is done, enacted and reenacted. It is not a static identity codified by one's sex category, but is an interactional process (West and Zimmerman 1987; Lorber 1994; Lucal 1999). Doing gender is a dynamic process by which gender presentations are shaped by historical idealized concepts of emphasized femininity and hegemonic masculinities (R.W. Connell 1987). Individuals then do gender in the context of conformity to established normative gender presentations that may change over time and according to context. Furthermore, gender 
presentations that deviate from normative roles are heavily sanctioned and therefore members maintain conformity to emphasized femininity and hegemonic masculinity (West and Zimmerman 1987).

Emphasized femininity and hegemonic masculinity are juxtaposed to reproduce inequality between the sexes (Connell 1987). The ideal type female is white, passive and conforming. In the educational context, emphasized femininity takes the form of the 'good student', whereas high academic achievement is equated to femininity (Jones and Myhill 2004). Teachers explain academic achievement through the lens of gender performance. Girls are expected to preform better as students and therefore their performance is attributed to their sex. The underachievement of boys is attributed to their masculinity or being a 'typical boy' (Jones and Myhill 2004). High achievement among boys is then explained performing masculinity in alternate ways or being 'atypical' in terms of their gender (Renold 2007; Jones and Myhill 2004). Teachers and educators reinforce and sanction these performances in the context of the classroom, which then become attributed to innate qualities of their corresponding sex. Doing working class femininity in education

Previous research would suggest that girls benefit from the gendered expectations and their performance in the classroom. Girls earn higher grades, attend college at higher rates and earn more degree in a shorter time than their male counter parts (Buchmann et al. 2008; Buchmann and DiPrete 2006; Riegle-Crumb 2010). Working class females are limited both by structural class constraints and by what Patricia Hill Collins describes as "controlling images" (2000). The images 'other' women to legitimate their subjugation and oppression. Women of color and working class women are objectified and 
pathologized, rendering them little access to normative femininity (Skeggs 2004). In Skeggs study of working class women, she finds that women reported doing their femininity in the context of being judged as hyper-feminine, excessively sexual, overly fertile and as poor mothers (2004). The women were conscious of the controlling images, and monitored their gender performances in the context of these images. Additionally, Skeggs found that doing working class femininity meant doing care work (1997). In Evans study of working-class girls, she found that women reported 'doing care work' while attending college. This social commitment is not accounted for in higher education and therefore limited females' continued participation in college (2009).

Similarly, Latinas' limited access to normative femininities is subject to controlling images. Traditional gender roles are modeled after controlling archetypes of femininity that are culturally bound within the family. The archetype of the Catholic Virgin Mother conveys the value of selfless devotion to family, responsibility for domestic life and dependence (Hondagneu-Sotelo 1994; Stevens and Pescatello 1973). The images define normative gender performances for females and may be incongruent with the expected performances in the educational setting. Latinas are confronted with the 'double bind,' navigating the gender expectations within the family but needing to adapt gender performances for academic achievement.

Gonzales (2012) finds the importance for Latinas to redefine their cultural values for success in higher education. Students that translate cultural values such as community, faith and compassion find success in the educational setting. Other studies point to the importance of shifting gender expectations for Latinas within the family or finding safe spaces on campus where they can construct alternative femininities (Muñoz 
and Maldonado 2011; Solorzano and Bernal 2001). Latinas monitor gender performances in both the institutional of the family and higher education, in the context of these controlling images. The female gender advantage in the field of education is then mediated by hegemonic performances of gender that is dependent upon females' race, class and culture.

\section{Doing working class masculinity in education}

Much of the current research focuses on the disadvantage males experience within the field of education. Males generally underperform females across racial and class boundaries, though the gap in achievement increases for Latinos/as (Riegle-Crumb 2010). Focus on male underachievement has been confined to the examination of differences in achievement within the institution of education. Gender differences can be more thoroughly understood through the lens of masculinity, which permeates relationships across institutions (Connell 1989).

Working class males are held accountable to do their masculinity in the context of hegemonic masculinity. Displays of masculinity, such as toughness and strength, reinforce normative masculinity and discourage boys from performing alternative forms of masculinity. Academic achievement is seen as 'feminine' and deviates from normative masculinity. To work, be tough and provide for one's family is considered masculine, whereas earning good grades, going to college and achieving academically is seen as effeminate. Sanctions are placed upon those that deviate from underachievement from within the group (Renald 2004; Willis 1977; MacLeod 1995).

Teachers may also see this behavior as anti-social, threatening and are more likely to negatively sanction underachieving boys who are predominantly poor or working class 
(Legewie and DiPrete 2012). Conversely, Legewie and DiPrete (2012) find that the gender gap disappears when working class boys are integrated with higher SES male peers. They suggest that higher SES schools foster educational competition among boys, which acts as an alternate form of masculinity. The educational context shapes the performances of boys more starkly than it does for girls. Working class masculinity is subordinated, with limited access to varied performances of masculinity, leading to underperformance.

Latino males face similar challenges in regards to their masculinity. Latino males are more likely to be labeled by the educational system as underachieving and as having "problem behavior." Latino males are overrepresented in special education, as being learning disabled and to be diagnosed with emotional or behavioral problems (Saenz 2009). Their masculinity is subordinated to hegemonic masculinity within the educational context, and may they be seen as threatening or lazy. Male students may internalize the performance of masculinity consistent with these controlling images, and are reinforced by educational actors with sanctions.

Additionally, these gender performances are cultivated within the family. Males are responsible for providing financially, protecting family and defending its honor. They are expected to perform their masculinity by being hard working, family oriented, brave and strong (Saenz and Ponjuan 2009). Feliciano (2012) found that immigrant males reported more commitment to the family than females, but gender differences disappeared in higher classes. Previous research theorized that the obligations to provide for the family financially may be more relevant for males in lower social classes (Feliciano and Rubén G Rumbaut 2005; Feliciano 2012; Saenz and Ponjuan 2009). 
Working hard and providing is then equated to masculinity, which may put pressure on males to opt for entry into the work force rather than higher education, leading to early departure from the educational pipeline.

\section{Family and Gender Performance}

For both genders, performance of femininity and masculinity is dependent upon the socialization process within the family and relationships. Female students may simultaneously experience a benefit and challenge to their academic success because of expectations of their gender performance. Evans found that working class white women benefited from reliable familial networks that provided support and motivation for success. Similarly, many studies have identified that Latinas benefit from strong peer networks and closer relationships with parents that encourage discipline and academic achievement. Females are given less freedom, have strict boundaries and increased level of responsibility.

Conversely, males are given more freedom, independence and have less salient ties with parents. For working class or low-income males, such performances may not translate well in the educational setting. Barajas and Pierce (2001) found that Latino males that participated in athletics during high school were more likely to attend college. These males were more likely to identity with the dominant culture because they received recognition for athletic performance. For Latino males, once in college, this advantage disappeared and students struggled academically.

Ojeda, Navarro and Morales's (2011) study identified commitment to family as mediating variable in predicting persistence of males. They assert that commitment to family and pride in family, rooted in machismo, mediated conversations with parents 
about college. This in turn, positively influenced persistence. Gender roles within the family are not stagnant and may shift and change over time, according to context. The family can both reinforce normative gender performances and subvert these performances.

\section{CONCLUSION}

In this chapter, I have outlined the theoretical frameworks that have developed through the course of this study. Academic persistence and success is a complex process that is influenced by many factors that at times overlap. The model (see Figure 2) illustrated at the end of the chapter maps out the processes theorized in this chapter related to academic success, which will be used to analyze the findings present in the following chapters. The model synthesizes the theoretical perspectives of 1) Social Reproduction Theory, 2) Critical Race Theory, and 3) Feminist Theory, considering the previous empirical research related to academic success. The model is not meant to stand alone as a theoretical model, but is used as an "ideal type" to generate expected findings and analyze the data in context of this literature (Portes and Rumbalt 2001: 69).

Furthermore, the model allows for understanding the complexity of how student understand the challenges and supports to their academic persistence, considering intersecting identities around race, class and gender. Using the model, we can examine which influences are class barriers, which influences are related to prejudice and which are products of other experiences that vary between racial-ethnic groups and/or gendered experiences. 
Figure 2 Influences of Academic Success Among Low Income Students

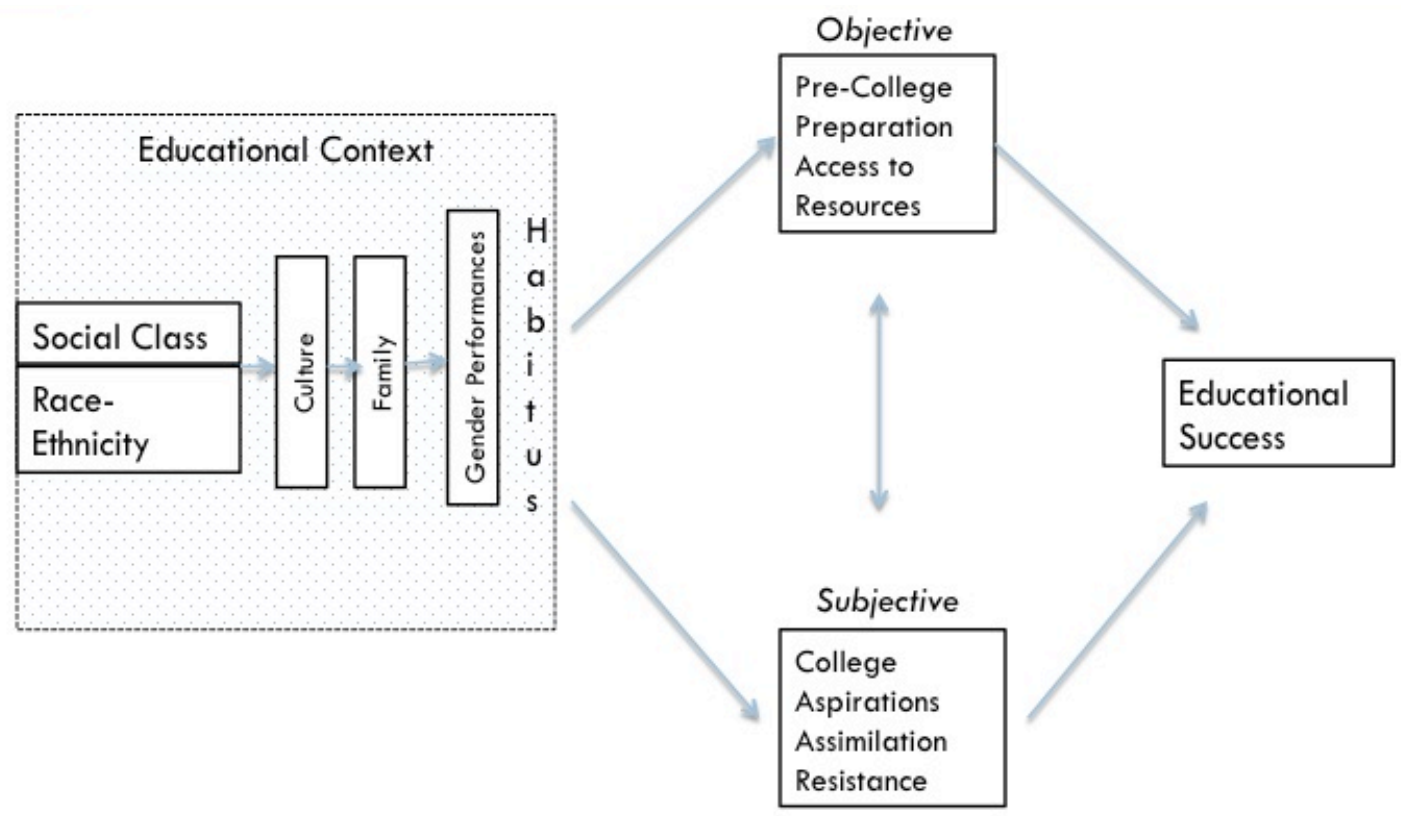

\section{Class Challenges and Supports}

It can be expected that all low-income students in this study will experience barriers that are a condition of their class. Specifically, students will have limited access to economic capital and material resources. This limitation will necessitate the increased need to work while in college. Balancing the two, work and school, will be seen as a significant challenge for students.

In addition to these material economic constraints, students may face challenges because of their lack of preparation and cultural capital. Low-income students are less likely to have high quality academic preparation, college planning services and take advanced courses. Low-income students are also more likely to be the first in their family to attend college and will therefore lack some of the cultural knowledge necessary to aspire to attend college, and then be successful once enrolled. Therefore, it can be 
expected that students in this study will have limited cultural capital, or cultural knowledge of the expectations and ways of being that are valued in the field of higher education. This deficiency will likely be interpreted as stemming from their parents' limited educational background. To overcome this barrier, students will need to access new networks in college. Student success will then depend upon networks outside of the family to import the cultural capital necessary for their success in college. Social capital then acts as a resource in acquiring this new knowledge and information in the college context.

The influence of social class on academic persistence is not a stand-alone factor, but must be considered within the given context of students' lived experience. High school preparation and the context of the school is important in shaping how students experience and interpret the challenges to their success. Low-income students are more likely to attend schools with limited resources, advanced courses and well-prepared educational staff. This constraint not only shapes students' level of academic preparedness, but also shapes students habitus, or their ideas of what is possible.

Additionally, the context of higher education plays an important role in influencing both access to material resources and students' habitus. As community college students, it can be expected that students in this study will see their pre-college experiences as influential of their college experience, as most in the study still live in their home communities. It is likely they will view their preparation as inadequate, challenging their success in college. Furthermore, it can be expected that the community college campus will act as a resource for students. Students will use these resources to overcome the challenges they face because of their class backgrounds. 


\section{Race-Ethnic Challenges and Supports}

Although, all low income student face similar challenges, Latino/a students may face different challenges because inequality is stratified not only by class positions, but race-ethnic categorization. Latino/a students then face structural barriers that their White counterparts may not. Students encounter dominant structures, such as educational institutions that may be incongruent with their cultural background. They are not able to fully assimilate to these dominant structures, because the system has historical excluded people of color. Race then is constructed as an indicator of one's culture, national original, immigrant status and language. Latino/a and students and their families need to navigate these dominant structures, relying on their community wealth. Families use their cultural resources to help members survive and navigate the system. It can be expected then that Latino/a students will draw on their cultural knowledge and family to a greater extent that their White peers. Maintaining ties with their family and culture will be important to overcome material class constraints.

Within the educational context students may experience racism and discrimination because of both their race, culture and language background. Students may internalize this oppression and opt out of the system or resist the stereotypes and use the system for mobility. On campus cultural organizations then become important to help students develop a collective consciousness of the racial-ethic structural barriers in order to succeed (Yosso 2013; Hurtado and Carter 1997). Students in this study have persisted despite these challenges, therefore, it can be expected that Latino/a students will resist the assimilation, but will see education as a mechanism for upward mobility. They may 
perceive their success in relation to the collective consciousness of their race-ethnicity and class.

Furthermore, previous research suggests that the cultural context of the college campus makes a difference for Latino/a students. Students that feel "at home" on campus are more involved and feel more connected to the institution, which is a strong predictor of academic persistence (Hurtado and Carter 1997; Hurtado and Ponjuan 2005). Considering that Small Town Community College is a Hispanic Serving Institution (HSI), it can be expected that students in this study would feel more "at home" on campus, which aids in their involvement and academic persistence.

\section{Gendered Experiences}

It is important to understand that the barriers and supports that are communicated by students are done so through a gendered lens. Gender is not a stable, immutable category, but an interactional process, where individuals perform gender in the context of the dominant culture. Students perform masculinity and femininity in the educational context. These performances are reinforced through the use of positive and negative sanctions. In this case, teachers, educators and family members cultivate these normative gender performances. Working class males are expected to adhere to hegemonic masculinity, demonstrating their strength and toughness. They are expected to be underachieving by educators and their academic failure may be seen as normative.

Conversely, working class females are expected to perform their femininity through displays of conformity and passivity. Academic achievement is then seen as feminine and females are expected to excel in college. Furthermore, Latino males and females have different obligations within the family that influence their educational 
performance. Families then reinforce the gendered division of labor by sanctioning gender performances that stray from cultural archetypes. These binary gender performances reinforce the gap in achievement between males and females. But this gap is significantly more prominent among low-income students. Among higher social class students, the gap nearly disappears. Gender differences are then not only a function of 'doing gender difference' but are influenced by the controlling images of working class males and females, and people of color. Therefore, it can be expected that students interpret the challenges to their success and barriers to success through gendered lens. In order to be successful students would shift their habitus to resist these controlling images that are a result of intersecting forms of oppression. 


\section{CHAPTER III: RESEARCH DESIGN}

\section{PURPOSE AND DESIGN}

The purpose of the study is to understand shared class challenges between lowincome Latino/a and low-income white community college students, and the differences that can be properly attributed to ethnicity-race. A second purpose of this study is to understand gendered challenges to academic persistence that may be experienced differently by low income White and Latino students. Furthermore, the current body of research has focused on experiences of low-income students at 4-year institutions. The context of the community college may impact student academic experiences differently.

Academic persistence has previously been defined as continued enrollment from one quarter to the next (Sheffield 2011). This definition assumes students' persistence will follow a linear path culminating in degree attainment, when in fact credit threshold is a more predictive measure of graduation (Adelman 1999). For the purpose of this study, academic persistence will be defined as being within one quarter of graduation while in pursuit of an Associate's Transfer Degree. This study will examine how students persist despite encountering barriers, and does not assume a linear path to completion. By examining students' experiences of academic persistence and overcoming challenges, the study will contribute theoretical knowledge and has the potential to inform future policy in the community college system.

This qualitative study is designed as a comparative in-depth interview study. Semi-structured interviews provide “deep meaning of experience in the participants' own words" (Marshall and Rossman 2010). A qualitative approach is necessary to explore students' experiences of persistence to uncover deep understanding of the complex 
processes of culture, identity gender. Qualitative methodology allows for understanding how the processes manifest themselves in the lives of individual students and yet is flexible enough to allow for the emergence of new meaning and theory.

Previous research has examined the persistence of white students and Latino students separately asserting that the challenges they face are exclusive of one another. The comparative design will examine the common class influences, while exploring intersections of race and ethnicity. Furthermore, previous quantitative and qualitative work on academic persistence tends to treat male and female students as a homogenous group, neglecting the gender dynamics that may influence persistence (Campa 2010; Espinoza 2010; Gonzales 2012; Ojeda et al. 2011; Strayhorn 2010). A comparative interview study will give voice to the experiences of both males and females, exploring the similarities and differences of their gendered experiences and its influence on academic persistence.

\section{Site Selection}

Small Town Community College (STCC) ${ }^{3}$ has been selected for this research. Small Town Community College is a favorable site to explore low-income students' experiences of academic persistence. The community college is located in a rural environment in the Western United States. Its service district is expansive serving three rural counties. The institution is a relevant site, because it is a Hispanic Serving Institution ${ }^{4}$ with $42 \%$ of its student population being Hispanic. Additionally, the majority

\footnotetext{
${ }^{3}$ Small Town Community College is a pseudonym chosen by the institution to maintain anonymity for the college and its staff and faculty.

${ }^{4}$ The US Department of Education defines a Hispanic-Serving Institution (HSI) as an institution of higher education that - (A) is an eligible institution; and (B) has an enrollment of undergraduate full-time equivalent students that is at least 25 percent Hispanic students. (US Dept. of Ed, 2011)
} 
are commuter students, attending STCC while living at home or close to home as the college provides minimal student housing. Therefore, this site provides a unique opportunity to explore students' experiences of familial commitments, relationships and their understanding of how this influences their academic persistence, because they are more closely connected to their families by proximity. Furthermore, I was able to access the student population due my experience working with similar institutions. The personal and professional experience gained before the starting the research process allowed me to navigate the bureaucratic nuances of this institutional context. Additionally, I come into the site and research context with extensive background knowledge of the student population at Small Town Community College and its service district.

\section{Group Being Studied and Sampling}

I collected twenty-two interviews for this study with 11 white students and 11 Latino/a students. The sample included 12 females ( 6 white, 6 Latina) and 10 males (5 white, 5 Latino). The sample was a purposeful sampling, which does not reflect the demographic population of the community college. Purposeful sampling was used in order to gain the in-depth perspectives of both white and Latino/a students and males and females. After receiving IRB approval from Portland State University and Small Town Community College, students were recruited with the help of student services, faculty and key informants at Small Town Community College. I first met with the Director of institutional research, Dean of Arts and Sciences and Dean of Student Affairs to set the criteria by which students would be initially identified for the study. Selection criteria for 
the sample included: white or Hispanic ${ }^{5}$, economically disadvantaged ${ }^{6}$, transfer degree seeking students with 60 or more college-level credits. The 60 -credit thresh-hold was identified with the assistance of the Vice President of Student Affairs, the Dean of Arts and Sciences and Institutional Research. This thresh-hold is predictive of degree completion at this institution. The thresh-hold measure is consistent with Adelman's (1999) research on degree completion, where he suggests that credit thresh-holds are a better measure in predicting degree completion. Persistence does not necessarily follow a linear pattern and may include stop-outs, dropouts or transfers between institutions. Neither grades, nor completion time was used as identifiers for this study for this reason. It is important to note that only students that have earned at least 60 credits of collegelevel credits ${ }^{7}$ were eligible for this study.

Once students were identified in Spring Quarter of 2013, the department of Institutional Research provided a list of student names and contact information. The Dean of Student Affairs then sent out an email to students soliciting their participation in the study. A number of students responded immediately, after which the researchers followed up with the student participants to schedule a day and time for their interview. A second email was sent by the Dean of Student Affairs to solicit more participation shortly there after. In addition to these efforts, key informants at the college were contacted to support the recruitment efforts. Most of the Latino/a students were recruited through these efforts.

\footnotetext{
${ }^{5}$ Hispanic is used in here instead of Latino/a because students are identified as Hispanic/non-white on Federal Financial Aid forms. Throughout the rest of the report, Latino/a is used to refer to students from Latin American descent.

${ }^{6}$ Economically disadvantaged criteria was used to identify students as being low-income by Federal Financial Aid standards.

${ }^{7}$ College-level credits refer to those credits earn in 100 level courses or higher that count towards their degree or transfer. Developmental courses or below-college level courses are not included in this threshhold.
} 
In May 2013, a fellow cohort and I attended a recruitment and outreach event held at the college in order to recruit more students for the study. After the researchers conducted the initial set of interviews, a new screening tool was used because age had not initially been included as an identifier. Two interviews collected from retired, returning adult students varied significantly from the younger student participants. Therefore, before student participants were scheduled for an interview, they were asked: What year did you graduate high school? How long have you been attending this community college? Only students graduating high school after 1997 were included in the study. These questions aided in screening potential participants because age was a variable that may have impacted the experiences of students significantly.

By the end of spring quarter 2013, 9 white (6 females, 3 males) students and 10 Latino/a students ( 6 females, 4 males) had been selected and interviewed. Two of the white male interviews and 2 of the white female interviews were excluded from the study because of their age and/or race-ethnicity. Students that were of mixed race or had nativity outside of the United States were excluded to maintain a homogenous group due to the comparative aspect of this study. The remaining 7 students in the sample (1 Latino, 4 white males, 2 white females) were recruited and interviewed over the summer using the initial list of students identified during the spring. Three of the interviews were conducted over the phone due to scheduling conflicts.

\section{Data Collection and Interviewing}

Once the student participants had been selected, I contacted each student to set up an interview time at his or her convenience. The interviews were conducted at a place of each student's choosing, in their home communities and/or on campus. Most interviews 
were conducted off campus to insure students' identities were kept anonymous. For those few that were conducted on campus, I made an effort to secure a private location where the student felt comfortable sharing their experiences. As stated earlier, three of the interviews were conducted over the phone to accommodate the students' busy schedule. Each student was asked to choose a pseudonym at the beginning of the interview to conceal their identities and encourage full disclosure of their experiences. In the case that a student was unable to choose a pseudonym, one was assigned for them. In a few cases, students insisted they keep their own names, which I honored. All identifiers were eliminated from the findings and analysis to ensure their identities were kept confidential. Interviewing

At the beginning of each interview, students were given a brief overview of the study's purpose and were asked to sign the consent form. An effort was made to give enough information to the student participants so they would feel comfortable sharing, but not detailed information to minimize the chance that the participant would make an effort to please myself as the researcher. My previous experience as a community college instructor was left out of this introduction intentionally and students were encouraged to share "all of the good, and all of the bad" during their interviews. Student participants were asked for their consent to be audio-recorded and were given the option of conducting the interview in the language of their choosing. All student participants chose to do the interview in English.

Each interview started by asking questions related to their attendance at Small Town Community College such as: How long have you been a student? When did you first start attending? Why did you choose Small Town Community College? The 
questions were designed to make students feel comfortable and to establish rapport. The second phase of the interview was designed to elicit the supports that students use to help them succeed in college. Students were given cue cards with examples of supports from the literature such as: high school preparation, college expectations/plans, family, faculty, non-faculty mentors, friends, classmates, academic support programs, on-campus or offcampus clubs/organizations, work, mentoring and the campus environment.

The interview cue cards were adapted from the literature to reflect everyday terms students may use. These cue cards were pre-tested with four students at Portland State University to determine if the cards resonated with students' lived experiences. Some cards were then revised for clarity before they were used in the field. Students were asked to choose those supports that helped them be successful in college. They were also given blank cards to write down any additional supports that were not represented. Once students had chosen their supports they were asked to choose the top 4-5 supports to discuss. Some students were able to rank order, whereas others were not able to delineate an order. Each cue card had a set of corresponding questions and probes, which were designed to answer the research questions and unanswered questions in the literature. Students were asked each series of questions related to the cue card they had chosen. The process continued until all of the supports chosen by each student had been covered. The third phase of the interview asked students to identity the biggest challenges or barriers to their success in college.

The same cued interview process was used as with the supports phase. Many of the support cue cards were the same as the barrier cards. The main cue cards used were: high school preparation, college expectations/plans, family, faculty, non-faculty, 
academic support programs, on-campus or off-campus clubs/organizations, friends, classmates, work and the campus environment. The only cue card that was not included from the support cards was mentoring. Each card again had corresponding questions designed to answer the research questions and any unanswered questions in the literature (See Appendix A for complete protocol). Students were given the opportunity to write down any missing challenges on blank cards.

The fourth phase of the interview process included cued responses to questions around identity. Understanding that this was a sensitive subject, I took great care and effort to establish rapport and ease into the subject. Questions began by asking students how Small Town Community College "fits who they are." Then students were given cue cards with a range of identities. ${ }^{8}$ Students were asked to choose any that fit "who they are." All cards were passed as to not make the any assumption based on my biases or the student's outward appearances. Students were again offered blank index cards to write down any identities that represent themselves. Once students had chosen their respective cards they were asked a series of questions for each identity that corresponded to unanswered questions in the literature and addresses the pressures students may face because of this identity and how this may support the student's success in college. Many of the Latino/a students in the study communicated some hesitancy through non-verbal behaviors during this phase of the study. As a white female researcher, I attempted to be cognizant of this barrier and as the study progressed, and took steps to help students feel more comfortable sharing their experiences. After students had chosen their identity

\footnotetext{
${ }^{8}$ Identity cards included such identities as: Latino/a, Hispanic, Mexican-American, Male, Female, Working Parent, White, European American, etc. For a full list of identity cue cards please see Appendix A.
} 
cards, I encouraged students to share anything on their mind and reassured them that nothing would be offensive. As a result, many Latino/a students changed their stature, dropped their shoulders, leaned in and shared their experiences. Throughout the interview process I recorded my own reflections by memoing after each interview. As a privileged researcher it was important to use a reflexive process to check my own biases and approach (See Appendix B for Methodological Reflections).

The final section of the interview protocol included questions related to what students would have done differently and what advice they would give future STCC students. Each interview concluded with an open-ended question allowing students to share anything that was not covered through the protocol. Students were thanked for their time and were given the opportunity to ask questions about the researcher and/or research project. Many students had questions related to what I was studying and the plans for the research project. Students were given a brief timeline of the research process and what they could expect.

The same process was used for those interviews conducted over the phone, but the cued cards were given each student participant verbally. After listening to all of the categories, students wrote down those influences that were supportive and those that were challenging. After participants had identified each of the supports and challenges they were asked the same questions that corresponded to each support as described above for the cue cards. The same process was used for the identity cards.

Overall, the data collected through phone interviews was consistent with the patterns found in the face-to-face interviews. Phone interviews presented some challenges, as they seemed to create a social distance between students and myself. What 
was lost in the interviews was some of the latent emotional content of students' stories because I was not able to read body language or non-verbal cues. Emotional content was coded for in face-to-face interviews because it alerted me to the importance of either the supports or challenges that students identified. Many times students struggled to rank order the support and challenges, so this method became an additional strategy to use in understanding students' experiences.

Even though phone interviews presented the challenge of social distance, they were essential to accessing a part of the student population that had been difficult to recruit. Early in the research process it had been difficult to identity white, male, working class students that would participate in the study. Efforts to recruit students through faculty and campus contacts were unsuccessful. After establishing contact by phone, the three students (white males) agreed to do the phone interviews. They were hesitant to be interviewed at first and face-to-face interviews seemed to be unfeasible due to work conflicts. After I suggested conducting the interview by phone, they agreed to be interviewed. All of the phone interviews were conducted late in the evening to accommodate their work schedules. Although face-to-face interviews were not the ideal method to use in this case, without these phone interviews valuable student experiences would have been lost and unrepresented in this study.

Before returning from the field, the researcher wrote a detailed memo of the interview reflecting on both the process and the content. Afterwards, interviews were transcribed orthographically, noting body language, tone of voice and expression of emotion (Braun and Clarke 2006). Any expressions or words were kept in their original language (Spanish, English and/or Spanglish). Final transcripts were given back to 
student participants to review for accuracy and content. In a couple of cases, changes were made to those transcripts where students expressed a need to revise. In most cases, the original transcript remained in tact.

\section{DATA ANALYSIS}

\section{Coding}

Throughout the research process, data was collected and analyzed simultaneously. Memos were written throughout data collection, transcription and analysis, which were included in final analysis. Thematic analysis was used to identify themes in the data connecting to the research questions, as outlined by Braun and Clarke (2006). A deductive approach was used to code the data, using thematic codes from previous studies conducted with students on persistence and academic success. Initial codes were taken from the cue cards given students. Each code category was identified as a support (S) or challenge (C). Initial codes included: family, friends, classmates, faculty, nonfaculty mentors, high school preparation, on-campus or off-campus clubs/orgs, academic support programs, work, the campus context, mentoring and identity. All initial codes were kept early in the process.

Previous literature has identified the above factors contributing to academic persistence or non-persistence, but is unclear as to how these act to support or hinder academic persistence from the student perspective. After outlining the initial codes taken from the literature, sub-codes were used to clarify the processes and mechanisms of student persistence. The sub-codes were initially generated from the corresponding interview questions associated with each cue card. For example, when students choose 'family' as a support, students were asked: 1) how family supported their success, 2) 
what specific support their family provided, 3) if their parents expected them to go to college and 4) if they discussed college and their goals with parents, and 4) The subcodes for family then became: Supporting success, Types of support, Having college expectations and Communicating goals. Under each sub-codes the process-oriented codes were added to describe how students experienced the support of family.

The codes originated directly from student experiences as described in their interview transcripts. For example, under how family supports success, new codes included: providing motivation, providing childcare, support and advice from siblings and providing space. This process was used for each code category. Those categories that were either not discussed by students or that were discussed minimally (off-campus club/organizations, on-campus clubs/organizations, friends) were left in tact in the codebook until all interviews had been coded. They were then eliminated or merged into other codes in the final codebook revision, which will be discussed in the analysis section in further detail. The same coding scheme was used for both low-income white and Latino students, and males and females to compare the experiences across groups. Each transcript was coded using descriptors to identity participants' demographic information such as: race-ethnicity, gender, years in attendance, bicultural identity, parental status and transfer plans. The descriptors were that later used for comparative analysis between groups.

Finally, other codes emerged from the student interviews that were not initially identified in previous literature. The initial codes identified by students that challenged their success were: Financial challenges and/or Money, Being undocumented, Not knowing what to expect, Balancing and Self as a barrier. Similarly students identified 
additional supports that were not included originally in the design such as: Mentoring for parents and Self-Determined, Individual effort. Students identified these challenges and supports through the interview process by adding them to the cue cards. The cards came up across the interviews and were therefore included in the coding scheme as initial codes in the 'Other' category.

\section{Thematic Analysis}

Using the coding scheme described above, a codebook was designed and used by a colleague and myself to code four full-length interviews to establish inter-coder reliability. Codes were then merged and collapsed to reflect any inconsistencies or redundancies in the codebook (See Table 1). The initial code categories of classmates and friends were collapsed together into a new code category entitled Peers. This category was used because students discussed classmates and friends interchangeably.

The support and challenges discussed were similar as well as how the relationships were formed. High School friends were coded for under this category to denote if a student was discussing their ties to a relationship before attending college. High School Preparation, college expectations and not knowing expectations were all merged under the category of Pre-college preparation. All three of the initial categories were discussed in relation to high school experiences and their positive or negative effect on college success. Furthermore, the college expectations was different from the code "having college expectations" in the family code category. The former referred to students' lack of understanding of what they could expect in college, whereas the later referred to college plans and goals that parents and family had communicated before attending. The Sister and Daughter, as well as the Brother and Son codes were merged 
together because the codes in each category matched the other. Students discussed their role in the family as a son and brother or daughter and sister simultaneously. Financial Table 1 Codebook Revisions

\section{Collapsed Codes \\ Initial Code Categories \\ Classmates + Friends}

High School Preparation + College

Expectations + Not Knowing Expectations

On-campus clubs/organizations + Academic support programs

Sister + Daughter

Brother + Son

Financial Aid Issues + Lacking money

Being outgoing + Being proactive + Individual effort

\section{Final Code Category}

Peers

Pre-college preparation

On-campus

clubs/orgs/programs

Being a Sister/Daughter

Being a Brother/Son

Financial Issues

Self-determined, individual effort

\section{Merged Codes \\ Initial Code Categories}

Non-faculty mentors

Working parent

Would have done different
Merged Codes

Mentoring

Being a Mother

Giving advice

\begin{tabular}{ll}
\hline Split Codes & \\
\hline Initial Code Categories & Final Code Categories \\
Other & Balancing Work, Family \& \\
& School \\
Other & Financial Issues \\
\hline
\end{tabular}

was used for Balancing Work, Family and School. It was split out of the Other code category and stands alone as a code category in the final codebook. Finally, the codes 
Being outgoing, being proactive and individual effort were merged into the new category of Self-Determined, Individual Effort.

Additionally, some code categories were merged into other categories to minimize redundancy in the codebook. Non-Faculty Mentors was merged into the Mentoring code category and a new sub-code was created to identify the type of mentoring students identified such as: peers, faculty, counselors, family and religious mentors. This category provided a more in-depth scheme to identify consistently the support student gained from mentoring and what types of mentors students sought out. The category of working parent was merged into the Being a mother category because the only students that identified as a working parent was mothers, therefore this code was a better fit under Being a mother.

Finally, the "would have done differently" code category was merged into Giving Advice. The same codes appeared in each code category so they were merged to eliminate redundancy. One initial code category, off-campus club/organizations, was eliminated because students did not discuss this as a support nor challenge. Being undocumented was also eliminated from the final codebook, as it was a unique occurrence in the one of the first interviews used to create the initial codebook. The final categories were left in tact in the final codebook and were used for data analysis (See Appendix B). I coded remainder of the interviews in Dedoose using the final codebook.

\section{Theme Building}

Once the data set had been coded, the codes were sorted into "potential themes, and collating all the relevant coded data extracts within the identified themes" (Braun and Clarke 2006). A dialectical process was used to diagram the relationships between codes 
and across the data set. Sub-themes were identified within each theme and were divided into challenges and supports (See Figures 3.1 and 3.2). Within each theme, the data was then analyzed for relationship of similarity and difference between racial-ethnic groups (White and Latino/a) and each gender. To compare similarities and differences between groups, the data was filtered by descriptor and code co-occurrence within each theme and sub-theme. In each step themes were reviewed and checked against the data excerpts, to examine for what Patton calls "internal homogeneity" and "external heterogeneity" (1990). The themes were supported internally with examples from the data and were distinct from one another, yet related. Each theme was then clearly defined and named in each section to reflect a broad overall story (Braun and Clarke 2006). Finally, excerpts were identified and utilized that illustrated the themes and sub-themes as they related to the research questions.

Figure 3.1 Themes: Challenges
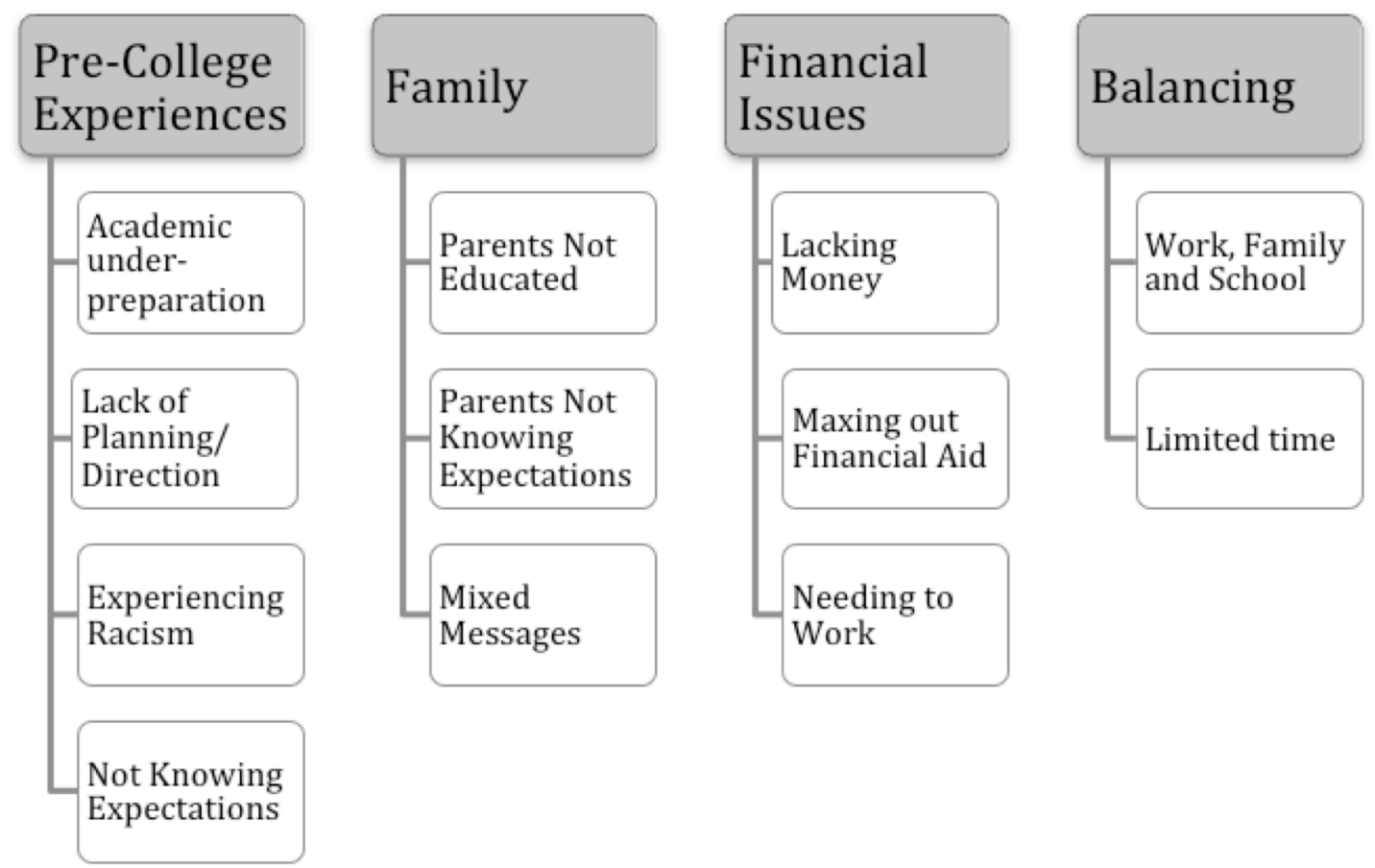
Figure 3.2 Themes: Supports

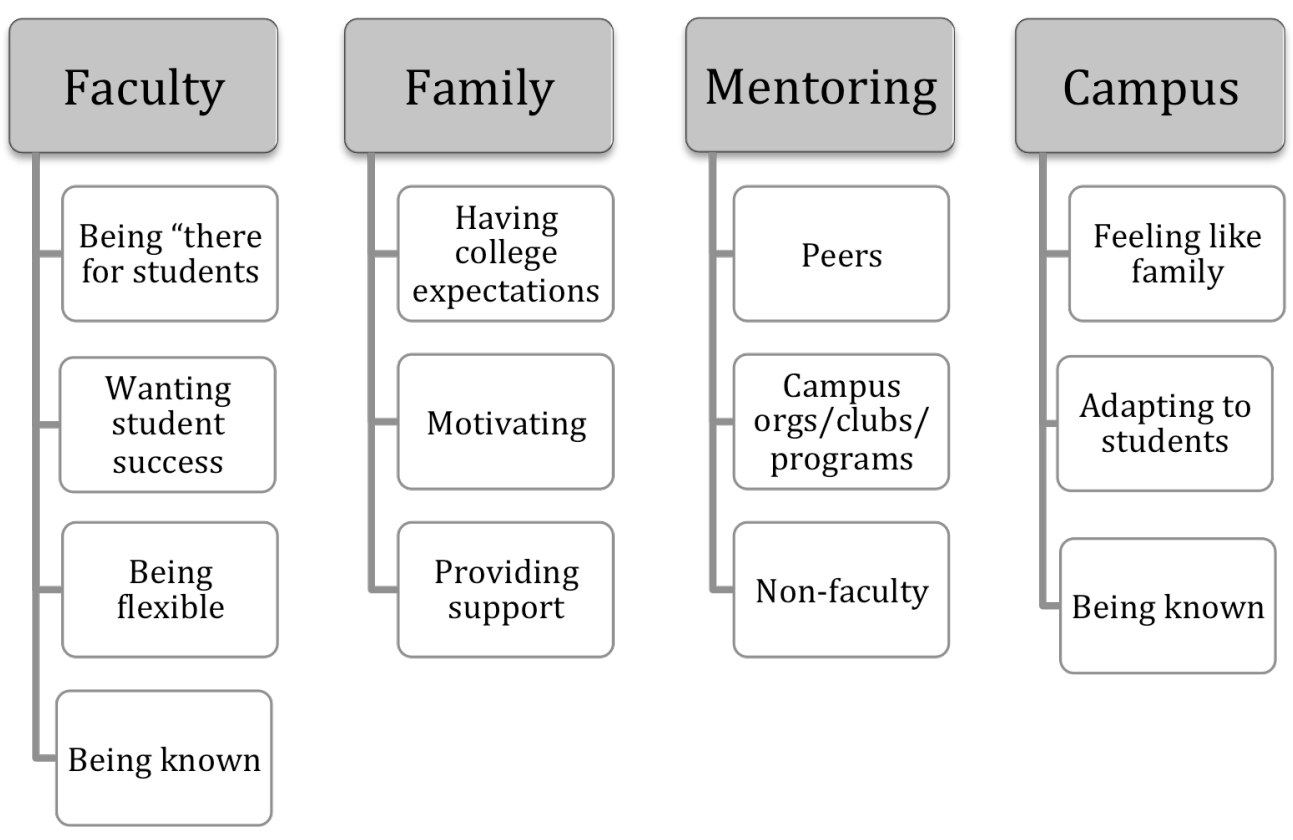




\section{CHAPTER IV: COMMON CLASS EXPERIENCES}

\section{CHALLENGES TO ACADEMIC PERSISTENCE}

Life as a low-income community college student means a constant struggle, not only to pay for college expenses, but it means dealing with life's unexpected events that cause additional financial strain. Throughout the interviews students expressed the intense stress and pressure felt due to financial issues and lack of money. Though it was not originally included in the cue cards, students either added this to the list of challenges or discussed the challenges related to lack of money in other areas of the interview, such as, family or work. The theme of money-related challenges was present across racialethnic lines and impacted both genders. The challenges of being low income and having limited resources continued throughout students' college experience and were never eliminated. For low-income students, this means working while you attend school, taking out loans and constantly dealing with the unexpected. These financial stressors may hinder academic performance and even lead to dropout.

Paying for college and financial constraints are not the only challenge low-income students face. Once enrolled, students described, "not knowing what to expect." They are unprepared for the new college culture and struggle to make the shift. Students' parents are unable to support them during this cultural shift because of their own limited educational background. This adds both to the stress students experience in college and the social distancing between themselves and their parents. In the following sections, I describe the challenges and stories of financial strain, culture shock and students' struggles to understand their new environment, in order to stay in school and reach the finish line. 


\section{Just Making It: Being Low Income}

Being a low-income college student means a constant battle to address how you will pay for tuition, living expenses, transportation, books and sometimes-family expenses. It is an ever-present reality, which students expressed was a part of their everyday consciousness. Susan, a Latina immigrant student, describes that family income is limited and therefore she struggled to pay for the many costs associated with attending college. Eddie, who is also a first-generation Latino college student, describes his challenges not only paying for college, but also paying for the cost just to get to campus. Eddie says, "No more free lunches at school, you need to pay for everything besides tuition and there isn't enough money. Traveling to campus also costs a lot and you don't know how to pay for everything. Maybe work? Maybe take out loans?” Even though he lives at home, Eddie is hesitant to ask his parents for financial support because he knows money is tight.

Small Town Community College serves a large geographic area so for some students their commute to campus not only adds to the cost of attendance, but also decreases the amount of time they have available for academics. Over half of the students traveled at least 20 miles or more to campus. Students like Eddie and Susan, travel as much as 36 miles one-way to campus. The cost of driving to campus can create additional strain on students. Eddie, who didn't have a car, had to take public transportation, which is limited in this rural area. Trips to campus take over an hour each direction. Not all students experienced this challenge, but those that did described decisions to skip class because they could not afford to make it to campus.

Dealing with the unexpected 
In addition to all the costs associated with attending college, many students faced unexpected work-related injuries or illnesses. These life events impacted them personally or a family member, which had a ripple effect on their financial wellbeing. José, a Latino male student, shared his life-altering story with me. Growing up, José worked in the fields picking apples and cherries. He would work long hours every summer in order to save up enough money to attend college. One summer, while he was working in the orchard, he suffered a terrible fall off the top rung of the ladder. Besides hindering his academic career neurologically and his ability to focus or sit for long periods of time, he describes this event as making it difficult from him to attend school due to the financial impact.

Before the accident, I was able to earn enough money so I could work just that one summer, and not work the whole, the whole school period. So I was pretty good. But since the accident, my pay has been dropped like, almost $\$ 5000$. And that, that 's a big gap, it's a big difference.

Now José works while he attends school and struggles to balance work and school. The event created additional stress and interrupted his attendance at college due to surgeries, paperwork and recovery time.

You know, falling off the ladder at work, going through all the L\&I, it's still going on now, almost two years. And it's, it just starts to wear you down. It's a big thing.

Unfortunately, José's story is not unique. Betty, a White single mother, also shared her story of getting injured on the job and how that has affected her life. She cannot work to pay for college, and is therefore dependent solely on financial aid. 
I can't work. I got in an accident at work, and I am banned by the state from working. I'm on L\&I, and the only way I can get money now is to go to school and take out loans, and that is how I feed my family, is off student loans.

Other students may not have been injured themselves but have a family member that has suffered an injury or illness that negatively impacts their financial wellbeing during college.

Raymond, a Latino student, describes the strain on his family due to his father's work injury. "My father has, he had shoulder surgeries and back surgery so he's not the same that he was as far as working. He's disabled and he's not able to work the same, so it's kind of right now it's been hard for him to get a job." Raymond's father, like many other fathers and mothers in this study, generally hold working class jobs that are dependent upon manual labor. Losing physical ability to labor then means losing wages. Raymond describes feeling responsible to his family because his father cannot find work. He feels the pressure to get a job and help the family out. Nora, a White female student, describes a similar situation regarding her father. "I live with my dad and he's disabled, but not disabled to the point where he can't do things by himself, but it's kind of hard." Nora cares for her father, which adds to her responsibility at home and affects her schoolwork.

\section{Finding a way to pay}

For most students, lacking the resources to pay for college and living expenses caused a great deal of stress. The uncertainty of not knowing where your next paycheck would come from or what financial crisis would arise takes a toll on students' ability to persist. All students, regardless of race-ethnicity and gender, commonly experience this 
story. Lisa, a White female student, shared her experiences first coming back to Small

Town Community College as being stressful because of limited funding.

It's definitely a stressor. The first year I was here at Small Town it was really hard getting back because the financial aid department helped me pay for my tuition, but they didn't help me pay for my books. So a lot of times I had to... it paid for tuition, and then I had like a hundred dollars left, which is obviously not enough for books.

Though some students do take out financial aid in the form of grants and loans, many do not receive enough funding to pay for all education-related expenses. The aid allows students to attend college, but not enough to make it stress free. Betty describes the limited resources she receives and the strain it creates on her family. "I get just barely enough financial aid to cover tuition and books, and I have to take all student loans out and that doesn't even cover the monthly bills and it has no room for daycare in it."

Alex, a Latina student from an immigrant family, describes the similar need to rely on financial aid. Early in her college career she dropped out of school. She could no longer pay for college, help her family and maintain her academic studies. Returning to school as an older student she now depends on financial aid.

I need the financial aid, I need the scholarship, I need the loan so I can go to school right now. Because what him (her husband) and I make is just to cover bills and raising two kids and trying to save for their education hopefully in the future. So I have had to take outside money if I wanted to go back to school full time.

One does not need to be a single parent to experience the struggle of paying bills while in college. Each student's story is littered with examples of how a deficit of funds leads to stress and academic struggles. Tyson, a white male student that grew up on a local family farm is accustomed to hard work and struggle. He describes working long hours, getting up early and working late. This is not enough though. "Each quarter it was 
\$1500-2000 dollars or $\$ 3000$, that's like a whole entire months pay!" Without financial aid or long work hours many students simply would not be able to attend college. Even though students qualify for grants, most still take out student loans.

Steve, a white male transfer student to Small Town, describes his experience with financial aid.

Like I said, my family is very low income. I had student loans and mostly student aid, financial aid, I wouldn't be able to do it without it. I do have massive loans piled up. I'll have to pay for those for sure (laughing), like everyone. Before I did that I had financial aid...I was living off those for transportation and housing.

Steve is single and does not have a family to support as many students do, but he still struggles to make ends meet even with financial aid.

\section{Needing to Work Hurts Success}

In addition to taking out loans and using financial aid, all students in this study worked while they attended college. Students worked to pay for tuition, living expenses, books, transportation and other school-related costs. In some cases students worked to support their families or pay their own bills so they would be less of a drain at home. Regardless of the reason students were working, all students in this study described balancing work and school as a major challenge to earning good grades and staying in school. Working meant that there was less time for school, but it was necessary in order to fund their education, directly or indirectly. Tyson describes this struggle to balance his time for school and work.

With work it was more that, you had to provide a living, pay for college, but at the same time, homework should take 2-3 hours. I'm not gonna get off work until 7 at night. You lose sleep, but work to pay for college, but study to get good grades, it's kind of a vicious cycle. 
This cycle, as Tyson describes, is common for students. Many work irregular hours in order to accommodate their class schedule, which means lack of sleep and exhaustion.

Karl, a White male student, also describes the challenge with his work schedule. "That, that was one of the things at work that is hard is how much I had to work. Not so much that I had to work, but the hours and when I got off." Work schedules and school schedules leave little time for students to study and rest. Students describe a battle with exhaustion in keeping up with the busy pace of both worlds. Johnny, a White student that already struggles with learning disabilities, describes the challenge he faces in maintaining focus on his studies due to his work commitments.

It was really hard, cause I would, on one day I would be focusing on, my entire attention on work and then the next hour it would be focusing my entire attention on my schoolwork and homework and stuff. And balancing those two was really difficult for me.

Holly Joy also describes the toll it takes on her physical wellbeing and focus.

Holly Joy worked her first two years at a local restaurant while attending school.

Not having enough hours in the day for everything. Being super tired, needing to study when I get off work. Needing to go to work when I get off school. Not having enough money, not having enough time, all that stuff.

In her final year, Holly Joy quit and only works part-time on campus. She attributes this decision to helping her graduate.

Other students discussed working at restaurants and in fast food industries where their schedules varied and they were given minimal notice of their shift schedule. Susan describes working at McDonald's while attending school and being called into work at the last minute to sub. In fact, I had to reschedule two interviews due to students being called away to work at the last minute. She says, 
Sometimes you know I sub, because I need the money to pay for my transportation or just any other personal expenses that I have. But I guess it can be a struggle too. In like, ya know, if I have a test that weekend, but I'm asked to be working that weekend, so I have to do both. If I can (laughing), if it's possible.

Students understand the challenge they are up against balancing the need to work and need to study, and trying to manage their time to meet both needs. They also know that sometimes there is no way around the lack of time and grades will suffer. Work must come first, because without it students would not be able to attend college. As Blanquita, a Latina female student, describes,

It's very stressing (work), and um, it takes time away from studying. That's when you see your grades going down, it's oh no! But the problem is that you can't stop working cause if you stop working then how are you going to pay for college? You stop college.

Students then are given little choice when it comes to balancing work and school because of their financial constraints. They have to continue to work even if their grades suffer. In many cases this is the result. Students do what they can to maintain their grades, but struggle to earn high grades.

Betty describes the tough choice low-income students make. She says,

You can't get A's and work at the same time. Like, for me it is absolutely near to impossible. You end up working the weekends, but you work 40 hours in three days and then you turn around and you're exhausted for school and it's, do you sleep? Do you study? Or do you go to class? I mean you can't do all of them.

For Betty, this ultimately meant illness and an accident on the job, which lead to a period of drop out for her. Not every student dropped out, but decreased academic performance due to exhaustion from work puts these students at risk for drop out.

Even though most students in this study identified themselves as students first, it did not necessarily mean they were able to put school first at all times. They did what 
they could in order to maximize their time for school and earn good grades, but studies were put on the back burner to maintain their income. Whenever possible students asked for flexible schedules at work or switched employers that would accommodate their schoolwork. Needing to work was a constant source of stress, exhaustion and lead to a deficit of time for schoolwork. This need was directly tied to the limited familial resources students had available to pay for college and related expenses. Financial aid did not provide enough support for the majority of students to attend college without working.

\section{CULTURE SHOCK: NOT KNOWING WHAT TO EXPECT}

Low-income students in this study struggled to stay in college due to lack of financial resources and the repercussions of this constraint. Not only did students have to figure out how to pay for college every quarter, but also they had to navigate a new culture once they paid their bills. Students identified feeling like they “didn't know what to expect" once they were in college. They felt that their high school experiences did not prepare them to be successful in college and their families did not have the tools to help them understand the new culture. All of which added to students' stress and sense of uncertainty, which threatened their continued enrollment.

\section{My High School Never Told Me What to Expect}

The shift from high school to college was difficult for most students. Expectations were different than they were in high school and students struggled to understand the new culture they had entered without any preparation on how to navigate this new environment. Students expected college to be like their high school experiences. Aaron describes his struggles to adapt after a gap between his high school experience and 
attendance at Small Town. He was an average student and didn't take his studies seriously in high school. He thought he would be successful in college if he just applied himself more in his academics, but he struggled to understand the new college culture. He says,

Not knowing what to expect...I wouldn't say lack of studying, but I was expecting it to be a lot more like high school. In high school, they'll tell you when to get it done, in college they'll expect you to get it done. It's that, it's like, I wasn't expecting it to be harder than high school.

Students describe experiencing this shift from teacher-centered responsibility to studentcentered responsibility. They are now responsible for their own learning and struggle in this adjustment.

Similarly, Blanquita remembers having to change the way she approached school after realizing that no one would tell her what she needed to do.

You're used to being like told what to do next. Once you're thrown out here after graduation from high school, you're like, oh my god!! And you don't have nobody to tell you if you're doing it right or maybe you're doing it wrong.

In this new environment students had to figure out new expectations and ways of being a student without guidance. Some students dropped out of college altogether and some "took a break" for a quarter. Louisa and Holly Joy recall not understanding what instructors expected, their grades suffered and therefore they dropped out. When students did come back they still faced this challenge, but had a better understanding of the new culture. Though for many students this still doesn't come easy. Chris, a returning Latino male student, describes the uncertainty he felt on his second attempt at college, "it was new to me again, so it was kind of scary. I wasn't good at it at first, three years later trying to go to school, so am I going to be worse than I was before?" Doubting and 
questioning one's ability is common especially for those that had stopped out along the way.

Students attributed their lack of understanding to both their own personal failings, but also the shortcomings of their high schools. Not only were the expectations different in college than they were in high school, but high teachers and staff did not share with students that college was different. Johnny expressed his frustration with his high school experience and felt like they should have done a better job at prepping him for college.

They never told me how, they never told me what it was gonna be like and what I was gonna be doing. They never told me what my days would be like and what I would be doing in like classes and homework and all this stuff. They never told me all that stuff, so it was a little nerve-racking but it just blew over my head at the time.

Johnny and others in this study were not in college prep courses, advanced placement courses nor took advanced coursework in math or English. With exception of two students, Susan and Eddie, most students never mentioned their high school counselors. They received minimal guidance on enrolling in college and no preparation on what to expect once enrolled.

Holly Joy always planned on attending college. She earned good grades in high school, but remembers her complete lack of awareness of what she needed to do to go to college.

I didn't even know to take my SAT's. All the other kids were taking their SAT's their Junior year. I was like, what you're taking the SAT's? Ya know? And so it was just kind of, my parents didn't go to college they didn't know what was going on. It kind of just passed me by. So I started at a community college.

Holly Joy didn't have support at her high school or at home because her family had limited knowledge of higher education. Like the other students in this study, they are the 
first generation to attend college, so not knowing expectations became a huge challenge along the way.

\section{My Family Doesn't Understand}

Although family was generally supportive of their academic pursuits, all students were the first generation in their family to attend college. As Eddie says, "we are the first through the fire." Students attribute their parents' lack of understanding in part to their lack of education. Students' parents on average had a high school diploma/GED or less. Some parents, such as Raymond and Aaron's mothers, did not finish high school and dropped out after becoming pregnant. Aaron, a White male student, shared his mother's story as both a motivating factor and challenge.

My mom was a high school drop out and she had me when she was 20 . But she decided I want to go back to high school. She wasn't happy about it. And my sister, was not a very successful student, she didn't try very hard in school and I was always like I'm gonna do as much as I can in school.

Aaron and others' discuss their parents' limited education in terms of their lack of understanding of the commitment it takes to do well in college. They also discussed their parents' misconception of the "college culture."

In Alex's home, going to college was never questioned, it was an expectation, but shares that her parents didn't know how to help her because they had only attended school up through $6^{\text {th }}$ grade in Mexico. "Neither one have a college degree, so they are new to that culture, they don't know how much work it really takes, how the hours of homework is of huge importance. Spending hours in the lab, in the library so you have the tools and resources." Alex's parents were not able to provide guidance and the tools necessary to help support her while in college. Students describe this lack of 
understanding as a social distance between them and their parents. They cannot talk to them about school or get help.

Johnny and Ana's stories were the exception. They were able to ask their parents for advice. Johnny's mom had attended a year of college so she was interested in how things have changed and provided Johnny support and advice. Ana's father was currently attending Small Town Community College at the same time as her. For Ana, having her father on campus made her feel safe and supported. "It gave me a lot of support, knowing that I had someone there that loved me and cared for me. That would stand up for me if anything happened." Most students were not this fortunate and felt disconnected from parents. They felt that their parents "didn't care" about school. "So we couldn't relate on the other stuff. The other stuff, the obstacles for college, because like, you do all this hard work, they don't care about, no body cares about," Eddie says.

Alex describes the loss she feels because her parents don't understand and she cannot go to them for help.

I couldn't have a conversation, like you hear some parents or children. I remember going to school, they would say ya know my mom does this, my dad says this. It was cool that they could relate to their daughter or son and motivate them, encourage them and mentor them more than anything. I didn't have that.

As Alex shared this story in her interview with me, her eyes welled up with emotion. She longs to have this relationship with her parents, but knows that education is a distance between them.

Susan shared similar emotion in her interview when re-telling her story of gaining admittance into a selective program at Small Town. Her parents always expected her to 
attend college and become a professional in the medical field, but were unaware of the significance of her achievement.

Yeah, sometimes, it's like hard, cause I tell them like I've been accepted into this program and they're like 'cool'...I'm like no, 'I JUST GOT ACCEPTED INTO THE PROGRAM, it's not JUST cool!' They're understanding, but it's hard for them because I'm the first one.

Susan acknowledged that their lack of understanding is not due to lack of caring but their own limited educational experience. Even though Susan and other students acknowledge this, it challenges their ability to stay motivated and persist. "It makes you wonder if it's worth it," Blanquita shares.

\section{DEALING WITH CHALLENGES}

The challenges for low-income students seem to be insurmountable and never ceasing. "The obstacles never go away. Once you overcome one, you get ready for the next one." Eddie's words describe the constant battle low-income students face to stay in college and persist to completion. Though these challenges may result in departure for many students along the educational pipeline, students in this study were able find support in the form of relationships that mediated these challenges. These relationships were found not only on campus but also off-campus in their communities and in familial relationships. Faculty played an important role in the story of all students, and many times were students' main source of academic information, advice, mentoring and motivational support. Students also sought out and were connected with staff mentors through campus programs and clubs. The relationships with faculty and staff members were all formed in the campus environment, which students discuss as being inseparable from the relationships that were formed. 
Students also discussed the importance of familial relationships in both their family of origin and new families. These relationships provide motivation, encouragement and unconditional support even when students' academic success was in question. Above all, these relationships helped students circumnavigate the financial, cultural and structural challenges they faced while in college by providing a safe space where students were known and their experiences were validated.

Mentors Help with Life's Dragons

“It's just a great environment, it's such a happy environment, it's such a personable environment. That's the thing that I love about this college, it just feels really personal." Lisa's comment expresses the sentiment felt by nearly all students in this study. The college, staff and campus are seen in a positive light because they all provide an atmosphere of caring and personal connection for students. Being known by faculty and staff on campus is important for students because they feel connected and valued. For Nora, faculty are not just a resource for advice or getting her questions answered, but they show genuine caring and interest in her personal well being. "They make you feel like they care about you instead of just, you're a paycheck. Like I have relationships with them, it's not just, help me with this, it's like we talk about stuff outside of school."

Eddie shares a story about his personal mentor who is one of his professors. He helps him stay on track and deal with life's challenges. He shares his story of confronting a challenging choice of whether or not to engage in taking drugs for the first time. Instead of dealing with this alone, Eddie went to his professor, Dr. Jones, and asked for his advice. He can't discuss this with his parents, but he knew he could get honest advice from his professor. This was not an academic challenge, but a personal one that could 
affect his academic performance. Eddie explains, "life is not all about college, this all makes you distracted and scared." In finding a personal mentor in Mr. Jones, Eddie can refocus his efforts on his academics while getting help with "dealing with life," as he describes it.

They help you deal with all the stuff around you. You're like oh, the dragons are coming...oh, they killed him, that's my mentor. Last minute, they kill the dragon out of no where. I'm not there yet, I'm tying to get there, some of us never get there. You're probably still fighting dragons.

Not all students find faculty mentors, but they are connected to staff mentors, which are discussed in a similar way. Maria shares that her mentor is always there for her. "If I had a problem with something... he's always there for me. He's very welcoming." She goes to her mentor for advising, guidance and encouragement. Ana also discusses going to a staff member because she feels comfortable with him, sharing her personal struggles.

It takes me a little while to get comfortable with someone to open up, but with him I feel pretty comfortable because he's, he's known in a way. And he knows where I'm coming from, he knows my family. I feel a lot of support with him.

Students feel a personal connection to mentors that help with life's challenges both within education and outside of it.

\section{Being Known and Being There: Forming Relationships with Faculty}

For most students, these relationships are formed not through a formal mentoring program, but through the simple gesture of faculty and staff getting to know students. Students describe the importance of faculty and staff doing things such as remembering their name and celebrating their successes. Pancho, a Latino male student who recently graduated, shared the role faculty played in making him feel known at Small Town. 
“They um, faculty knows you by your name. When they find out you're graduating, they're all excited, they're like congratulations!" Lily, a White female student, also shares the importance of faculty knowing her by name. "Yeah, taking the time to get to know my name has been very helpful, just knowing that they care enough to know my name is great!"

Students describe being known by faculty and staff not just in the context of the classroom or a program on campus, but that faculty or staff see them in the hallways and greet them by name. They ask how classes are going and show caring about students' success. It may not even be faculty that students are personally connected with, but it is an atmosphere where faculty knows students. "Even some of those instructors that you don't want to take, they're still welcoming to me. That's how I felt if anybody needs questions, it's like an open door kind of thing," Louisa describes.

Chris was very worried about his ability as a student going back to college after a gap from his first attempt. He describes how faculty made him feel like they were there to help him out and cared about him personally.

They're always eager to help you out. Oh yeah, I'll help you out. The teachers, they're awesome teachers, the best teachers I've had. It's remarkable how much they're willing to help you out. They never made me feel like, are you kidding me? They're always willing to help out, they were never rude.

Chris felt safe asking for help and received the validation he needed to be successful academically.

Many students share Chris's struggles of returning to school after a gap or not feeling academically prepared for college. Students felt faculty supported their success by caring about them personally. This is a stark contrast to students' experiences with many 
of their high school teachers. José shares that his high school teachers never expected him to attend college. He wasn't a strong student, nor had clear direction during high school. Therefore, they didn't expect much of him. In contrast, faculty members at Small Town believe in his potential and encourage his success.

They don't try to bring you down they just bring you up. It really helps push me. When I first came in, (I thought), maybe I can't do it. No, you can do it. I was always told, you can't, you can't, you can't. Now being told the opposite, it threw me for a loop. Once you've been told a second time, you're like ya know, I can do it. It's been really good.

Tyson also struggled at times with academics and his confidence to succeed in some of the upper level math courses. He describes the way faculty members care about student success and the time they take to make sure students actually understand material.

The majority, if they knew you were struggling, if they knew you were there, they'd work around it. They'd help you out. I had one teacher, if you flunk their class, it reflects bad on them. They help you out, they also want to see you pass as a student.

Tyson saw that faculty members wanted him to succeed and that they took responsibility for students' success. Betty also describes the push from faculty members as motivators of success.

They are excited for you when you succeed. Like when you get A's and B's on your test, they are happy, they are like that's a great score! You did really well, you know, you missed a couple but don't worry about it. They like, they help encourage you for perfection, but they don't criticize you when you don't meet it.

Faculty members support students both personally and academically, as they encourage students and take shared responsibility for their success.

\section{Making the time}

Faculty members at Small Town are "there for students" and know their students, but they also make their time available for students. Students share that they can go to 
faculty because they have time to discuss coursework or get the help they need. It may be in office hours or outside of that time. Johnny shares the importance of the time that faculty members make available for students.

I could always e-mail them every now and then to ask them things and they would respond whether it was day or night. And I sat down with them and have conversations about the material and they would tell me their office hours and they would tell me where to meet them.

Knowing that faculty was available to help was a support for Johnny and others. Like Johnny, Lisa feels support from faculty because they are willing to "bend backwards to help you out." Having good office hours, being open and understanding are qualities that she feels make it easy to approach faculty. Some faculty members even took extra time to help students with work outside of the classroom. Chris was studying to pass his exam for the police academy but was struggling with his English grammar. He shares that his English teacher provided him extra support and materials to help him prepare for the test. Other faculty took extra time during class, spending more time material that students struggled with. Chris describes his experience in a math class where the professor slowed down for students. "With him you wanted to learn the information he was putting out. If he had to make him a day behind if the students weren't up to pace with it, he was willing to be put behind to help the students."

Faculty members' willingness to take the extra time and be flexible with their schedules made students feel like they were cared for and could be successful. For students that were parents or had commitments outside of school this was especially important. Amy, a White mother of two young children describes the impact this had on her academic success. "If my kids were sick, even if their policy said no excuses. If you 
always turn in your work, they're really kind about it. If I just had a day or weekend where I couldn't get stuff in."

Alex, also a mother, describes the importance of faculty's willingness to be flexible. As a working mother with little extra time available it has made a big difference when dealing with the unexpected.

They've (faculty) been very flexible with helping me more with finding the material or even extending the due dates at times, that was amazing! Because not all instructors give extensions, they're like no. I took my time to put this class together, you meet the deadline. But you can't, you need that little flexibility sometimes, because life happens. You don't plan on it.

By being flexible faculty help mediate the constraints of the unexpected in the lives of low-income students. It not only allowed students to complete coursework and maintain their academic standing, but students feel cared for when life presents challenges.

\section{The Faculty and Staff Make Campus Home}

All students discuss the campus environment in a positive light and describe it as "feeling like home." They discuss the campus in same way they discuss being known and cared for by faculty and staff. "This is basically, family," Louisa says of the campus. Faculty members and staff know students by name, which makes them feel at home. Tyson, a White male who is from a small farming community, also describes the campus as being like a family.

It's more of a family friendly atmosphere. You have all different walks of life, and you all got along...it seems like it's just, a family oriented school, that cares about you personally, that's small enough to want to help you out, which is nice.

Again, students feel that faculty care for them and this permeates the campus environment. Students feel comfortable and safe on campus because faculty are welcoming and are invested in their success. As Maria, a Latina female student, says, 
“...the faculty, it's very comfortable. They're interested in the education of the students." Ana echoes this sentiment, after describing why she chose to attend Small Town over a large prestigious public university. "I feel like they care more about the students than the school prestige in a way. So, it's, they want YOU to be successful and there's not many people."

Like Ana, many students attribute the ability of faculty to connect with students to the size of Small Town Community College. "Well I think that with such a small campus and with such a small amount of people in each class, you're able to build that intimacy with your professor," Lily shares. Because of the small size, students and faculty can interact on a more personal level and take the time to help students. Karl, who is from a community much larger than Small Town, describes the importance of a small campus and classrooms. "I like Small Town because it's really small. So if you have any questions, it's easier, I don't feel nervous if I have to go talk to them if I don't really get this." For many students the small environment means that approaching faculty and getting their help is much easier. Pancho, who had attended a much larger community college previously to Small Town, describes the difference for him.

It's small classes, which means the teachers actually give you more attention. Instead of like when you go to a bigger college, to come to a community college where there isn't a lot of students. Teachers can really focus on all the students.

For most students, this is one of the main reasons they decided to attend Small Town Community College. It was small and felt more comfortable. In some cases, students or their families knew faculty or staff outside of the classroom before attending college. The small intimate campus setting helped students feel more connected, which aided in their ability to seek help when needed. 


\section{FAMILY'S UNCONDITIONAL SUPPORT}

They'll support me and push me. They want to see me succeed. I'm not walking alone. - Steve

Although family is a challenge for most students, it is also discussed as one of the biggest supports in students' lives. Parents may not understand what college is like or how to prepare their children for what to expect, but they are encouraging and supportive even when students face failure and struggle. Sometimes they are the only ones left. Lily says, "no matter what I do they'll support me." Students describe this support as unconditional. Parents or family members may not be able to support students academically or financially, but provide encouragement when students face challenges.

Raymond describes the role his family plays in supporting his academic career. His path has not been easy and he has stopped out along the way, but his family is always there as his support network. "You have to have some kind of network with people, somewhere you can always go back, that cares about you at the end of the day. These things I talk to them (family) about.” Johnny describes the role his family plays in a similar way. They are there for him despite any failures.

They've been my support group... whenever there are days when I want to give up or like whenever I get bad grades, or just get really frustrated with the hard work and stuff, they would just be there and just tell me that I'll figure it out.

Family supported and encouraged students even when the goal of finishing college was questioned by the students themselves. Family is there to remind them to keep going. As Tyson explains, "family just kind of like said come on keep going you're almost done!" Having College Expectations and Teaching Success 
Parents' support during college is grounded in the expectations they have their children. Nearly all students discuss growing up with the expectation that they would attend college. Parents communicated this expectation regularly as a means to improve their future financial wellbeing and quality of life. Raymond describes the lessons his parents shared with him at an early age regarding the importance of education. "They've always told me to get an education. Get yourself educated and get yourself out there, cause no body cares about you and you have to get on your feet." Education is seen as the key to future success. Tyson's father communicated a similar message growing up, "We didn't have much money growing up. He would tell us, better go to school. He would help us do everything to go to school. If I don't go it's kind of letting him down." In most cases, it was never a question whether students would attend college or not, it was just expected. Lisa describes her experience growing up with this expectation.

It was kind of one of those things in my family where they kind of raised me with that expectation of I was gonna to finish high school, or get my GED in the case of home schooling and then go to college. It was one of those things that we definitely talked about almost where it was an inevitable pathway.

Students discuss the pressure of meeting their parents' expectations as a support in their quest for a college degree. Ana describes how this helped her stay motivated while in college. "It's helped me because they put a lot of pressures on me. And I put a lot of pressures on me too. Since I'm the first grandchild, first cousin, first everything!" Holly Joy discusses the importance of earning a college degree in her family. No one in her family has ever attended college — she is the first. "My mom and my grandpa were super like, education, education! We were poor, I wouldn't say poor, just not a lot of money, I think education was important." 
For most students this expectation was cultivated early in their childhood and parents supported their children's academics early on. Susan smiled as she recalled how early on her parents supported her education. "They really, my mom sent me to school when I was $2 \frac{1}{2}$ so um, they just want the best for me." Lily also recalls similar memories of learning from her parents early in life.

They taught me from a very young, uh, I was pretty smart even before I went to kindergarten, I knew my alphabet, I knew my numbers, how to read, so they helped me from a very young age. And they are still there to support me and they always give me encouragement.

Lily appreciates the support her parents gave her early on, which has continued into her adult life. Parents supported students by teaching behaviors early in childhood that helped them be successful in school. They may not have known what to expect in college, but they gave support to their children by teaching them successful study behaviors along the way. Alex remembers how her parents were strict with her throughout elementary school. "Mom and Dad both, as soon as you get home, do your homework then your chores. Make sure that nothing takes you away from your studies." In doing so, Alex's parents and others, taught students to put schoolwork ahead of other things, which helped students prioritize their time and teach behaviors for success.

Family as Motivation: Being a Role Model

Being the first ones in their family is discussed as adding to their motivation and duty to be a role model for their siblings or future generations. They may not know what to expect because they are the first, but it provides extra motivation to overcome this challenge. Pancho describes the motivation his family provides him, even though he no longer lives with them. 
As far as my family back home, maybe motivation it's just let's get it done. I'll be the first college graduate from my family, well from my immediate family. We have the college graduates from uncles and...but as far as my brother and sister, I'll be the first college graduate out of my family.

As he describes the motivation he receives from his family, his eyes began to well up with emotion. He shared that when he receives his diploma he plans on sending it back to his brother, whom he says raised him. His education, he said, is for his brother and his family. He hopes that one day his children will not struggle to attend college because they've seen their dad earn his degree. Amy shares a similar sentiment about being for her children. "I think, just like playing with them, realizing how smart they are, setting a good example for them, cause I want them to go to college. And I want to learn about the things they can do ya know?"

All student parents discuss being a role model for their children as a source of motivation to succeed. But even those students that are not parents share similar stories.

Students like Eddie and Blanquita discuss being a role model for their sisters. Eddie says,

I believe big brothers pave the way for little sisters. I always see myself in that image. Your brothers went to college, so awesome yeah! I wonder how my sister is going to feel proud of me, oh your brother goes to the university, so yeah! I'm going to college too I want my sister to be like, 'that's my brother.'

Blanquita shares a similar story about being a role model for her sisters:

Well as a sister they look up to me. So it's like, I have to be like, I have to be good, ya know what I mean? I've noticed that my sister that's 15, she's looking towards the same career as me, I'm like wonder why? I guess I'm like their role model, because they do look up to me.

Blanquita goes on to discuss how she cultivates good study skills and praises her sisters for their academic achievements in high school. As the first one in her family, she wants to pave the way for her sisters as a positive role model. Like many other students in this 
study, it helped Blanquita to stay on track and give meaning to her educational goals that went beyond her own individual achievements or failures.

\section{CONCLUSION}

Being a low-income student means struggling to make ends meet throughout college. Paying for college was a significant source of stress for all students. Many students faced further hardship because they or a family member had a work place accident or illness related to the job. These unexpected events created more stress and at meant a break from college. Students applied for financial and grants to help with college, but it was not enough to cover all expenses. All students worked to pay for school and/or living expenses while attending college, and in some cases to support their families. Working was exhausting and negatively affected their academic performance. Students had to work - there was no choice.

Even after students found a way to pay for college, they struggled to understand the new culture and expectations once enrolled. Students describe feeling like they didn't know what to expect. They attribute this lack of preparation both to their high school's inadequacy and their parents' lack of knowledge of high education, as they did not attend college. Students struggle to understand this new culture and adapt to the new environment.

For all students, faculty support was one of the most important relationships to their success. Students received support in the form of mentoring, a personal approach and familial atmosphere. Faculty members made an effort to know students' names and cared about their success. Students had a positive view of the campus and viewed the faculty as a representation of the college. Faculty made the college feel like home. 
Additionally, students received support and encouragement from their families.

All students said that their parents expected that they would attend college and reinforced this growing up. Even when students faced failure in college, parents and family members encouraged them and believed in their success. Students were motivated by their family's support and wanted to be a role model for their siblings and future generations. This motivated their success and gave them the support to deal with the challenges that came their way. 


\section{CHAPTER V: EXPLORING RACIAL-ETHNIC DIFFERENCES}

All students in this study experienced challenges because of their low-income background. They struggled to pay for college, balance working and school, while making the transition to a new college culture with minimal support. Though all students in this study share similarities because of their low-income background, they experience some of the challenges quite differently because of their race and ethnic background.

Being a Latino/a student meant experiencing racism and negative stereotyping throughout one's life. These experiences began early in their educational careers and followed them into their college experiences. Students describe racism they encounter from high school teachers, community members and peers. At times students felt that this racism made them question their abilities. Most Latino/a students also discuss the challenge of language learning in secondary school and the stigma that is attached to being a non-native English speaker. This has carried over into their college academic careers as they still struggle with confidence in their language abilities.

To compound students' struggles to "fit in," they describe the challenge of "living between two worlds" or becoming Americanized while still maintaining ties to their culture and family. The tension is felt between themselves and their parents as they shift in between these worlds. Even though a welcoming campus environment at Small Town Community College greets students, the memories of racism and challenges of acculturation continue to influence their college success.

White students in this study do not experience racism in their high schools, but do discuss feeling academically underprepared as a major source of challenge when entering college. They place below college-level courses and need to spend a significant amount 
of time in developmental course work. White students hold their high schools responsible for their lack of preparation. Even though Latino/a students may also be underprepared, they did not discuss this as the primary challenge in their experience.

White students did discuss feeling discriminated against because of their race. They felt excluded from resources on campus and in their home communities. The result was perceived tension between White students and Latino/a students on campus, which lead to a racial-ethnic divide. This experience was in contrast with Latino/a students' strong sense of community and belonging on campus, even though White students still felt connected to campus. In the following sections, I compare and contrast the experiences shared by Latino/a students and White students to better understand how racial-ethnic identities influences academic persistence for students in this study.

\section{BEING A LOW-INCOME LATINO/A COLLEGE STUDENT}

\section{Doubting Yourself: Memories of Racism and Stereotyping}

All Latino/a students in this study shared stories of racism and racial-ethnic stereotyping they experienced in their home communities. Students describe the events with strong negative emotion that carried over into their college careers. Most are still living in their home communities while attending college at Small Town Community College and still come into contact with racism in their everyday lives. Even though the majority of students live in communities where Latinos/as are the majority population, overt racism is still present. These experiences are specifically rooted in their high school experiences with teachers and peers. At times this makes students doubt their own abilities as college students. José grew up in a small community where nearly $90 \%$ of the 
town is Latino/a, but his experience of overt racism made him question whether or not he could be successful in college (U.S. Census 2010).

People are like oh you're gonna be a drop out. Oh you're gonna be this. Maybe on the dropping out part, you're not gonna do anything good. You're gonna be in the orchards. There's so many stereotypes. Everything is just, it kind of brings you down...It challenged me because it made me think, maybe they're right, I can't do this.

Raymond also described his experience in a different community where he feels like some still doubt his abilities because he is Mexican. He shares the stereotyping that many in his community believe about Mexicans, which at times brings him down. "Stereotypical challenges, as far as cultural and personal and ya know...oh, 'he's a wetback or he's a drug dealer or he's a machismo or he's lazy or he's dumb or he works in the fields or they just, you're just going to be THAT'." The stereotypes and racial slurs seem to permeate students' experience in their community. These are overt negative stereotypes that students come up against during their daily lives, which are tied to "working in the fields" or "working in the orchards." The message students hear is "you will never make it."

Unfortunately this message is not just held by community members, but it is found in students' experiences in high school. Teachers and educators perpetuate some of these stereotypes within their classrooms. Susan lives in a community similar to José's. The town is an agricultural community, which relies heavily on agricultural laborers and food processing plants. In the past three decades the Latino/a population has grown exponentially and now comprises over 70\% of the town's population (U.S. Census 2010). The high school is predominantly Latino/a at $86 \%$ of the district's total enrollment. But like José, Susan still experienced racism even from adults within her school. 
Well one time, I had a teacher that, she said that she knew that all Susans, and especially Latina ones, were all lazy. So like, she kind of like treated me like, why are you treating me like this if you don't know me. Oh she's like, 'all Susans especially the Latinas are like not caring about school and things like that.'

Alex also describes her experience in school in a similar way even though she lived in a different community. She describes being stereotyped by the school district as early as elementary school because she was a migrant student. "We used to migrate back and forth during the seasons," she describes. The school district expected that Alex would fall behind and not be engaged in her schoolwork.

Students also experienced more passive forms of exclusion and cultural stereotyping. Ana is from a community where the Latino/a population is still the minority. She describes feeling out of place and disconnected. She remembers early on feeling different. She says, "especially cause I came here when I was 8 , and it just like reminded me when I barely first started going to school, like I was the only one there, dark skinned, dark hair, dark everything. And I just didn’t feel comfortable.” Ana reflects on how her experiences before college really made her question where she belonged. She didn't feel like she fit. Alex shares a similar feeling as she moved between communities.

It never made sense to me because I thought well, I'm Mexicana, I wasn't sure if should belong to a Mexicano group or should I belong to the bilingual group or should I just be...(laughing). And it was very annoying because, yet they would look at me and they wouldn't accept certain things, but yet on other things, yes I was accepted.

Alex didn't feel accepted by what she perceived as her "own community," nor did she feel accepted by the White students. She felt excluded, which added her sense of selfdoubt. José also shares painful stories of violence in his community because of his race. José is from Mexico, but he is fair-skinned, fair-featured and considers himself a White 
Meixcan. In his small community this caused tension and resulted in exclusion and violence. He shares his experience when first moving into this town:

I was white, and my cousin introduced me to his friends and he's a more dark Mexican. And basically I almost got stabbed, because I was white, light complected. They were like 'he's white, don't bring him in here.' My cousin just went up and was like, so like that kind of stuff. Then coming over here I was like 'what do I say, am I white or Mexican, am I gonna get stabbed?' So it stays in the back of my mind, in your unconscious.

José went on to explain that he was not accepted in his community because of his race.

His Mexican peers did not accept him nor did his White peers. He tries to limit his interactions now within his community or even those on campus that he went to high school with. As he explains, he tries to put it "in the back of his mind," but it is still there.

Eddie describes the nuances of these forms of racism and exclusion using his own "ideal types." He describes three ideal-type forms of racism, though he says he's only experienced two out of the three. The first he says are the "friendly racists"- the ones that "always joke around." These he describes are more passive racists. They notice race, but don't necessarily act on it. The second are the "prejudicial racists"- they are insulting and make racists comments directly. The third he describes as "your KKK racists." "The worst kind is the kind that goes out KKK style. That's the bad kind, KKK style. Those are the ones that are violent you know," he says. Eddie acknowledges that these are all forms of racism and the second form, prejudicial racism, may lead to the most violent form of racism. He has not experienced violence himself, but knows it's a possibility. Eddie's analysis is was not simply a theoretical exercise, but a way of describing his encounters with White peers and adults in his community. He and others continue to experience both "passive" and "prejudicial" racism as long as they live in their 
communities. These memories and experiences aggregate their stress while attending college and thoughts of self-doubt.

\section{Mixed Between Two Worlds}

Latino/a students in this study describe feeling "part of two worlds" or "mixed between worlds.” They are Mexican, Mexican-American, Latino/a or Hispanic, but they are also American. Some students are recent immigrants and struggled to learn language and adapt to a new culture, where others have never known life outside of the United States. Students describe these two worlds as their family life and their school life. At home they are tied to their culture and language, whereas at school they are "Americanized." This can create tension between themselves and their parents. Susan shares her struggles,

So at home I'm expected to speak Spanish, and be I don't know, a little more conservative. But then like, when you're out in the real world, society is like telling you to become more Americanized, be more of an individual, not like, you're still family-based, but I think it's being more of an individual. At home it's more about family, caring for them.

Students describe trying to balance both of these cultures and may need to adapt their behaviors in order to be successful. Susan says, "I keep my values and morals, so I can balance society or culture." Ana shares a similar strategy.

I feel like I've kind of molded into that environment (American culture). But I still want, I still try to keep my traditions. Like for Christmas we make tamales from own home country. And just like little things like that we still try to stick to our roots.

Even though she felt out of place when she first came to the United States she feels more integrated now, but tries to maintain ties to her home country. This is not an easy task for most students and parents are not always supportive of students' Americanization. 
Alex describes the struggle she faced with her parents when deciding to enroll in college. She feels like her parents don't understand what is expected of her at college. As shared earlier, her parents only attended school in Mexico up through the $6^{\text {th }}$ grade, so they have limited understanding of the college culture. They are unfamiliar because they are new to the American culture and educational system. This creates more social distance between herself and her parents, as Alex becomes more Americanzied. White students face a similar challenge because their parents have not attended college, but the tension is compounded because Latino/a students are not only becoming acculturated to a new educational culture, but also to new language and values.

\section{Learning English: feeling embarrassed}

All but one Latino/a students in this study are bilingual and grew up in monolingual Spanish-speaking households. Students recall memories and struggles of learning English. At times they experienced stereotyping related to this barrier or perceived barrier. Ana grew up in a household where Spanish was the primary language spoken, but she learned English at an early age. Even though she is fluent in English and Spanish she still faced discrimination and stereotyping because of her perceived inability to communicate in English. She shared a story within her community. "One day I was at a restaurant and this lady starts attempting to speak to me in Spanish. I can speak English too, just because I'm dark doesn't mean I didn't know... and she was speaking to me in a really bad tone too."

Blanquita shared how being language learner in school meant being bullied by other kids. She arrived from Mexico when she was 6 years old, speaking and understanding only Spanish. She says with strong emotion, "it was a challenge to learn 
English. I would always cry because I didn't know how to speak English. I didn't want to go to school because it was difficult. I would get bullied by them because I didn't know how to speak English.” Blanquita says she still struggles with her spelling and confidence in English, because of these memories and lack of preparation.

Maria who is also a more recent immigrant to the United States describes her experience being in ESL classes and not feeling prepared for college. "I was taking ESL classes, but they didn't really help me. Yeah. By the time I got to college, my English was not really good, so I've had to study more and go the English lab." This is a common story for all Latino/a students in this study. Regardless if they were recent immigrants or if they were born in the United States, they struggled with English and their language confidence while in college. Nearly all students tested below college level English and needed extra support to succeed in their classes. Maria says she needs extra time to complete her assignments, because she continues to struggle with the language. "I need a lot of time to do my homework."

Many students need to utilize the English lab or go to office hours for extra help. Alex still lacks confidence in her English ability even after successfully completely her degree. She describes her struggle to trust English fluency at college and at work. "I'm a little intimidated by it, I feel kind of embarrassed. I feel like it's (English) not good enough. I've been told that's not the case." Even though she receives positive feedback from professors and coworkers regarding her English skills she still lacks confidence in this area.

RESISTING THE CHALLENGES

Proving Them Wrong 
Although all Latino/a students share stories of racism and discrimination, they do not treat these experiences as permanent barriers to their success in college. Instead, students describe these experiences as motivating factors, which "push them forward." A common theme that comes across in these stories is the script of "proving them wrong." Eddie, who is well aware of the stereotypes and racism he is up against, explains the importance for him as a Mexican student. He says,

We're all Mexican. We're trying to make sure our people are put on a pedestal. You don't want to be that stereotypical lazy Mexican. Bald-headed gangster. You don't want to make people right. You want to make sure you're right. When you're Mexican, you're always right, even when you're wrong.

Eddie feels the pressure to resist these stereotypes, but when asked if it helps him or challenges him, he replies, "it only pushes me forward." It is used as motivation to be different and prove those in his community wrong.

Eddie and other Latino/a students in this study are from communities where the poverty rate is among the highest in the state. These communities are ridden with high crime rates, violent gang activity and high unemployment rates (US Census 2010). The economies are dependent upon agriculture, but most work as seasonal, low-skilled laborers, which affords minimal job security. Drop out rates in local high schools are high and many Latinos/as struggle to make it through the secondary educational system. Eddie described the sentiment expressed by many students in this study of wanting to be different and the motivation to negate these statistics. Blanquita described her motivation as a Latina with pride:

Well, it's given me not power, but ya know how there's some people that say oh no, you're a Mexican, you're only going to work in the fields and blah, blah. You're supposed to work in the fields, and this and that. There's that type of people. Or, you know the Latino population, the graduation from college is still 
low. I'm like, NO, I'm going to prove you wrong! No, I'm not going to spend my life working in the fields. And I get mad and I think it's just my, I want to get revenge thing. Kind of, I'm going to prove you wrong and then you're going to be working for me, ya know?! That's my little revenge. It's not really going to come true but that's what motivates me to further myself in my education (laughing).

Blanquita is not alone in using the script of "proving them wrong" as a motivator or having those "naysayers" work for them someday. José describes his experience resisting these stereotypes and moving forward with his educational goals despite the lack of support in his community. He says,

And you don't let it get to you. Like me, nothing gets to me anymore. That's probably the good things about it, you don't care. If you do care, that's when you, like I said, it makes you question. And if you don't, it makes you basically you do your full potential. Cause you don't do what anyone else things, you do what you think.

José and others use these negative stereotypes and experiences as empowerment to resist and prove their communities wrong.

\section{Paving the way}

Latino/a students in this study are the first to attend college and may even be one of a small group of Latinos/as in their communities to attend college. They resist the stereotypes and racism by moving forward and paving the way for future generations and future Latinos/as. They view their attendance and success at college as not only a victory for their families, but for their people. As Eddie described, "I do it for my peoples. My race, mi raza." There is a sense among Latino/a students that they are representing their entire ethnic community. This could be a tremendous source of pressure, but students described this role as a motivating factor in their educational success. Blanquita tears up with pride when she describes her accomplishments: 
I'm proud of being Mexican. Studying and kind of like ya know, right now, that I'm going to get my AA, I kind of feel proud of myself because ya know, I came from Mexico, work my way up all by myself...As you see now, the Latino population is growing. They're graduating from universities and colleges. And it's kind of like, I get sentimental, it's like yeah, I'm one of those! You kind of get into that mood.

Pancho also smiles with pride when he described that Small Town has its largest graduating class in history. He says, " they had to move it outdoors this year, because it's so big." He is proud to be a part of this graduating class and describes the importance of this first step for his family. "So it's a stepping stone, we're hoping that our family just keep moving on from this. I graduate June $14^{\text {th }}$, my nephew graduates June $17^{\text {th }}$. So there will be two of us. We're just so happy it worked out." Pancho and other Latino/a students, describe their education and degree as a victory or turning point for their family and community. It is collective and representative of something larger than their individual effort.

Raymond describes his role in this effort. "So me and my life I have to educate myself and align myself with people that understand and do the best I can. Enlighten others and give hope for the future." Latino/a students in this study see themselves as successful and represent what is possible in the future. As José shares, "it shows people that I CAN do it! If I can do it, then other Mexicans that come, it's like oh he did it. I'm the first domino to tip over, then everyone starts going." By attending college and earning their degree successfully, students feel they are paving the way for future Latinos/as, which gives them hope and motivates their success.

Being bicultural and being proud 
All Latinos/as in this study identified themselves as "bicultural." They lived in "two worlds," which at times was a challenge, but it also contributed to their success and sense of pride in their education. Eddie describes the pride he feels in his own culture and how that helps him be accepting of others. When I asked him about how being bicultural had helped him, he wanted to more about my own cultural background and my family's immigration to the United States. His openness to learn about my own background is an example of students' authentic interest in other cultures and pluralistic views. Eddie shares,

I think being a Mexican, cause come we're all migrants to this country of opportunity. We came here for the same reason. I don't about your family, five generations back from Ireland or something...that's just shown me how to be accepting of people.

Eddie's words are discussed in the contrast to the racism he has experienced in his home community. At Small Town he feels that the type of racism he has experienced is not acceptable on campus.

Pancho also describes openness to new cultures and sense of pride in his own diverse background. Pancho grew up in a household that was very diverse. "I'm from different cultures, different people always around me, I was able to relate to anybody. I could talk to anybody, I could relate to anybody. I would never really look at the color of their skin." His mother was from Ecuador and his father was from Honduras, but he grew up in Los Angeles. He shares memories of eating around the dinner table where all spectrums of races, languages and foods were present. This helps him in college because he can connect with students from various backgrounds and feels at home when diversity is valued. 
Susan also describes her bicultural helping her success in a similar way. She says,

I think I'm more open minded, being accepting of other people that are the same way. I'm not going to judge someone, be like, the same way as them. Cause they're from a different culture I'm going to be more understanding of their culture and be more open minded.

In addition to being open-minded and accepting of others, Latino/a students described valuing their own diverse cultural background. Most are bilingual and feel like it is a tool to connect with others. Though it was difficult to learn English, their native language is an important aspect of their identity. Alex described the pride she feels in her culture and language. She says, "I've always loved using it (language) as a tool, because it's helped me understand a lot of different families and people." Alex sees her ability to communicate in both Spanish and English as an asset. She shared that her mom taught her this lesson early on. She says,

Because my mom, that's the one thing I loved - learn the good not the bad. Use who you are, for you, not against you. I think that's very important. I think that if people would just embrace it in a positive light. I might be difference, I might be Mexicano, I might be Chinese, but my background is going to help me understand...I think as a nation if we could reach that, it would help us so much more.

Alex and others value their own diverse backgrounds and those that may be different from their own. Being bicultural helps students be accepting and proud of their own cultural background. Students maintain cultural traditions, language and practice to stay connected to their country of origin and families. This helps students to navigate the new college context, but at the same time maintain a cultural connection to their roots and family.

\section{Being Latino/a and Feeling at Home on Campus}


Latino/a students find motivation by proving them wrong, paving the way for other Latinos/as and by maintaining their cultural ties. This motivation is not an individual effort but is supported by the environment at Small Town Community College. Students described feeling at home on campus and felt that the campus diversity helps them be successful as first-generation Latino/a students. Alex described this feeling in contrast to other campuses she has visited. "I will say that Small Town does not make you feel the color of your skin, whereas when I visited a couple of other campuses I certainly felt like they were very prejudiced towards Latinos. That was my feeling."

Students are able to encounter other students that share their similar racial and ethnic backgrounds, which makes it easier for them to connect to classmates and feel at home. José shared,

The majority of the people at Small Town are Hispanic. I can relate to them, like where are you gonna work? The orchards. Oh, I work there too! Not like at McDonald's or whatever. I'm like yeah, I know how to work just as hard as you do. And it makes you connect with people a lot easier.

Students can share stories, language and culture with one another. Ana discussed her comfort at Small Town in contrast to her high school experience where it was predominantly White. At Small Town she can speak Spanish with her peers, share similar foods and cultural traditions. She shared, "That's what you'd usually get when you go somewhere with someone of Hispanic origin. I guess we're more alike in that way, or we're more familiar."

This sense of being home or belonging on campus is cultivated through relationships on campus that are formed with other Latino/a peers and staff. They are formed through involvement in organizations and campus programs such as TRiO and 
MEChA (Movimiento Estudiantile Chican@ De Aztlan). These organizations are the gateway to accessing resources and having a support network on campus. The organizations are led by a small group of Latino/a professionals at Small Town. Every student had developed a relationship with at least one of these Latino/a professionals and shared the important role they played in their transition to college and their academic success.

\section{MEChA: Sharing experiences and building community}

All but one Latino/a student was involved in MEChA during their time at Small Town Community College. MEChA, Movimiento Estudiantil Chicano de Aztlán, is a "student organization that promotes higher education, cultura, and historia." MEChA was founded as to promote liberation of "la Raza" through political involvement and education (www.nationalmecha.org). At Small Town Community College MEChA is run by one of the few Latina professionals on campus. She invites students to participate and become involved in MEChA. Blanquita shared her story of first being invited by the advisor and becoming connected to other Latino/a professionals at Small Town. "I decided to go to the MEChA meeting for the first time and I think he was the advisor, a second advisor or something. He was pretty friendly too and he knew a lot about scholarship and stuff." MEChA is a place for students to connect with Latino/a staff members, which helps them find a friendly place and a way to access resources. Blanquita and others find out about scholarships and share books and other resources.

Students like José also found MEChA to be a place where they can connect with other Latinos/as on campus. They shared experiences, encouraged each other and know 
they are not alone. José described the sense of belonging he feels through his involvement in MEChA:

It helped me be with other Latinos in the college that are basically going through the same stuff I'm going through. Our families being low income, they help me out, they're the ones that help me out. They're the ones that help me, motivate me to like, I'm doing it, you can too.

José found a support network when he attended MEChA. He could share struggles, find support from others' successes and know that he was not alone on campus.

For many students their involvement in MEChA also connected them to Latinos/as outside of Small Town Community College. Latino/a students attended conferences or events at a state-wide or regional level. Ana described her experience attending a Students of Color conference and how experience expanded her horizons.

It was really good (the conference), cause it was the student of color conference and I got to experience a whole bunch of things that I would have never thought of. Like, there's so much diversity in people that it's pretty incredible. And um, usually people think that MEChA is for like just Mexicans, but I'm not Mexican.

Ana goes on to share that she encountered other races and cultural backgrounds that made her feel welcomed and broadened her definition of what it means to be Latina. Through her involvement in MEChA she is connected to a broader sense of diversity found outside of Small Town.

\section{TRiO: Being connected and accessing resources}

Another important place on campus where Latino/a students feel at home is in the TRiO office. TRiO programs are federally funded programs such as: GEAR-Up, Upward Bound, Talent Search, Student Support Service and the Ronald E. McNair program. They serve first-generation, low-income and underrepresented groups starting in middle school and continuing on through post-secondary education. At Small Town Community 
College an office suite is dedicated to serve TRiO students through Student Support Services. Students in this study refer to the office as "TRiO.” All Latino/a students discussed the importance of TRiO and the relationships they formed with staff as being key to their academic success. Blanquita shared that without TRiO she would have "been lost." It helped her navigate higher education and gave her the support she needed. She says,

Well, honestly if I wouldn't reach out to them, to that I would've been lost. What am I supposed to do now, what classes am I supposed to take, but they're like there to help you along the way. They tell you, they kind of like, pull you along the way.

José describes his experience in a similar way. TRiO pulled him up from his

lowest point when he questioned his ability to continue.

That's the big one that's helped me out. TRiO was there when I was basically at my lowest. I went through a party stage, my grades went down. They were like, ya know what we can help you, pick you up. They set a little plan for me, got me into the program. They helped me with my, they got my classes, they helped me out with everything. Everyday they would check up on me. I would be in their room everyday, they would be like how is this? How is this? That was the push I needed after I started and that really did help out.

For many students, TRiO prevented their dropout and "pulled them along" as students describe. Not only did TRiO provide motivation, encouragement and accountability for students, but they also provided material resources. For low-income students this is a very important service.

Pancho describes the help he received in the form of books and tutoring. There was a time when financially we were really struggling, basically telling me don't worry about books. Don't worry about your books, we're gonna get them for you. They got me every book I need, even books that I didn't need. When I struggled in that one math class, they got me a tutor. No worries, no cost, just come over here, get your tutor and it helped me out. 
Students also discuss receiving laptops, advising and transfer planning through TRiO. Maria, who is now attending a four-year university, attributes her success in transferring to the advising she received through TRiO. She says, "TRiO, the program helped me really much with books, so I didn't have to pay for those. And also with laptops, that helped. They helped me to um, answering any questions that I had. Also, they helped me to apply for the university." All Latino/a students in this study had transfer plans beyond their graduation. Most had already been accepted into universities and/or programs of study. Students attributed their plans in part to the support they received from TRiO in both applying to universities and the campus visitations TRiO organized for their students.

Although TRiO provided students many important resources, one of the most important roles TRiO played in their success was the connection to other Latino/a students and staff on campus. TRiO is not a cultural organization, but the TRiO program at Small Town is directed and staffed by Latino/a professionals, which represent over half of the Latino/a staff and faculty employed by Small Town. Students find a safe space in the TRiO office where they can build close relationships. Ana shared the way TRiO helps her. "I've built a really close relationship with all the staff. I feel like I can go to them for whatever I need. They help me.” For Ana, she feels comfortable here because one of the TRiO advisors knows her family and it is easier for her to trust him. She also feels like TRiO is a place where she can connect other students. "In classes, we would, at the beginning we wouldn't really talk to one another, but then we would see each other in like the library or in the TRiO lab and then suddenly we just started getting together, and 
like working together." The TRiO staff makes the connection for students and reaches out with resources and a caring message that pulls students along when they feel lost. BEING A LOW-INCOME WHITE COLLEGE STUDENT

Unlike Latino/a students in this study, low-income White students did not experience racism and stereotyping that their counterparts did in their high school experience or community. Being a low-income White student didn't mean an easy transition to college because they did not face this challenge. White students share a disadvantage and doubt in their abilities that Latino/a students describe, but this selfdoubt is not attributed to racism or language learning, but to their lack of academic preparation and success in high school. Even though White students generally felt positive about the campus environment, they also discussed feeling excluded because of their race. The sentiment is not only felt on campus by White students, but is also felt in their home communities.

Feeling Underprepared: Struggling Academically and Lacking Direction

All White students in this study felt academically underprepared for college. They either did not focus on academics in high school, did not take the right coursework or struggled academically. Karl, who is now excelling in college, discussed some of the challenges he faced initially because he did not take his high school academics seriously. He says,

I didn't really take a lot of the classes I was supposed to in high school. My whole senior year, it was like my required classes, like English, I didn't take any math, I didn't take...I took library, teacher's aid, work release, and stuff like that, so I wasn't really prepared. 
Karl took enough credits to graduate and did enough to pass his classes, but this did not prepare him for the advanced coursework in college. He is now preparing to transfer as an engineering major, but regrets not focusing more on high school academics because it has put him behind in his career goals. He shares,

That's why I have to take a third year here at Small Town. I didn't take all the pre-req's to and I didn't test high enough in math to get where I needed to be to take physics and calculus. I didn't prepare myself very much... So I had to take 2 below college level classes, which when I started taking them, the first two classes were super, super easy. So I didn't really study that hard.

Karl is not alone in needed to take below college level coursework. Over $70 \%{ }^{9}$ of students attending Small Town Community College enroll in developmental math and English upon entering college. Many students spend additional time taking developmental courses in order to enroll in courses that will transfer to a university. Betty describes how long it took her to catch up. She says, "I was so far behind that I had to start at the lowest level of math and English they offered here, which was like 86 in English, and uh, 90 in math. Um, and it took me two years just to get up to college level classes. I was that far behind.” Nora also described needing to attend Small Town for longer than other students because she was behind academically. "Well I tested into the lowest math possible, so it made it so I had to be here longer than a lot of student because I had to take four quarters of math under college level. I had to spend a lot more time on it."

Students like Betty and Nora spend significantly more time attending community college and pay for these credits even though they do not count towards graduation nor transfer. Lisa said she spent an additional time taking math courses even though she took

\footnotetext{
${ }^{9}$ The source for this figure is not documented in the text in order to honor the anonymity of the institution.
} 
advanced math coursework in high school. She attributed her academic struggles to her high school's lack of academic preparation. She describes,

They were really catering to the lower end of like the, the typical average students or the below average students. Which, when you get to college, really does not help, because you're, you go through all this boring homework and then you get to college, and then you find out it's actually really difficult, and it's not going to set the standard for you.

Like many White students, Lisa blames her high school teachers for not preparing her academically. Students expect that college academic work will be similar to their experience in high school, but this is not the case.

In some cases, White students lacked academic skills because they dropped out of high school altogether and earned their GED. Amy shared the challenge this created for her when she entered Small Town.

I never finished high school, I got my GED a couple of weeks before I found out I was pregnant with my daughter. I didn't even get that discipline... And so it was really tough to have to learn how to sit there and do my work and I guess like in high school, where I did do a program where I did do my work at home.

Amy is now transferring to complete her Bachelor's degree online to become a teacher, but her degree from Small Town has taken longer than average and has come with struggle. She shared that in her first quarters at Small Town she felt "overwhelmed" and almost dropped out after receiving poor grades.

This is a common story among White students. Lily also recalls,

I went to my freshman year (high school) and then I dropped out. And so by the time that I wanted to go back it was already my $11^{\text {th }}$ grade year and I didn't have anything to fall back on. I didn't have any, like, math or English training from high school, and so going to the skills source program where I could learn and catch up on all the things that I had missed. And then I took my GED tests. 
Many White students in this study spent more time completing degree requirements and some dropped out or stopped out along the way. Holly Joy described her struggles during her first attempt at community college. She had lacked direction and goals when she started school. She says, "I kind of like went for a quarter, and then I would take a break for a year or two. Then I would go back for a couple of quarters. I always knew I wanted to go, but I didn't know what for and stuff."

Like Holly Joy, most White students' parents expected them to attend college, but students had few career aspirations. They used college as a way to find their direction. The process meant longer completion times and potential academic failure along the way. Aaron described this struggle during his first year at Small Town. He says,

At the time I didn't really have any goals. I just wanted to do this eventually, I'm going to do this eventually, so I guess I might as well do this when my memory is kind of fresh. I didn't pass either my math or English placement tests, it's kind of fresh I might as well learn now instead of later, when I have to relearn everything.

Aaron did not have a clear plan when he enrolled in Small Town, but felt like he needed to do it because it was an expectation from his mother and he had for himself. He may not have been academically prepared or had a clear idea of what he wanted to study, but he went ahead and enrolled anyway. This is a common story White students experienced.

\section{Campus Racial Divide and Feeling Excluded}

Although all students in this study viewed Small Town Community College positively and felt that the campus fit who they were, the White students shared some challenges they faced in relation to their racial identity. Small Town Community College's Latino/a population has grown over the last 10 years. Now the Latino/a population is just over $40 \%$. White students discussed the presence of a large Latino/a 
population on campus and felt excluded from programs that served Latino/a students.

Betty described feeling excluded and lacking a cultural support network due to her race.

She says,

If you're NOT Hispanic and you're not colored or if you're not something special, you get nothing, your financial aid is zilch, you can't qualify for any of the scholarships, you, you get penalized for being white and the groups, they have an extra group on campus that's just for Hispanics, and we have extra programs to help people who are out of culture and that's great, but what about not penalizing us for just being us, like we can't change who we are, just like they can't change who they are...there's no support group for just being a white person.

Betty and others shared strong negative feelings about lacking support programs because they are White and not Hispanic. White students generally perceived that they were left on their own because they did not qualify for programs.

Steve described his perception of TRiO programs. He shared a story about a time when he talked to fellow peer at graduation.

I ran in to this guy, he had this black and red sash, are you in honors or what, they call it a trio program or something. It was a program for first generation college students, oh, ok I'm a first generation white person, but that doesn't matter. I could have had my books paid for and not have so many loans. I understand they've had some crazy things happen in the past. I think if we need to treat each other as equals, race needs to not be on the questionnaire. I've had huge challenges being white.

Steve had limited knowledge of TRiO programs and perceived that the program excluded White students. As he struggled to pay for college, he saw that other Latino/a students received an advantage from programs like TRiO.

White students felt excluded from programs on campus, but also discussed having a disadvantage in their home communities because of their race. Like Latino/a students, most White students still live in their communities and encounter issues of race and racial tension daily. Most live in communities where the White population is the minority (U.S. 
Census 2010). Amy shared her experience in a small community where she feels racial tension is high. She says,

That's another thing like here, cause there's a lot of Mexicans around here, that's a majority. And so, I feel like, I don't know how to say it, they don't maybe expect me to go to school or that I don't need to. Or that I'm like, I feel like, people look at people differently, like if they're Mexican or White.

Amy feels like she is excluded and different from the majority of the people in her community. She was not raised here and does not fit in with the Latino/a community nor the White community. She shares,

I feel like I'm an outcast here. They definitely have, so I don't have like a whole community either. It's really hard to explain. It's hard for me cause I was never raised racist, but I feel like people are a lot here, because it used to be a white town and now it's not, so it's a lot harder. So it's a focus for a lot of people.

For other White students this sense of exclusion and racial divide is not only found in their communities, but is also present on campus. Holly Joy describes this division in comparison to her experience growing up in a more diverse urban environment. Here, she says, the campus is divided.

It's kind of hard because in the city everyone is blended together, but here it's white and then Mexican. So at school it's kind of divided and that's kind of hard because I never really saw just whites. But here I'm white and you're Mexican, so it's kind of weird.

She and other White students described feeling like they are not connected to other Latino/a students on campus. The two groups are divided and are at odds with one another. They shared feeling like they experience "counter-racial discrimination." Holly Joy elaborates on the difficulty she has in keeping an open mind.

It's kind of more like a racist environment than I'm used, so it's challenged to keep an open mind, because it's not just the white people that are racist against Mexican people, but it goes two ways. It's hard when someone is kind of racist against you, it's hard not to retaliate, so it's hard to keep an open mind about it. 
But that's part of the environment at school, it's divided. It's, I guess it's normal, but it's kind of strange for me.

Amy also expressed this similar sentiment and described feeling like she needs to "put up a wall" when it comes to interacting with Latino/a students. "Cause then when you're going to school and you're trying to interact with them, you've heard so many bad things and you know better then to be racist, but it's like hard to interact, I just put up a wall." For most White students, racial tension and division are salient issues on campus, in their communities and at home. Latino/a students perceive the campus as a place where their culture is valued and they can connect with others that share their experience, but White students perceive a campus that is divided, where they are excluded because of their race. FINDING SUPPORT FROM FACULTY AND FAMILY

One of the most significant challenges White students face in college is feeling academically unprepared to be successful in their coursework. They did not take classes to in high school that would prepare them to be successful, nor did they excel academically. All students discussed taking below college level courses in order to bring their academic skills up to college level. This meant longer completion times and paying more for their degrees. White students also struggled to find their direction while in college. Before entering they did not have clear plans even though they had always expected to go to college. In dealing with these challenges, White students received support in particular from faculty at Small Town Community College.

Although both Latino/a and White students felt that faculty members were very important in becoming successful students, White students in particular discussed the advice and resources they received from faculty as key to their success. In addition, 
students were referred to academic support programs by faculty, which helped them receive the much-needed academic support. White students also received support from their family in the form of sibling relationships. Although they were the first generation in their families to attend college, they were not necessarily the first in their family to attend college. White students relied upon siblings for advice, support and encouragement during their time in college, which helped them navigate the new culture. Finding My Direction: The Role of Faculty

White students struggled in college to find their direction. Most did not know what they wanted to study or how to navigate the new environment, and they could not depend on their parents to guide them through the process. Students relied on faculty for advice, direction and many times academic advising. Aaron described the support he received from a faculty member. This faculty member was officially his advisor on campus and therefore he developed a relationship with her after meeting with her and taking multiple classes from her. Aaron is pursuing an Art transfer degree. He described how he came to know his advisor:

I'm doing Art for my degree. So I've taken a lot of art classes for my degree. So I've really only taken 2 teachers from that department. So I've gotten closer to those 2. One of them is my advisor. I don't really talk to her much, but she knows, if I need to talk to her. It's really helped me cause she's my teacher and advisor. Having taken her class multiple times, it's been helpful.

At the start of his college career, Aaron did not know what he wanted to study. At first he took music classes, because it had always been something he had been interested in. After exploring his way through his first year or two, Aaron still did not know what he wanted to do or what classes he needed to take. Only after taking multiple classes with his advisor was he able to create a clear plan for his career and college coursework. 
Holly Joy shared a similar experience. She always thought she wanted to become

a nurse. After taking her nurses assistant test and spending time in a nursing home, she decided it wasn't for her. She went to her faculty advisor for help.

I was actually going for pre-nursing, then I took the CNA class. I worked in the nursing home, and I was like nope, not for me. I always wanted that kind of work, I was going to nursing school to become a PA, and so I was like, what am I going to do now. Then I talked to her and she was super encouraging. She's was like, 'you're a good student, you can do it! This is what you take, ya know. This is how you change, this is a pre-med planning sheet,' and stuff like that. She's always around ya know. I asked her questions about what am I supposed to do next year. 'Am I supposed to take four sciences classes at the same time?' It's just really helpful to have her around, yeah.

Holly Joy is able to meet with her faculty advisor regularly and goes to her for advising and advice. She also received advice and help in planning for transfer to a university. Before meeting with her advisor, she was unsure where to go and what direction to take. Her advisor called other faculty members at universities to help Holly Joy with transfer planning.

Finding academic support through Supplemental Instruction (SI)

White students not only found support from faculty in the form of advising, but they also received information and referral to academic support programs. White students discussed struggling more academically than their Latino/a counterparts. They discussed feeling behind and being unprepared academically. White students discussed the importance of faculty reaching out to them during class when they were struggling with the material. Steve remembers his experience in math when he was failing. Without outreach from faculty he probably would not have passed some of his classes. Steve shares, 
I took finite mathematics, that was two quarters ago. I almost failed that class, I was struggling so hard in that class. I'm sort of a shy person when it comes to, not sure, but insecure, I'm embarrassed sometimes when asking for help. Some of the teachers made note of it, they announced it at the beginning of class a lot of times. The teachers were very encouraging about that. It seems like they just started implementing it this last 2 years. That's when I first found out about SI. But before that you'd have to go somewhere to go ask for help that you didn't know and find out about it, but this is way easier.

Steve received a referral to a program called Supplemental Instruction (SI). This program provides struggling students with a free peer tutor. The tutor attends class, takes notes and organizes study groups for students. They are available to answer questions and help students one-on-one that are struggling to understand the coursework. Betty described how Supplemental Instruction works:

SI is a program that helps students with basically tutoring and it someone's, it's one on one tutoring and sometimes it's one with a group tutoring, um, so you have like one tutor and like six or seven, whoever shows up. And those are the most beneficial things ever, if you actually go them, because it's someone who sits in the class and they hear the same stuff you do but they have already passed the class. So, they can help work through problems and where you get stuck and they can explain it differently than the teacher did, so sometimes when you don't understanding what the teacher's saying you've got to ask three, but them explaining it to you gets, makes it click. So, it's awesome.

Students receive help quickly and directly during class. They can also receive help outside of class in the form of study groups with their SI tutor and classmates. Betty says without the help of SI she would have failed.

Some White students also became involved in SI as a tutor after they had used the program. Once a faculty member saw they had been successful in a course, they were referred to become a tutor for SI. Aaron explained how this works,

They'll pay you. I went in and I signed up for tutoring for that class. And I tutored one student for that class. And the next term I didn't have any people come in from that class, but then I got a call from tutoring and she said I have this class 
that you got a 4.0 and he wants you to tutor. It would be fun, I have to sign up for this class. She said she already got me signed up. And so I ended in SI.

Aaron was first involved in SI to receive tutoring himself, but after he had some academic success, he became involved as a tutor. He received payment for tutoring in the program and shared that it helped him to give back to his fellow classmates.

\section{Not Alone: Finding Support from Siblings}

For all students in this study family was an important support in their college careers. Families provide encouragement and acted as a source of motivation. All students struggled because they could not turn to their parents for advice on how to navigate college and were not able to prepare for the shift from high school to college. Even though this was the case for all students, White students in this study had support from within their family that the Latino/a students did not. Although they were the first generation from their family to attend college, with exception of Amy and Aaron, all had siblings that had previously attended or graduated from college. These students had a support system that Latino/a students did not have- someone to go to in their family that could offer advice and support on how to navigate college.

Tyson is a middle child and is not the only one in his family to attend community college. He has taken longer than average to complete his degree and feels pressure to finish. His family is still there to encourage and support him, especially his older siblings that have already earned their degrees. Tyson described the support he receives from his older siblings. He says,

A lot of times if I was struggling, they'd come to me and say, you getting everything, kind of joking. Somehow it would just click in their head. Being a brother and sister they know how you think in a way. It helped you out in a way.... Kind of like your guidance counselors. 
Tyson and others know they can find support from their siblings and ask for advice at any time. It is easier to ask for help because they know you. Tyson described the relationship he has with his brother who he can go to for support at any time. "Seeing my older brother has gone to college, has made me think if he can do it I can do it. It's that brotherly advice, if you felt shorthanded, he'd give you your, we call it, your loving canteen full.”

Knowing that his brother has already graduated is a source of encouragement for Tyson and others. As Lily described, "It's been fairly easy for me, it's actually been a big encouragement knowing that if I ever have any questions or I need any help, my sister is there for me." She also felt encouragement and pressure to follow in her sister's footsteps. Johnny described his sister's example as helping him "not feel alone." He says, "with my sister's help and watching her go through everything that I went through during this whole college experience, I felt more not so alone." White students are not the "first through the fire," but have a role model and source of support from within their family that they can rely upon. They felt like they are not alone and can overcome the challenges they face because their brother or sister has already done so.

\section{CONCLUSION}

Both White and Latino/a students continued to struggle in college because of their experiences in high school and their home community. These challenges were quite different for students because of their race-ethnicity. Latino/a students faced racism and stereotyping both in their home community and in their high schools. They faced discrimination due to their language ability and questioned their academic ability to speak 
and write English even though they were bilingual. Latino/a students struggled to externalize these messages. White students did not encounter such messages, but were unprepared academically for college and lacked confidence. They placed in below college level courses and needed more support to pass their classes. Some dropped out along the way because of academic failure.

For both groups, their pre-college experiences continued to challenge their success. For Latino/a students, they continued to face racism in their home communities, but found a safe space on campus. They felt the campus was a place where they could connect with other Latino/as, and find role models. MEChA and TRiO became places where Latino/a students found support from each other and other Latino/a professionals on campus. "Proving them wrong" or resisting these negative stereotypes and racism became a form of motivation for Latino/a students. Students discussed not only resisting for themselves as individuals, but for their entire racial-ethnic community.

Discussion of resistance was absent from White students' stories. They did not find a cultural community on campus, but instead felt that they were excluded because they were White. They perceived that there were programs for Hispanic or Mexican people, but nothing for people like themselves. Instead of finding this type of support on campus, White students were referred to academic support programs on campus by faculty. All White students used a service called Supplemental Instruction, whereas only one Latina mentioned using this service. This program was very important for White students because they gained the needed academic support and connection to other students. Even though they perceived a lack of support on campus, through this service, White students received needed support. 


\section{CHAPTER VI: GENDERED EXPERIENCES OF ACADEMIC PERSISTENCE BEING A LOW-INCOME FEMALE COLLEGE STUDENT}

All students in this study faced challenges balancing work and college coursework. The women in the study faced a particular challenge in addition to balancing work because they were responsible for caregiving or caretaking in the home. Women struggled to take care of children, parents, and the household duties, while working and attending school. This challenge was not easily mediated and became an overwhelming source of stress for all females. Female students constantly made tough choices; deciding which realm of their world deserved prioritization. In many cases, they did not have a choice, but their role in the home dictated precedence of the care-giving role above school and work.

For female students, these roles were linked to the perception of girls or women both in society and within their families. Females were expected to take care of children and the home. Even though parents expected them to attend college, there was still a perception that females' most important role was in the home. Female students struggled against this double bind, which created tension between themselves and their parents or family members. This tension and struggle limited students' choices and academic achievement.

Being a Caregiver: Balancing Work, Family and School

All female students in this study discussed being a caregiver as an important role and challenge they faced while attending college. Women, regardless if they were mothers or not, took on the work of caring for children at home. This meant a limited amount of time and energy to spend on schoolwork. Amy is a mother who works part- 
time and stays at home with her two young children when she can. Even though she is married, she is still the parent with primary responsibility for caregiving and caretaking of the home. She shared how exhausting it can be to take care of everything at home and be a student. She says,

It makes me more tired and grumpy because I know I get frustrated to cook and clean and get lunches ready and do all that still and on top of that at $8 \mathrm{pm}$, if they're in bed, it might be hectic, they need to go to bed, so it might be 9 and then I'm really frustrated. You guys have to go to bed, I'm really frustrated! Then I'm in the kitchen doing school work, but it's just hard.

Amy, like other female students, discussed the constant stress this creates in their lives and in the lives of their children.

Even after a full day of work and caretaking females still need to attend class and do homework. Louisa, who is also a married mother and a Latina, described how her daily schedule leaves minimal time for schoolwork. At the end of the busy day, she struggles to stay on top of her studies. She described a typical day:

There are challenges every single day. I don't get home until 8pm...My husband works nights, he goes to work at $5 \mathrm{pm}$, leaves and doesn't come home until $6 \mathrm{am}$. I'm the one that gets the kids ready, tells them to get ready, I have a 10,11 and 16 year old...After school I drop them off, I go to school, I have classes until 1 or 1:50, then I have to pick them up, depending on if my parents help me out, $3: 15$ go take them I either have physical therapy, tutoring, CCD, I have to usually pick up my son from baseball. So it's a big round trip Mondays, don't forget allergy shots. Or doctors appointments, it's a lot, it's hard, it's like I'm a single mother.

Amy and Louisa are both mothers, but their experience in balancing school and home was not unique to motherhood. All students that were not mothers were still responsible for caretaking in the home of either siblings or parents. Maria, a Latina student, shares how it is difficult to balance helping her sister and making her own homework a priority. She says, "I have a little sister so I have to help her with doing her 
homework. Sometimes I have a hard time to help because I have to study. I have to help her every Wednesday, I help her. My mom says I have to help her and then I go study.”

Maria and many other female students are responsible for helping their siblings with homework, making them dinner and doing chores within the home. Blanquita actually describes her role as being a "mother" to her sisters. Her mom is working during the day, so she is the only one home during the week. For Blanquita, this means taking over and making sure the home and her sisters are taken care of. She says, "I am a daughter, a sister, um... sometimes I'm a mother to my sisters. I'm not a mother myself, but to my sisters. They rely on me."

Ana described her role in a similar way. After her family had experienced financial challenges and issues related to health, she had to take over the caregiving role in her family. She says,

So I had to step up my game also and like help around the house. Because my mom was at work. And like a lot of the time I feel like my little sister is like my daughter. I pretty much raised her in a way. And I guess it's like taking a big hit with how the struggles I've had during college and I guess during the first couple of years during my high school career too.

Female students take over as mothers and caregivers in their family, which means a limited amount of time to devote to their schoolwork.

Lily, a White female student, also describes this challenge in a similar way. She cares for her mother who has epilepsy. She describes how this challenges her success in college:

Taking care of my mom because she has epilepsy. And being able to just dedicate time to be with my family, be with my parents, since I'm their only child. It's not as easy that it used to be because I'm independent now and I have other responsibilities and sometimes I feel like I neglect my parents, but that's the way it has to be. 
Lily is forced to make a tough choice — care for her mother or do her schoolwork. Female students are forced to make these tough choices. They must choose between their work and family. With no other means to providing for the caregiving in the home students have limited choices. Many times there is no choice and caregiving must have priority over everything else.

Susan, a Latina student, describes how her days are dictated by her role in the home. She says,

Well, like I guess like, I have a schedule. Monday through Thursday I actually just worry about school and then Fridays I worry about cleaning the house so my mom won't have to do it when she gets home. Then um, Saturdays have to manage work and then Sundays like, catching up day for school. That's pretty much my schedule.

Susan and others describe this balance as one of the toughest challenges they face while in college. Many times there is no way to balance everything. Betty, a single mother, shared the challenge this creates for her. She says,

That is the whole challenge, um, where's the balance? Where does school become more important than your family or where does family become more important than your school? Because, without school you can't provide for your family but what good is school if your family hates you, like if you never see them, if you're never there, then it's, you're just setting up the next generation to fail.

Betty and others feel forced to make a choice between school and family, and in the end they put their families first. This may mean neglecting their schoolwork and lower academic performance. Betty shared that there is no way around this challenge, but just one tough decision that has to be made. She deals with the consequences the best she can. She says:

Coming to school's hard enough and it just makes the whole family dynamic so hard when you throw in work because you're never home, you never see your 
kids, you never have that moment of break, it's just, it's work, work and then your class, which turns into work and you end up falling asleep when you're not supposed to or just not even caring about your grades anymore you just want to pass classes. Like, a 1.0 because yay. And you're like, that's not good.

Ana also shares how this affects her performance in college. As she described this challenge, her body language changed. She looked down, spoke softer and shared pain she experienced. She says, "and like homework or whatever I have to do with school, but I sometimes like let it slip because I care a lot about my family, about my siblings. And, but then, again, I'm just like, I wish I could focus more on school, then taking care of them."

Female students care about their siblings and children, but receive very little outside support from other family or community. They are solely responsible for care in the home, which limits their ability to be successful as students. For some students this actually meant dropping out along the way. Holly Joy, who is now a university student studying pre-med, described how caring for her brother earlier in her college career made it impossible for her to be successful academically. Now that she is not living at home anymore she can concentrate on her schoolwork. She says,

It was kind of hard because my little brother had some issues. When he was younger he got into a lot of trouble, so he actually moved in with me. I was trying to go to school at the time and it just kind of added to the stress and bills and stuff like that. It was like I had to help the family out. But since I've moved here it's enough of a distance that it's better.

Holly Joy dropped out of college to care for her brother at the time. Without moving away from her family she felt she could not have attended college.

Alex, a Latina mother, described a similar experience. This is Alex's third attempt in graduating from Small Town. Alex was prepared academically, but during her first 
time in college Alex was responsible for her siblings and fulfilled the caretaking role at home. She reflects on how this limited her ability to succeed in college. She says, "That was tough, I was single yes, I didn't have any kids, but I still had, kind of be like a mother to my family. I've always been the one, they always come to me, oh this is going on, what do we do here, what do we do now. I'm thinking...aren't you the parents?" Even though she didn't have her own children she was still a mother. Alex was also working while attending college and could not balance her household duties, work and coursework—she dropped out.

\section{Girls don't go to college}

For all female students in this study, their role within their family was limited because of their gender. They were expected to take care of children and household duties, which defined what it meant to be a "woman." Although parents expected their daughters would attend college, they received mixed messages. They were needed in the home, but also needed to go to college to provide a better life for their current or future families. Parents, spouses and the larger community reinforced these mixed messages. For female students, going to college meant "failing their role as a woman." Betty, who is a single mother, faces strong judgment from her parents because she is attending college. She says,

There's no, there's no other reason for girls to be on this planet in my family, so for me to have a child and leave her to go to school is like the biggest sin you could possibly commit. Because I am failing my role as a woman. It is not to make the living, it is be at home and raise the children. And that's been really hard to try to get over growing up that everything I'm doing is wrong when it really isn't.

Betty and others know that these messages are not accurate, but they have grown up with these scripts - "Girls are not supposed to go to school, girls are made to get 
married, have babies and cook dinner. Period," as Betty says. Alex, a Latina female student, describes the painful experience she had with her father when she was accepted at universities away from home. After telling her father about her plans, she received very negative feedback regarding her options for attending college. She shares her story and holds her father responsible for her decision to attend community college instead of a university. She says,

Honestly? Um, my father's mentality. He limited me. I was actually fully accepted to Abilene Christian University, Central University, and possibly another university, but my father told me, and I quote, 'the day you leave my house, you are no longer a virgin in my eyes.' That was huge for our family. And so it devastated me. And I was afraid. He said he wouldn't help me with any money for school, so you have to do it all on your own.

At the time Alex was not a mother, but she did take care of her younger siblings and helped the family by working. Her father's unwillingness to support her decision and help her with college, made Alex decide to attend Small Town Community College. Eight years later, Alex has now graduated from Small Town. Going to college does not necessarily mean that female students are exempt from traditional gender roles at home. Amy, who is a married mother, described a similar message about females in her community and family. She says,

Sometimes I guess especially around here, people look at females like they don't need to work, they don't need to do anything, they stay home, ya know... So I need, even though I'm female, I need to have a job too. And it hasn't helped me cause I don't get support, because it's like you should be focusing on the kids.

Amy feels pressure to stay at home and take care of her children and home. The only way she can attend college regularly is to take online classes. She doesn't receive the help and support she needs to attend college, because those in her community and family see her 
mothering role as her primary responsibility. She is left to do both mothering and school alone.

One does not have to be a mother to experience the dominance of these mixed messages. Lisa, who is a White, single female students, described how her grandfather questions her ability in college because she is a female. She lives with him and he is the male role model in her life. Lisa tries to ignore his comments, because she knows he wrong, but it difficult at times. She says,

My grandfather is a little bit, shall we say chauvinist? I suppose? He tends to put women down a lot, and it kind of affects me a little bit, to hear him say kind of rude things like that. And of course on the one hand most of the time I just toss aside his comments and write them off as being completely inaccurate. And of course there's this little nagging voice in the back of my head that maybe he's right and maybe I'm not doing as well as I could.

Lily, who is also a White, single female student, shares the barrier she perceives as a female in the future. It worries her that someday, because she is a female, she will have to give up her career. She says, "Well, I've been thinking that if I get married and become a mother, I'll have to sacrifice some of my career or schooling to take care of my children. And that's always a thought in the back of my mind." When thinking about her future, Lily is concerned that her efforts in college will translate to decreased opportunities later in life because she sees herself as a potential mother. Being a potential mother would limit what she can achieve in her career.

\section{Culture and Gender Roles: Intersecting Identities}

Even though all females in this study discuss being limited by their gender roles, Latinas attribute these limitations to their cultural background. Latinas share that their fathers expect them to be caretakers of the home, marry and have children. Again, they 
received mixed messages, because they are also expected to go to college in order to earn a better living in the future. Most Latinas' mothers are in the work force and therefore they are responsible for taking care of siblings. They fulfill the role that their mother would have if they hadn't been working. Blanquita described how she feels the pressure of this expectation from her mother.

It's just that and also when they start working I think it's during when the apple season. And they're picking apples, I have the responsibility of my sisters. After college, I have to come straight home. To make food for them when they come home from school, I have to clean the house. Basically, I'm like their second mother.

For Blanquita and others there is no other option but to try and balance their roles as a caregiver and student. Their parents do not understand because they have never attended college and females are expected to fulfill this role. She says,

I guess she doesn't understand. It's hard because she's never gone to college...It's a challenge because they don't get you.... and for them to tell you stuff, it's not that I'm being lazy and I don't want to do chores, I do my chores, I do my chores when I'm done with everything.

Blanquita and other Latinas feel like their parents do not understand them, not only because they did not attend college, but because they are the first females to attend college. Ana shares this feeling, she says, "I think that being a female has been a challenge because in like, Hispanic cultures, the girls are supposed to be like a homemaker. Like they don't really expect much from them." Ana feels this pressure not only from within her family, but from her culture. "There's not an expectation for girls to aspire to be anything in life except a mother and cook, clean and take care of children," she says. Culture, as Ana describes, prevents her and other Latinas from aspiring to careers outside the home. 
Alex attributes her limitations as a Latina to her father's expectations and his cultural values. She says, "Dad unfortunately at the time, was a serious macho Mexicano. He didn't want to accept that we were in another country and had to adapt to another culture. Not that we had to lose ours entirely, but we had to allow some changes for the betterment of our lives." All females share the struggle of feeling limited by their gender and their prescribed roles as females. Latinas, like Alex, struggle not only to deal with limitations regarding their gender roles and expectations, but also struggle to live between worlds and cultural values. They may be shifting their own values, but parents maintain and hold onto those from their home country.

\section{Family tension and the role of culture}

Female students experienced the double bind of fulfilling gender roles in the home and pursing a college degree. Going to college meant conflict and tension between themselves and their families as they stepped outside of traditional gender roles. They cannot meet all of their family's expectations. Lisa describes how for her, this means rebelling against her parents' expectations at times. "Cause I basically just had to follow the sorts of models that they wanted me to, kind of be the responsible child, which I have...it's a little bit difficult because there has been those sort of rebellious moments where I wanted to just go off and do whatever I wanted to do," she says.

Betty also described a similar feeling because of the pressure she faces from her parents. For her, it means the possibility of dropping out of college completely. She says, I can't even get my mom to babysit my kid so I can go to class, like it was, they, hey put these unreal expectations on you, but without the support, you can't, they just become your biggest enemy and you end up either rebelling against them and dropping out of school to say screw you guys. 
Betty does not receive support from her parents because she is not meeting their expectations as a mother. This causes tension between herself and her parents, which makes it difficult to concentrate on her coursework.

Amy also describes a similar scenario. Though she is married, she receives no support from her husband. Her attendance in college has caused tension in their relationship. She doesn't know if their relationship will last. This means she doesn't receive support from his family either even though they live in the same area. She describes the tension between herself and her husband:

Like me and her dad are not always on good terms, so it's not always a stable relationship all the time. It's like he's here, but not here together, but for the kids. If it didn't work out in the end...even though I'm female, I need to have a job too. I don't get support, because it's like you should be focusing on the kids.

Shifting gender roles and expectations results in tension. For Amy, it may result in the end of her marriage.

For White female students, the tension and their rebellion from their family's expectations may result in fights and arguments. Nora is a single mother who lives at home with her parents. She described how in her household there is a tremendous amount of stress and fighting. She says this is one of the biggest challenges to her success in college. She says,

Really the only challenges with my immediate family, like my parents, mostly my dad, just, um, he's always like...where are you going? What are you doing? And that's just irritating, because I live with him and that's why he does that. It gets on my nerves and makes me stressed out and we fight and stuff. It's just stressful.

Nora does not see any way around this as long as she lives with her dad. He will try to control her and monitor her behavior even though she is an adult woman. 
Blanquita describes a similar experience with her parents, but her response is somewhat different. She too lives at home. She is not a mother but is still responsible for her sisters. When she stays at college to study, her parents question her and distrust her motives. She describes how her parents mistrust her:

When you stay after class in college, like ok, I'm going to stay to do work to study at college so at home I can help them out. And I don't know, I think it all depends on the restrictions, they're really strict about it. Like, why are you staying late? This and that. I guess that's how I was raised, with very strict parents. They think the worst of me instead of the good.

Blanquita does not directly confront her parents as other White female students discuss, but she quietly rebels to complete her schoolwork. In order to study outside of home she lies to her parents. Blanquita shared a story that illustrates this strategy when questioned by her parents why she is going out:

I teach quinceneras. And when I don't, there's not a day I don't teach, I say that I'm going to go teach, but I actually go the library to study there. Cause if I tell them I'm going to the library, they'll say 'are you sure you're going to the library?' And it's like, ok, whatever, so I just don't want to deal with that. So I say I'm going to teach quinceneras, ok be back soon. Then I actually go to the library.

Blanquita thinks it is sad she has to lie to her parents to complete her schoolwork, but she sees no other way around it.

Maria, also a Latina student, shared a similar challenge in dealing with her father's expectations. He feels that she should be at home and she struggles to find time and space to do homework. Instead of lying to him, she ignores him and disobeys his wishes. She goes to campus even when he expresses his dissatisfaction with her behavior. "I just ignore him," she says. The challenge for Maria and others does not diminish as time goes on. Female students just have to deal with the stress and tension of not meeting 
their family's expectations. White females overtly confront their parents and family, which leads to conflict and fighting. Latina females covertly rebel against their parents' expectations at times in order to maintain the family bond. Both struggle against mixed messages and gender role expectations while attending college.

\section{BREAKING BARRIERS AND BECOMING INDEPENDENT}

Despite facing challenges both from within their family and in their larger communities, female students persisted with the goal of breaking these barriers for women. Their desire to become independent as women and be role models for other girls motivated their success. In shifting away from traditional gender roles, they were able to find role models on campus and in their community.

Holly Joy, who was preparing to enter a pre-med program, needed to take a higher load of math courses. She shared that most of her classes were dominated by men. Even though she felt alone, it motivated her to break this barrier as a female student. She says, "In math and science classes it's hard to feel like, sometimes the boys are like really loud. They think they know everything so it's easy to feel like you're not as smart as them. It's a good motivator, to get the highest grade on the test or something, to beat them." Holly Joy knows that she can be successful, but feels like she needs to prove herself and break this barrier.

Blanquita, who feels very limited by her family and culture, described a similar need to break these barriers. She wants to be different from some of her other friends she grew up with. Many had either dropped out of high school, had been married or started a family. Blanquita wants to have a career and be independent. She says, 
I don't want to end up like them. I see them how they live their life. It's like oh my god, not to criticize them or anything, but I don't know want to be like that, I want to be independent myself. I also want to have a career in case ya know, you don't get lucky or anything, you can be independent and not rely on a guy. Basically, coming from a Mexican family, I've seen that the woman relies on their guys and I don't want to be like that. I want to be independent. I think that's a way it has helped me through success, I don't want to be relying on people. I want to be independent.

Blanquita wants to be independent, which she sees as a deviation from her cultural norms.

Amy, a White married student, describes her motivation to become independent in a similar way. Amy says she may not always be able to rely upon her husband. The relationship is not stable, so she needs to be able to take care of her family. She says, "So if anything ever happened to him or it didn't work out in the end. So I need, even though I'm female, I need to have a job too." Without a college education, Amy and other females could not adequately support their families. With a college degree in teaching Amy feels like she can support her children and still care for them without being dependent upon a husband.

Female students share the need to break gender roles and become independent from men. They do this for themselves, but also for their children and/or siblings. They want to show their children or those they care for that it is possible to be successful as a female. Blanquita receives little praise from her parents and at times questions why she is in college, but she remembers that she is doing this not only for herself but her sisters. She says, "I don't want my sisters to feel that way because I don't want them to feel like I suck, or whatever, I'm not going to do anything." Females also see their success in college as providing for their family. For Betty, her daughter is the number one motivator 
of her success. "Yeah, but it's worth it, because it's all about me and my kid, and its about succeeding for her," she says.

\section{Succeeding Together: Finding Support through Female Faculty and Friends}

Even though female students face many challenges in breaking gender norms they find support from female faculty and friends on campus. Knowing that other females have become successful and have "made it" is a source of encouragement and empowerment for students. Betty, a White female student, shares how these women are a source of inspiration for her. She says, "they have worked really hard to get where they are and they fought against the guys to get their positions, so when they see another woman who is fighting as hard as they are, they're likely to give you a job and promote you because they can relate to your situation." For Betty, her connection to other female faculty members and community members gives her a sense that doors that have been closed will open with the help of other female professionals.

Ana, a Latina student, shared a similar sense of empowerment as a female when sharing how faculty has helped her be successful. Female faculty and staff at Small Town contrast how she normally sees women represented in her community. She says,

But I saw at Small Town, a lot of faculty like, staff that was female. I would be like they were able to become something in life. I want to be something in life too, so that just like reassured my hopes and dreams for myself. And it was just nice to see so many females working in an educational environment and a professional environment instead of just males, males, all males.

Ana knew breaking some of the gender barriers she faced as a Latina were possible because other females had done so before her. Becoming an independent woman was possible. 


\section{Finding support from friends}

Female students relied heavily upon one another for motivation, emotional and academic support. They found friends on campus and maintained some ties with friends from high school when attending Small Town. These friendships held them accountable in school. They could share their challenges, successes and learn from one another-they were not alone. Betty described the support she receives from her friends at Small Town.

You build friendships... when you walk around campus alone you see someone from class and you say 'Hi', and it just makes you like feel more connected in your academics because it's not something you're struggling to get through by yourself you have this, oh hey I know you and then you start sitting next to people and you take classes sometimes the same or it just helps you pull into the college experience better and I think that if you the more support you have the more successful you're gonna be.

For Betty and others, these friendships not only help them to feel connected to their academics, but they supported one another outside of class once the relationships had grown stronger. This support is in the form of socializing, but also emotional support in dealing with some of the challenges students face while attending college.

Blanquita described how this helps her after doing poorly on a test. She says her friends provide her emotional support.

They're always like, oh come you can do this, ya know. Good luck in your test. How did the test go? Always asking each other, ya know. Are you doing ok? No, ok, we should go study then. I have good friends that motivate me. They're like you did a good job, don't put yourself down because of that. I guess that helps me too.

Like many female students, Blanquita receives minimal praise from her parents at home. Her friends support her though and praise her successes.

Nora's story is similar to that of Blanquita. She too received praise and positive feedback from her friends. Unlike Blanquita though, Nora maintained many of her 
friendships from high school. She also makes new friends that keep her accountable and motivated. For Nora, this support is crucial to her success at Small Town. She shares how this helps:

My friends that I have before coming here, they've all been really supportive. They always ask me how I'm doing in school, and when I tell them, they're always like, 'Oh, that's amazing!' The friends that I've made here have helped me be successful, because it makes me accountable. I don't want to disappoint my friends by not showing up to school.

Emotional support from their friends is very important and makes up for the mixed messages they receive at home from family. Within these friendships there are no competing expectations and they are not alone in their efforts to become successful as female students.

In addition to finding emotional support and connection, female students find academic support from their friends. They study together, share strategies and help each other problem solve. Louisa described a typical study group with her friends.

We'd go during lunch and sit out here at the cafeteria and we'd go over homework. Or do homework at night and then the next day we'll go over it at lunch. Ok, what did you get for 1, true? Then we'd go over it. Then we'd debate...so it actually helped a lot to know that they would be there just in case you had questions.

These study groups were informal. They were not formed through a program or faculty efforts. Female students connected with one another and started study groups on their own time and effort. Female students attributed their academic success to these cooperative-learning efforts. Blanquita couldn’t believe how much her grades went up after she joined a group of friends for study groups. She says,

Oh my god, my grades went so up because you're interacting with them and involving and I think I'm that type of learner that likes to be active in learning. And I think that's how it's helped me be successful. When I used to study by 
myself, I would like, not do so bad, but not so good. I want to you know, do good. I started joining them in their study groups and everything and that's what helped me a lot.

Female students study together, learn together and support one another. As Louisa says, "We're all in the same boat, might as well get together and help each other out."

\section{BEING A LOW-INCOME MALE COLLEGE STUDENT}

In stark contrast to their female peers, male students in this study identified very few challenges they faced because they were male. For the most part, male students were supported by their family members and given time and space for schoolwork. They felt empowered as students in the classroom, and did not face the challenges female students did in balancing work, home and school. Most males felt like they did "have it easier." As Steve explained, "I never had to deal with any what do you call it, sexual discrimination, gender discrimination. I don't know the experiences of women, maybe harder in the world. But personally being male, no."

Male students did not explicitly attribute their gender as contributing to some of their challenges, but some challenges were exclusive to males. All students in this study struggled to balance work and school, but male students, both White and Latino, struggled to identify themselves as a student first. They felt as males, they should be working. Many struggled to make school a priority because their first focus was working. On campus, male students felt that their working identity was reinforced. They were not expected to be successful students, but were expected to leave college to enter the workforce. Male students were challenged to stay in school while balancing their working identity and questioning their place in higher education. 
Even though male students faced the challenge of being a worker, their working identity also provided counter-motivation to pursue a college degree. As working class males, their options were limited without a college degree and therefore working while attending college reminded students the consequences of dropping out. Family also supported males' success in college by providing them time and space that was not available to their female counterparts. Similar to female students, their family motivated their academic success and was seen as a collective effort that would benefit their whole community. Male students frame this effort in a different light. They not only want to help their family, but make their family proud and honor their family's name.

\section{Men are Meant to Work}

All students in this study needed to work while they attended college. For male students, work presented not just a challenge in balancing their time, but was tied to their identities as males. Men are meant to work, was a message they encountered. This gender role was reinforced for most males at home in their family. José, who comes from what he calls a traditional Mexican family, says his father expects that he will work. If he is not working, he is seen as less of a man. José works part-time throughout his time at Small Town, but shares that when he isn't working he feels guilty—like he should be working. He says,

I have to work. I have to work. It's always stuck in my head. If I'm not working during school time, I feel like, uh, the way I look at it I feel like I'm useless. I feel working, when I don't work I feel useless. I can't do anything but work. That's one of the downfalls, cause I'm always like...that's the only thing that's bringing myself down cause I feel useless. Like I'm not working so I can't do anything.

José struggles to maintain a balance between his work and school life, but always feels like he should be working. 
Pancho described this challenge in a similar way. Pancho is a father and is working part-time. He, his wife and two young children live with his in-laws while he attends college. His wife is working and she is the main provider for their family at the time. Pancho feels the pressure to provide for his family, because it's his role. He says, "as far as being a male, that's the only barrier. You have to balance, do I go to school or provide for my family, or how could I do both. Sometimes it's really hard. I put the pressures on myself, that's just how I am." Pancho considers applying for a job at a local factory in his last quarter to support his family, but knows he may not finish his degree or continue his education.

Many male students face this pressure regardless if they are supporting a family or not. Male students primarily identify themselves as workers first, and secondly as students. Some male students say they're both. Tyson says, "it's kind of both," or in Johnny's words, "it just kind of shakes back and forth.” Karl, who grew up in a working class family that worked in construction, discussed how he wished he could identify more as a student. He says, "I've always considered myself a worker more than a student, but I want to get into more into a student so I can focus more and get better grades and have a better chance of getting into a better school. I've kind of settled." Right now, he says, his classes are not too difficult so he can focus on work right now, but worries about transferring to a university someday.

Johnny also shared how it has been difficult to transition into being a college student, because he has always seen himself as a worker and has been a good worker. He struggled to envision himself as a "good student." 
I did learn that I was kinda more of the employee type of person than the uh educated kind of person...I just spoke about this my mom last month that I was apparently wasn't really, not much of the college person-type even though I'm still going, and uh, there will be days when I could just work a part time for like ever and just leave it at that but I know that's not possible and I know that I would want more than that eventually.

Like Karl, Johnny contemplates the idea of "just working" instead of being a college student. He has gained valuable experience in the workplace and feels competent in this role.

Raymond described how working has contributed to a similar sense of confidence and pride. He says, "work is just made me a lot more ambitious is the word. Ambitious, ambitious." Raymond is in the process of pursuing start up funds for his own business. It is a challenge to maintain his coursework while doing so and he struggles to decide which realm of his life has priority. His parents want him to earn a college degree, but Raymond wants to pursue his business endeavor. It gives him a sense of ownership and pride that he doesn't find in college.

\section{Girls are Smarter: Expecting Failure}

Even though male students did not perceive challenges related to their gender, they were well aware of faculty's perception of their potential failure as male students. "Girls are smarter," was a common phrase male students repeated when asked about their identity as a male student. Male students perceive that educators and faculty members expected that they will either fail or not perform well academically. Raymond described this perception,

They expect girls to be smarter, they expect girls to be more organized. It's an expected thing. And a male is just going to be a male. Sometimes a male is dumber or can't multitask. There's a lot of stereotypical things with males that they put. A male is only good at this, a female is only good at this. 
Most males deal with these stereotypes as Raymond says, "I just deal with it."

Pancho described how he encounters this stereotype at Small Town. He attributes the perception to his age as a returning student. He shares,

Being an older male in college is kind of interesting. I think a lot of professors don't take you serious. They might look at you like you're just going to come over here and do one semester or two semesters and stop. Cause you're that older male and they know you have to work, you either have to take care of somebody else or take care of yourself. In America it's instilled in your brain, males have to work. So males technically don't have school and other things. So I've got that before, like oh, he's not going to finish.

Pancho and most other male students feel this pressure both from within their families and at Small Town. They feel like they are not expected to be good students or even finish college.

Racialized Masculinity: Intersecting Identities

For some Latino male students this challenges their idea of what they think is possible. For José, he faces not only the perception that males will not be successful in college, but also that there are very few Mexican males in college. Upon first attending Small Town he questioned his place there, wondering if he really could be one of the few Mexican males to attend college. He shares, "cause when I went there, when I first started there weren't as many Mexican people there, Mexican males, there were a lot of Mexican females, but not Mexican males. Made me think about, maybe I can't do it, cause everyone else is gone."

Latino male students maintained their identities as working students, but also shared how work can become a motivating factor to attend college and earn a degree. All students were the first generation in their family to attend college. They all want to 
pursue a college degree to both to provide a better life for themselves and for their families. Eddie, a Latino male, shares his feeling about the jobs he has worked. "So I felt like a mule working at the factory, cherries, McDonald's," he says. Eddie, like many other students, both male and female, come from working class background and have worked in jobs that provide little job security and low wages. He knows that without a college degree he will more than likely be working these types of jobs. College provides a pathway to a career instead of a job. Chris, who is attending Small Town for the second time, shares how his job at a local food processing plant motivated him to go back to college. He says,

I was going to Small Town and I was working at the food processing plant and kind of doing the whole $40+$ hours per week, it was just way too much. Even people say they can do it, the grades will show. If some people can do it, then kudos to them. I certainly can't do it. And I just decided that I can't do this do more. I knew I didn't want to stay there for the rest of my life.

Both Chris's mother and father work at this plant. While he sees that their work is valuable, he wants something different for himself. He wants to have a career.

Like Chris, Raymond wants something different for his life also. He has seen his father struggle working in physically demanding jobs. Raymond's father is recently unemployed, because he can longer work as he suffers from shoulder pain. Raymond wants a different life. He says, "work, well it helped me realize that an education is important, because if you don't have an education you'll just be working and working and working. And it really does pay off even though it might be in the long term. Some form of education does pay off." Raymond and others see that education is a pathway to a different career, a different form of work. Working in low wage jobs gives them 
motivation to pursue a degree and resist some of the negative stereotypes of Latinos in their communities.

\section{BEING SOMETHING DIFFERENT}

Even though male students faced stereotypes in attending college, they were able to reframe what it meant to "be a man." Similar to female students, to some extent they redefined their traditional gender roles and adopted a new way of being male. Aaron shares that he has always felt restricted to rigid gender roles, but in coming to college he feels like he can be himself - that there are different ways to be male. He says,

I think it's just the idea of being unique. Just because I don't fit in with the roles, I, It's like I, went to college, it was the idea of self-discovery, well, not necessarily, but learning what I am, what I'm passionate about, what I want to do with my life. While I don't fit in with these ideals, in college I can be with others that I fit in with, find people that are passionate about the things I'm passionate about.

Being in college has exposed Aaron and others to a broader array of options in how he can be male. Being male doesn't just mean working, being strong or tough. He can explore his love of art and music.

José also shares this similar feeling of shifting his role as a man during his time at Small Town. He says,

It's kind of helped me in a way where, knowing that just because you're a guy, doesn't mean that you have to be the only one to support. You don't have to just work, but you can go to school too. So it's really helped me, from a different view. To get different, I don't know how to put it... change my views on things.

In his family, males were always expected to work. Even though his father sees his lack of full-time work as less masculine, José is able to see a different way of being masculine at Small Town. 


\section{Taking Initiative and Gaining Confidence in the Classroom}

Not all male students express this sentiment as explicitly as Aaron and José, but all share how their confidence and level of involvement in the classroom has increased while attending college. Male students see their masculinity as contributing to their success, because they aren't afraid to speak up or use their voice in class to get answers and share ideas. Raymond shared that he has taken initiative to advocate for additional courses at Small Town. "I talk to a lot of staff...I've kind of opened my mind with staff there. I've voiced my opinions in discussions like that," he shares. Instead of accepting that Small Town doesn't have everything he needs as a student, he advocates for himself and others. Pancho described a similar way in which he takes initiative to get his needs met. He shares:

I'm headstrong, I'm not gonna sit and wait for something to come my way. If I see I'm struggling in something, I'm going to figure out a way to go around it or get help with it. Before Small Town had all this online stuff, I struggled in math, I'd go on YouTube. I figured it out. They're teaching the same thing they're teaching... It's just things as a male, I gotta figure out a way to go around this. That's what I did.

Pancho and other male students speak up during class, ask professors to slow down and find a way to get the help they need.

Male students also share feeling like they need to prove themselves in their coursework and look for opportunities to do so. For Karl, a White male student, this means testing time. He says,

I know what my grade is, I know my capabilities. I know if I work, I'll pass whatever I'm doing at the time, so that doesn't, so if I have a test, I really, I really love taking tests, I look forward to them cause it shows me, it's kind of a, I like...I've played a lot of sports. It's like going to like track meets and stuff. I like going to the meets rather than the practices, cause it shows me how good I am 
compared to the other people in the class or compared to the other people on the team.

As a former athlete in high school, Karl approaches his schoolwork as a competition.

This is a common theme in the way male student discussed their academic success.

Tyson, a professional bull rider, uses his rides as an analogy for his college career. He says,

Your mind it's like a checklist, cause in the rodeo, ya know like a bull rider or bare back rider, you have certain equipment, to keep you safe... school work taught me to do the same thing, you start at your head and ya know if there's anything with history, a test or something, you just kind of get in your head, pic it apart and then go from there, and then number it.

Male students do not work with each other, as females do, but compete with one another.

They find a way to make their voices heard in the classrooms and on campus.

\section{Support from Family: Giving Time and Space}

Unlike female students, male students had few obligations in their families and were given the support they needed from their families to attend college. They were given the time and space to do their homework and maintain their responsibilities outside home. Aaron described how his family supported him in this way by giving him "time for himself." He says,

When I go home it's like no body bother me and I'm just going to do my thing and relax. I'm gonna get my homework done, then relax, sleep whatever, get it done and relax. They're my family, but they aren't say oh, you need, do you need to be driven to school today, or whatever. I do whatever I have to. It's more about me than the family, so I have time for myself.

Aaron's family gives him the space to focus on himself and his schoolwork without worrying about his family's needs. Although they do want to spend time with him, he says they understand that he needs his space. 
Pancho, who is a father, described the support his family and wife provide him in a similar way. Pancho has two young children so it is difficult to put schoolwork ahead of spending time with them, but for Pancho, it is important to finish so he can provide a better life for them. He spends time on the weekends with them, but during the week he studies. His family gives him space to do so without interruption. When asked how his family helps him he says, "Just the space you need to study. When I get home they say like 'leave dad alone,' he needs to study. My wife did really good at that." Pancho and other male students commonly described being "left alone" to do their schoolwork, or that family understood they needed their space.

Johnny's family even encourages him to make more time to study away from the family. He says,

My family is pretty good at holding their own sometimes and whenever they want me at home or they want me to stay at school, most of the other times they'll just want me at school they don't want me skipping classes or staying home just because I feel like it, they'll just want me out of the house just to be at school when it's time.

Johnny and other male students felt like they have encouragement and support to put schoolwork over familial needs.

Tyson, who comes from a large farming family, says that his family gives him this support because his is representing the entire family. They are invested in his success. "When you're studying they leave you alone and let you just study. In a way it's kind of the family name and tradition," he says. For Tyson and others, their family makes their school a priority. Tyson's success is success for the whole family. Honoring the family name 
Like Tyson, male students gain tremendous motivation in making their family proud, by honoring their family name. As Tyson described, his success is the success of his entire family. He goes on to share how his family shared in his accomplishments. "After ward it's good, they see you graduating. It's that love that connects ya. Anytime it's an accomplishment for ya, it's an accomplishment for the family. You're proud of them in some way," he explains. Tyson has recently graduated and hopes to take over the family farm one day. Even though he is not transferring or directly using his degree in his career, his family is proud that he has finished college.

For Eddie, a Latino male, his accomplishments in college are not just about making his immediate family proud, but honoring his entire family's name. Eddie's family immigrated to the United States from a small ranch in Mexico. It is a rural community with roughly 10 families, he says. His family is large; some have immigrated to the United States and others stayed in this small community in Mexico. "We come from like a ranch of 10 people, I mean, come on like a ranch of 10 people in the middle of Mexico and we're going to universities?! You know, come on, it's great. And we're trying to do something good here," he says.

Eddie and other male students share the sense of pride they have in their familial name. Going to college and earning a degree is a way of honoring their name and familial heritage, while making a better life for those that come after them. Raymond describes the importance of honor in his college path. He says,

The honor, honor, the honoring your parents, honor your family, honor your lineage...It goes to honor and respect and to not give up, be somebody. Because you really want to motivate the other people around you to do the same especially if they're your blood. It puts out good citizens, if you can do that with yours, then they can affect other people in their lives, because you're not always going to be 
there. Your family member is going to grow up to be who they're going to be. If you can install some value, at least give them some direction, that multiplies the effect on the people they talk to as well. It's a multiplying effect.

For male students, their educational success is tied to their family's success. Their success represents their family's name, which paves the way for future generations. This motivates male students and gives them a sense of pride and duty to their family.

\section{CONCLUSION}

All Low-Income students face the challenge of balancing multiple realms of their lives. For female students this meant balancing work, school and home. All female students were caretakers and caregivers in the home, regardless if they were married or were mothers. Females struggled not only to balance their time, but struggled against the perceptions of what it means to be a woman from within their family and society as a whole. They felt limited as women and were told often that, "girls don't go to college." These mixed messages from parents created tension and conflict. Female students tended to rely less on their families for support but turned to female role models on campus and peer relationships. There they found support, encouragement and academic help. They could pursue their independence and break the gendered barriers that have been reinforced in their family life.

Male students did not attribute their struggles of balancing work and school to their gender at all. Conversely, they felt that males generally "have it easier" than females. They had few obligations to family, and family acted as a support for male students in a way that it did not for females. Family gives males time and space to study, and understands that they need to prioritize school above familial needs. Male students then come to see their success as representing the family as a whole, whereas female 
students seek to break away from the family. For both genders, this acts as motivation to pursue a college degree, but the support is quite different.

Although male students seem to have it "easier" as they say, males still share how difficult it can be to balance work and school. As the case with all students, time is limited and work is exhausting, but males share another important challenge with work. Most feel like they are primarily a worker. Being a man is equated to being a worker. Even when they aren't working, they feel like they should be. They struggle to put schoolwork first and find a different way to "be a man." In college, they share that professors reinforce this role and expect their failure, because men are meant to work. They are not expected to be there long and try to ignore these negative stereotypes. Male students do not generally form friendships or peer support groups on campus, as females do, but instead assert themselves in class and engage in friendly competition with one another. In doing so, male students feel like they honor their family's name and are providing for future generations.

Although males and females of both racial-ethnic backgrounds shared many stories in common, there were differences between groups. Latina students described their gender roles being influenced by their cultural background. In particular, they described feeling limited by their family and traditional gender expectations in Latino/a households. Both White and Latina students were limited by these gender roles, which caused conflict within families, but each tended to respond differently. White females describe overtly confronting and fighting with their parents, whereas Latina females covertly rebelled against parents to fulfill their educational goals. Each experienced these 
mixed messages and tension, but the constraints due to culture and class resulted in a varied response.

Similarly, male students described their gender role expectations in a similar way. All male students struggled to balance their working identity and expectation to work. However, there were slight differences in the way Latino males described their motivation to attend college. Their motivation was connected with their identity as a working male, but it was used as counter-motivation to resist some of the negative stereotypes and controlling images of "Mexicans" in their communities. They wanted a different career, one that would offer them autonomy and negate the perception that Latinos only "work in the fields." 


\section{CHAPTER VII: DISCUSSION AND CONCLUSION}

Earlier I presented and described a model of student academic success based upon previous studies and theoretical exemplars. The model accounts for structural objective constraints on student success, such as limited financial resources or access to quality schools. It also accounts for those sometimes in-tangible subjective constraints, such as aspirations and goals, which manifest themselves in students' motivations and intentions to persist.

One key contribution of this using this model is a sociological perspective on the educational literature on persistence. Using this empirical model, we find that persistence is not only a condition of whether or not a student integrates into the new college environment or his or her background characteristics, but persistence is also conditioned by the structural systems of inequality (Guiffrida 2006; Tinto 1987). It shapes and influences if and how students are able to integrate into the college environment. In the following sections, I will discuss how this study aligns to what is known in the literature in light of the empirical model presented earlier. I will summarize how students encounter these systems of inequality in their educational careers. Finally, I will elaborate on the how the findings from this study contribute to the model presented earlier and how students persist despite these structural barriers.

\section{Social Class and Academic Persistence}

All students in this study struggled because they were low-income students. This was not necessarily a condition of their cultural background, but was a constraint related to the material conditions of being low-income. All students came from working class backgrounds and their families could not offer them additional financial support while 
attending college. In fact, some students needed to support their family in addition to paying for college.

Although students took out loans and applied for financial aid, it was not enough to cover all school-related expenses. Students' choices were constrained then because their limited economic capital, which meant they needed to work. As other studies have confirmed, work limited time for schoolwork and was a source of stress (Walpole 2003). Low-income students had to make tough choices when balancing work and school. Working was not a choice, because without this source of income they could not attend. As confirmed by numerous studies on the negative impact of working for low-income students, students struggled to maintain good academic standing while working (Dougherty and Kinzel 2006; Eddy, Christie and Rao 2006; Lee and Frank 1990; O’Connor and Noga 2009). Students' academic performance suffered, which for some meant prolonged completion or dropping out along the way. Therefore, economic constraints or lack of economic capital had a direct negative effect on their academic persistence and success. It limited time and energy for school and challenged students' ability to persist.

Once students had figured out a way to pay for college, they struggled to understand the new college culture. They felt unprepared and lacked the cultural capital to navigate the new educational environment (Bourdieu 1977). All low-income students in this study were the first generation to attend college. As previous studies suggest, their parents had not attended college themselves and lacked the understanding to pass on to their children (Crisp and Nora 2010; Porchea et. al 2005). This challenge not only affected students' ability to be successful at college, but put strain upon their familial 
relationships as students felt an increased social distance between themselves and their parents.

Even as students experienced this social distance, they received support from their parents and family in the form of encouragement and motivation. Parents expected that their children would attend college and this aspiration was cultivated from early childhood for most students. Previous studies have highlighted the importance of what Yosso (2004) terms, aspirational capital, for Latino/a students, but this study suggests that parental aspirations are important for all low-income students (Feliciano and Ruben G Rumbaut 2005; Feliciano 2012; Portes and Rumbaut 2001). Parents communicate these aspirations early and therefore mediate some of the objective material constraints of students' social class background.

Finally, students blamed their high schools for their lack of cultural capital or preparation for college. They felt that their high school experience should have better prepared them for what they should expect at college. Previous research has identified the predictive force of pre-college experiences in determining success for low-income students, but this body of research has focused primarily on academic preparation and performance (D'Amico 2001; Crisp and Nora 2010; Porchea et al 2010). Findings from this study suggest that while academic preparation is important, preparation for college is more than course taking and grade point averages. Students attending community colleges can be admitted with low grade point averages, minimal course work in math, English and science, and are not required to take SAT's or ACT's. Only two students in this study took advanced coursework in college, yet they also felt unprepared for college and held their high schools responsible. The main shift, they say, is from teacher-centered 
responsibility to student-centered responsibility. Students are no longer given directions, but are now responsible for their own learning. The transition is challenging and some students dropped out along the way.

\section{Racial-Ethnic Differences}

Although all students in this study faced challenges related to their pre-college experiences, there are important differences due to students' racial-ethnic background (See Fig. 4). Latino/a students routinely faced racism and stereotyping in their high schools and home communities. This became both an objective and subjective constraint on Latino/a students' success in college. High school teachers reinforced the message that students would not be successful because of their racial-ethnic background and their abilities as students were in constant question. Students struggled to externalize racist messages and maintain their college aspirations.

Figure 4 Racial-Ethnic Differences

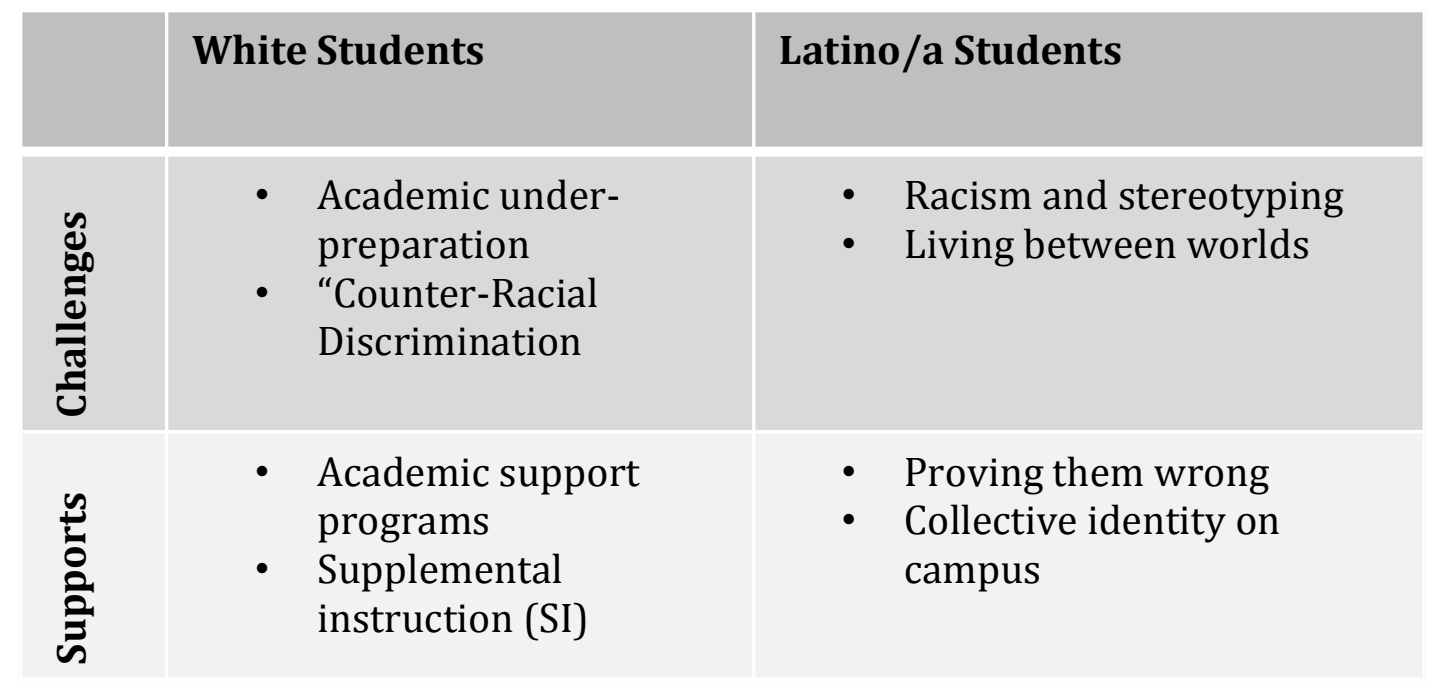

As Critical Race Theory emphasizes, racism is an ever-present force in students' lives that structures opportunities and outcomes for Latino/a students, in addition to their 
social class background. Latino/a students are stereotyped because of their language and immigration status. They face these intersecting forms of oppression that act as barriers to enrolling and persisting in higher education. Munoz and Maldonado (2011) and Villalpando (2004) found that students face these structural forms of racism and nativism in college, but in this study students also faced these barriers prior to attending college in their home communities.

Despite these challenges, Latino/a students found motivation and collective strength in their identity as Latinos/as. As Campa's (2010, 2013) study of MexicanAmerican community college students found, students were resilient in the face of these obstacles. Campa (2010) terms this behavior as critical resilience; the ability to navigate institutional barriers and learn the codes of power, while maintaining one's culture. Students in this study are not only resilient, but resist the racist ideology experienced in their communities. "Proving them wrong", becomes a new script of resistance for Latino/a students. Latino/a students use their cultural wealth as a resource for resistance (Yosso 2005). Students maintain group ties with their culture of origin and acculturate into American culture, even though this creates tension with their parents. They view themselves as bicultural which allows students to navigate dominant institutions while maintaining a positive racial-ethnic identity. Being bicultural is seen as an asset to be "used for good" and contribute to educational success, even in the context of racism. These findings confirm the positive effect of maintaining in-group cultural ties and limited acculturation (Altschul, Oyserman, and Bybee 2008; Portes and Rumbaut 2001).

Latino/a students in this study continued to maintain their cultural community on campus through involvement in MEChA and TRiO. Even though TRiO is not designed as 
cultural organization, the program at Small Town Community College is directed and staffed by Latino/a professionals. These two organizations act as safe spaces for students to access resources and find a support network in college. They increase students' social capital and support students' nascent collective consciousness. As Giroux (1983) and Yosso (2005) suggest, Latino/a students in this study maintain the view that they system is legitimate, while at the same time seeking to transform or resist the systematic oppressive forces of the educational system. Latino/a students are motivated to pursue their own educational goals with the hope that future generations of Latinos/as will not face the same challenges.

Language of resistance or resilience is absent from the stories of Low-Income White students. Instead, White students find support from faculty members to remediate their inadequate academic preparation and integrate into higher education. Even though most students are inadequately prepared academically for college, White students discuss this as a major challenge, whereas Latino/a students do not identity this as a source of challenge. White students therefore find support through academic support programs on campus that help them overcome their inadequacies and gain confidence in their academic ability. Other White faculty members, whom they rely upon for advice, resources and direction, refer White students to these programs.

Unlike Latino/a students, who form a collective support group, White students encounter these resources as individuals and do not discuss these programs as a support group or network. Therefore, these support programs and relationships with faculty members do not increase students' social capital in the same way that involvement 
MEChA and TRiO does for Latino/a students. They received support but the network is limited.

Furthermore, White students perceive the campus quite differently than Latino/a students and feel excluded because of their race and ethnicity. Although they are still the majority demographic at Small Town, they feel as if they are the minority. This may be due in part to their experiences prior to attending Small Town as most live in communities where they are minority demographic. In all but one of the communities Small Town serves, the Latino/a community comprises over $80 \%$ of the entire population (U.S. Census 2010). Therefore, White students stories may reflect the counter-effect of becoming the minority population. Similar to what MacLeod (1995) found among the "Hallway Hangers" in his study of the working class white males, White students may mistake their disadvantage as an issue related to their race, when in fact the inequality they experience is related to class constraints.

All low-income students struggle to pay for college and understand how to navigate the new culture, but White students perceive they are more challenged due to "reverse racism." White students lack a collective consciousness that aids their success, and instead attribute their struggles to a sense of group identity based upon "counterracial discrimination." This perception is rooted in the idea that their disadvantage is not related to their class position, but their racial background. White students take on an oppositional culture, but one that does little to aid their success.

\section{Gender Roles and Academic Persistence}

Previous quantitative research has identified a growing gender gap in college completion rates. Gender disparities are further compounded when race is added as a 
variable. Among Latinos/as, females earn $61 \%$ of all Bachelor's degrees (Buchmann et al. 2008). Although this study cannot fully explain the reason for the gap, it contributes insights on how gender roles and expectations may influence the college experiences of male and females differently, which in turn influences academic outcomes. As West and Zimmerman (1987) suggest, gender is not a stagnant category, but is an interactional ongoing process by which gender is done and re-enacted. Gender performances can change over time, but are subject to sanctioning if one deviates outside of normative gender roles. Working class males and females are further subjected to controlling images of what it means to do their gender in the context of their class location within education. Working class girls are expected to be submissive, be mothers and judged as hyper feminine (Skeggs 2004). Women are caregivers and caretakers, and their primary role is confined to the home. Other studies have suggested that these gender roles are held more rigidly for Latinas, and are influenced by cultural values (Hondagnneu-Sotelo 1994; Steven and Pescatello 1973).

In this study, all females shared limitations because of their gender across racialethnic backgrounds. This finding suggests that gender plays an important role in shaping both students' expectations and limitations in higher education. Parents expected that their daughters would attend college, but at the same time female students were still expected to maintain their gender roles in the home. Family became a source of support, but also the biggest challenge for female students. They were caught in a double-bind and struggled to maintain both worlds.

Although all females faced challenges because of their gender roles, Latina students described that these challenges being tied to their parents' cultural background 
(See Fig. 5). They felt their family limited them, because they held traditional cultural gender roles. Additionally, Latino/a families were constrained by material class conditions. Both parents worked outside the home in physically demanding jobs. Latina students fulfilled the care giving and care-taking role within the family, which was needed for the economic well being of the family.

Figure 5 Gendered Intersections

\begin{tabular}{|c|c|c|}
\hline & Female & Male \\
\hline 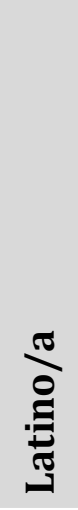 & $\begin{array}{l}\text { Balancing work, family and } \\
\text { school } \\
\text { - Family hinders-gender } \\
\text { roles } \\
\text { - Gender roles are tied to my } \\
\text { culture } \\
\text { - Unpaid labor in home, } \\
\text { economic need } \\
\text { Conflict and covert rebellion } \\
\text { against family }\end{array}$ & $\begin{array}{l}\text { - } \text { Men are meant to work } \\
\text { - } \text { Waculty expect failure } \\
\text { my race- } \\
\text { counter-motivation }\end{array}$ \\
\hline$\stackrel{\stackrel{\mathscr{Z}}{3}}{3}$ & $\begin{array}{l}\text { Balancing work, family and } \\
\text { school } \\
\text { - Family hinders-gender } \\
\text { roles } \\
\text { - Conflict and overt rebelling } \\
\text { against family }\end{array}$ & $\begin{array}{l}\text { - } \quad \text { Men are meant to work } \\
\text { - Faculty expect failure }\end{array}$ \\
\hline
\end{tabular}

Therefore, their restriction to the home was both a cultural expectation, but also a condition of economic need.

Finally, all female students describe conflict within their families due to gender expectations, but there was a subtle difference in the way Latina and White females responded. Latina females describe covertly rebelling against their parents' expectations and sneaking away or ignoring their demands, whereas White females overtly confront 
their parents and rebel against them. Both result in conflict, but Latinas attempt to maintain ties to family while still maintaining their educational goals.

In order to be successful in college, all females had to redefine their gender roles and break from those that had been cultivated within their family life. In essence, they needed role models that do gender differently than their experiences in their family. Female faculty members served as role models to female students. Similar to Latino/a students' script of proving them wrong, female students resisted normative gender roles and sought to break barriers, making a path for other women. They found support groups on campus and relied upon each other. Peer groups provided encouragement, accountability and shared group identity. This social network mediated the lack of support female students received from within their family life. Social capital, in the form of friendships and classmates, became an important support in helping students persist (Barajas and Pierce 2001; Bordes-Edgar et al. 2011; Feliciano and Rubén G Rumbaut 2005; Feliciano 2012; Gloria, Castellanos, and Orozco 2005).

Male students in this study discussed few challenges being a male college student and felt they "had it easier." In contrast to female students, they had few obligations to family and felt that family was one of the strongest supporters of their success. They were given time and space to study and prioritize their schoolwork over familial needs. This finding supports Ojeda, Navarro and Morales's (2011) study of the role of familismo, or commitment to family for Latino male college students.

In this study, both Latino and White males find a similar type of support from family. Commitment and pride in their family motivates their success in college. Educational aspirations and success come to represent the entire family, not only the 
individual male. Previous studies have suggested that this collectivist orientation is a function of cultural values, specifically of the Latino culture (Hardway and Fuligni 2006; Ojeda and Morales 2011; Sabogal et al. 1987). This study suggests that there are important gendered differences that shape how family either supports or constrains students' educational success depending on their gender roles within the family. Both White males and Latino males find support from family, just as White and Latina females face constraints from within the family regarding their educational success. Therefore, commitment and obligation to family, or familismo, may not be a function of culture, but a function of gender roles that are somewhat consistent across cultural backgrounds for low-income students.

Male students in this study did face challenges that were influenced by their gender even though males did not explicitly attributed to these challenges to their gender. As working class males, students' identities were defined in relation to their working identity. All male students either identified as a worker first and student secondly or maintained both identities, switching back and forth simultaneously. Female students primarily identified as students first and workers secondarily. Mamiseishvili (2010) identified a correlation between working identity and academic performance, but this may in fact be a function of gender identity and less about how prioritize work or school. Male students share a feeling that they should "always be working" as males. The working identity is the main source of their gender identity. This is a challenge for most males, because they feel confident in the work environment and struggle to translate that confidence into the educational context. Masculinity is defined by their ability to work and provide for their families. 
For male students it can be an easy alternative to drop out and go to work instead of pursing an education, especially in an area where family-wage jobs are still available (US Census 2010). This message is reinforced in family life, where students feel the pull to support their families and pursue a college degree. Males are expected to be providers and this message can truncate college aspirations and goals. Further compounding this effect is the perception that faculty members expect male students to fail, especially working class males.

All working class male students struggle against this controlling image of the working male, regardless of their racial-ethnic background. Gender roles within Latino/a households and White households reinforce normative gender roles. Latino males face a different challenge in overcoming the racism they have experienced, which is tied to their working identity as a male (See Fig. 5). The controlling image of the "lazy Mexican" or that "Mexicans will only work in the fields" becomes counter-motivation for Latino male students.

All male students use their current work situation to motivate their educational achievement, but Latino males use it to resist not only the dominant image of a working class male, but also as a Latino male. They seek to break these negative perceptions, or racialized masculinity, and be something different for themselves and others (Saenz and Ponjuan 2009). This is tied back to resistant capital and community uplift, but is viewed through a gendered lens (Yosso 2005; Campa 2010).

White males do not need to resist these controlling images in the same way and instead translate their masculinity into the classroom setting. As all male students describe, they take initiative and invoke friendly competition with one another. In doing 
so, male students began to redefine what it means to do masculinity. Taking pride in their education, taking initiative and making their voice heard were important mechanisms in performing alternative forms of masculinity.

\section{STUDY CONTRIBUTIONS}

\section{Identity and Resistance}

One of the motivations for this study was to unpack the structural influences on academic for community college students, in order to better understand how some of the hierarchical structures have influences on different groups. This comparative study contributes insights on how objective structures are experienced subjectively by students. Class influences are felt among all students in this study, but they are not always interpreted as such. White students struggle to pay for college, lack cultural capital and are academically unprepared just as Latino/a students face these similar challenges, but they do not share a class identity.

Students' perceptions of challenges and supports were directly influenced by their identities. These identities are multi-faceted and not easily captured in one single study, but patterns could be seen among those that identified similarly. Latino/a students were keenly aware of how their racial-ethnic background influenced the challenges they faced and acted as a resource to mediate some of those challenges. In essence, their group identity was the most salient identity motivating their academic success. Resistance to racism and oppression became a source of empowerment as a collective response. Latino/a students did not perceive their individual attributes or deficiencies as creating challenges to their success as White students perceived. Instead, the barriers to their success were overwhelmingly objective. They were described as external to the 
individual even though at times students struggled to prevent internalization of these negative messages. Latino/a students found a support groups and networks on campus that reinforced group identity and transferred resistant capital (Yosso 2005).

Similarly, female students attributed many of their challenges to the prescribed gender roles within their family. Being a female college student was one of the most salient roles because it objectively limited their access to college and ability to be successful. Balancing care-taking roles within the family limited time and energy for schoolwork, and added to the cost of attending college. Like Latino/a students, females struggled to externalize these messages and find an alternative script of resistance. The response was not an individual but a collective response, whereas female students found support and group identity on campus with other female students.

White students were generally unaware of their racial-ethnic identity and how that contributed to their success. Those students that did identify as being White only saw their background as a barrier to accessing resources. They felt excluded and perceived their identity as occupying a minority-status, even though White students still comprise the majority of the student population. Overwhelming, all students discussed the challenge they face in college with limited financial resources, but they placed minimal importance on their identity as a low-income or working class students. The goal for most students was to move out of this classification and have economic and class mobility. White students in this study did not seem to have a class identity, nor did they find a support network on campus that fostered this identity. Therefore, students' class status was given limited influence in students' educational careers and students were unaware of the similarities they may have shared as low-income students. 


\section{Context of the Community College and a Hispanic Serving Institution}

All of these identities are embedded within a context. Previous studies have identified that the university and campus environment is important for student belonging, which is a predictor of persistence (Crisp and Nora 2010; Gloria, Castellanos, Lopez, et al. 2005; Hurtado and Carter 1997). This study confirms the importance of the college environment, but also suggests that the college and community where students reside are not separate, but have equal impact on student success. Community college students are immersed in their home communities, which at times acts as a support and other times as a challenge. Family is an integral part of one's home community. It acts as one of the greatest supports for students, shaping what students believe is possible for their future and mediating some of the challenges students face in college. At the same time, family limits students' success because of gender expectations and their lack of knowledge of the college environment.

Furthermore, the context of this particular study is important to discuss. Latino/a students in this study felt "at home" on campus and were connected to their culture. They could share experiences with other Latino/a students, and felt that their own culture was congruent with that of the campus (Gloria et. al 2005). The presence of a cultural community helped students feel that they belonged in college and Small Town was a good fit from them. This supported their persistence and academic success.

The findings from this study contradict similar studies conducted at large, elite research institutions, where Latino/a students experience racism and negative racial climates (Hurtado and Carter 1997; Hurtado and Ponjuan 2005). This study points to the role of the institutional context in student persistence, in particular for Latino/a students. 
As a Hispanic-Serving Institution, Small Town has increased its Latino/a population from $18 \%$ to $42 \%$ in the last 6 years (STCC Institutional Research 2014). With this increase, Small Town has increased funding for student programs and staff members. Although this study was not designed to explicitly determine how an HSI designation influences student persistence, it does contribute understanding how cultural communities can support persistence of students of color. The increase in Latino/a students at Small Town Community College was important to students in establishing this cultural community. Mediating Relationships: the Role of Family

Another insight of this study is the influence of the family and gendered experiences on persistence. Students' aspirations are experienced at the familial level and gender roles are reinforced in the institution of the family. For female students in particular, family may be a limiting agent in educational aspirations and attainment. Students' experiences as low-income students are influenced by the gendered expectations of males and females that are cultivated in, but not confined to the family. All female students face objective constraints on their time while attending college because of gender role expectations. The constraints may not only be influenced by gender, but are compounded due to students' class position. In essence, they occupy a class of their own as unpaid laborers. This labor is not recognized by educational systems, nor is it legitimized as paid work. Female students from middle or upper class backgrounds do not face the same material constraints on their time and may be able to "buy out" their roles in the home. Therefore, female students struggle against structural forces that remain hidden and unrecognized. 
At the same time, family is one of the greatest supports that students discuss. Family is also the social place where students transfer social capital and aspirational capital. Students receive this support and motivation, while simultaneously experiencing the constraint of their gender roles. Family shapes the lens through which students view the challenges and barriers to their success. The institution of the family both structures how students view their opportunities and at the same time either reinforces or cultivates resistance of the structures in society. Parents of low-income students have limited agency alter the field of education or prepare their students for college, but they can build students' aspirational capital, which may be a powerful influence on students' persistence (Yosso 2005).

\section{Faculty and "Caring Pedagogy"}

When students came to Small Town, they found an environment quite different from their high school experience. Although at first they felt lost, faculty members helped students transition to the new environment. Previous research has identified that faculty play a role in student success. Astin (1993) and others suggest that students that attend office hours, meet with faculty outside of class and participate in research projects are more likely to be involved and persist. Even though students in this study discuss attending office hours, the influence of faculty in their success cannot be encapsulated into to these three activities. Simple gestures such as, faculty knowing their name, greeting them on campus and making themselves available and flexible contribute to student success. These behaviors resemble what Valenzuela (1999) terms a "caring pedagogy." Faculty members care about students personally and want them to be successful. Their success as faculty members is interdependent with the success of their 
students. Similar strategies were found in previous studies on the important influence faculty have on student persistence at community colleges (Levine and Nidiffer 1996; Thompson and Kelly-Vance 2001; Schreiner, Noel, Anderson, and Cantwell 2011).

Not all faculty members at Small Town are spoken of in this way, but those that do adopt this pedagogy are the most influential supports in students' college careers. Students feel at home on campus because faculty are "there for them." The faculty becomes inseparable from the campus and come to represent the institution as a whole.

\section{STUDY LIMITATIONS AND FUTURE RESEARCH}

As with any qualitative study, the generalizability of the study is limited by the number of participants and the context. Despite the limitation of generalizable findings, this study contributes important knowledge and lessons that can be transferred to similar contexts. Small Town Community College is a small Hispanic Serving Institution (HSI) in a rural district. Similar results could be expected at other small Hispanic Servicing Institutions in rural environments. There could be differences related to the rural context and studies conducted in urban environments may produce different results. Although, findings from this study are comparable to Campa's study $(2010,2013)$, which was conducted in an urban community college in Texas.

Another important variable to consider is the institutional context. Small Town earned its HSI status in within the last 6 years and the influence of this designation on student persistence is currently unknown. Current studies of HSI's found that Latino/a students have higher completion rates at HSI's compared to similar non-Hispanic Serving Institutions, but it is unclear as to how this designation makes a difference in the persistence of Latino/a students (Crisp, Gloria, and Nora 2010). Furthermore, research on 
HSI's has not explored if or how this designation may influence the persistence of all low-income students. Future comparative studies of Hispanic-Serving and non-HispanicServing institutions are important in order to understand how this status may influence student persistence. This study suggests that all students may benefit from faculty that is engaged in student success and programs that are expanded to support student success. It is unclear whether this is an effect of being designated as an HSI, with more emphasis on student success and retention, or if it is a characteristic of this particular institution.

Findings from this study also point to the need for more research in the area of shifting student demographic populations, where White students become the minority population. Exploration of how racial dynamics change, adapt or are resisted are important in understanding how institutions can prepare to serve all students and develop a more pluralistic environment.

Future research on student persistence should also explore those stories of students that have dropped out of college in order to better understand the how barriers influence persistence. All but two students in this study did not have continuous enrollment in college, but their stories still may vary from those that have dropped out as they had already graduated or were nearing graduation. Interviewing students whom have recently dropped out or were put on academic probation could illuminate the reasons why students leak out of the educational pipeline. Furthermore, students in this study were self-selected or recruited by key informants on campus to participate. As a result, students in this study may reflect a more favorable view towards the campus and/or campus staff and faculty. Again, future research comparing those experiences of students 
that have dropped out, to findings from this study is needed to confirm the challenges and supports that influence student persistence.

Additionally, this study points to the need of future research studying the role of gender and masculinity in higher education and its influence on student persistence.

Findings from this study indicate that success and student aspirations are viewed through gendered lenses. From its incipience, this study was not primarily focused on the role of masculinity in education. Questions were asked about students' gendered identities, but more focused attention is needed on the influence of this lens in particular for working class males. Previous research has focused on Latino males or male students in general (Saenz and Ponjuan 2009; Strayhorn 2010). This study suggests that working class males encounter different controlling images and expectations on how they are to perform their gender within higher education and in their familial context. This study began to explore how culture, race and gender intersect and influence persistence for Latino students differently than their White counterparts. Overall, most Latino males were unaware of these intersections during the interviews. Future research should explore in more depth how these issues intersect for males of color and how gender roles influence educational outcomes for all males.

Finally, working class females, both Latina and White, face significantly more challenges when compared to their male counterparts. The experiences of female college students have been studied, and their successes in the educational system have been well documented (Buchmann and DiPrete 2006; Buchmann, DiPrete and McDaniel 2008; Feliciano 2012; Riegle-Crumb 2010). What remains unanswered is how despite this success, women and particularly women of color, continue to be disadvantaged in the 
workplace. This question is beyond the scope of this study, but is important in understanding how education simultaneously plays a role in class mobility and reproduction of inequality for women. Future research should explore the role of gender in higher education longitudinally, following low-income women beyond graduation into the workforce.

\section{CONCLUSION}

Low-income students face many challenges as community college students that are not easily overcome during their pathway to degree completion. The challenges are both material objective constraints that limit choices and academic success, and they are subjective, experienced at the individual level that shape how students view their possibility of success and ability to persist. Previous research on community college students has segmented student populations into categories of analysis. Students are either low-income, Latino/a, and male or female. While the strategy is efficient for administrators, researchers and policy makers, students do not always fit neatly into these boxes-neither do their challenges.

This study suggests that students experience their class, race-ethnicity and gender on a continuum and at intersections of these identities. They do not experience them as categories, but instead they are real challenges that at times impede their academic success. Some of the challenges White students face are similar to those of Latino/a students because of their social class. In contrast, Latino/a students face challenges regardless of their social class due to racism and stereotyping within their communities and educational experiences. Just as female students experience limitations due to roles and expectations ascribed to their gender, not only their race-ethnicity. All of which, 
interact and intersect at differing points in students' lives, which influences their persistence.

All low-income students, across groups, experience these challenges continuously throughout their college careers. As Eddie describes, "once you overcome one, you get ready for the next one." They do not simply confront one, gain understanding of how to deal with it and then move on to the next phase of their education. Instead, students experience a continuous stream of challenges in which they work "up-stream" so to speak, against the structural barriers that reproduce inequality through the educational system. Students experience these barriers differently depending on their race-ethnicity and gender, and use different supports to deal with the intersecting forms of oppression they encounter.

Even though students experience these structural challenges throughout their college career, they persisted to completion. Their individual effort and determination should not be neglected as an influential component to success, but without key supportive relationships from both within and outside of campus, students' stories may have concluded differently. Supportive relationships helped students to mediate challenges they experienced as a first generation, low-income community college students. Family provided a system of support to help students aspire to attend college and earn their degrees. Although, family lacked important knowledge or cultural capital valuable in higher education, they acted as a primary support of student success.

Faculty members and staff were the primary supportive relationships students relied upon on campus in order to persist. "It is clearly people, rather than programs, services, or institutions, who retain students" (Schreiner et al. 2011, pg. 336). Faculty 
members and staff are the institution from students' perspective, and their responsiveness to the needs of low-income students is essential to include in a model of persistence. They help students mediate the challenges they faced. By adopting a "caring pedagogy" faculty members shift the local field of education, leaving room for some educational mobility. After all, "students do not stay or leave institutions as much as they stay in or leave relationships" (Schreiner et al. 2011, pg. 333). As Louisa best describes, "it's the people behind it that make it happen."

Although faculty members and important relationships on campus mediate these structural challenges for students, they do not make the challenges disappear. Within the learning experience students are given a chance to displace some of the barriers with the support of these relationships on campus. By prioritizing these key relationships at the institutional level, colleges and universities invest in the most effective resource for student success and persistence. 


\section{EPILOGUE}

From the beginning of this research project, the design was intended not only to contribute empirical and theoretical knowledge to the academic field of sociology, but was also designed to aid the institution in their efforts to support student success. The findings from this research will be shared with Small Town Community College in an effort to honor their partnership and contribution to this project. The following section discusses some recommendations for policy and practice at Small Town Community College based upon the findings from this project. This report will be shared with Small Town in more detail at a later date.

\section{RECOMMENDATIONS FOR POLICY AND PRACTICE}

\section{Increase Funding of Financial Aid}

Many of the challenges faced by low-income community college students stem from their lack of resources. Although students in this study applied for financial aid while attending college, it was not sufficient to cover all expenses related to college attendance. Low-income students may not only have to pay for college and their living expenses, but they may also need to support their family financially with either paid or unpaid labor in the home. This obligation and financial constraint, not only makes it difficult to attend college, but also makes it difficult for students to perform well in college. As students are faced with these tough choices, many work and choose family over their school commitments. For many, this negatively affects their performance, which in turn can mean academic probation and further repercussions for financial aid.

This study points to the importance of adequately funding students' college education so low-income students are not forced to make a choice between their family's 
well being and their education. Increasing financial aid and grants for students would increase students' ability to not only attend college, but also persist once they are enrolled. Increasing Work Study dollars would support low-income students by providing a more flexible source of employment and one that is more closely tied to their academic careers. If students are able to work on campus they will also be more connected to faculty and staff that can further support their academic careers, while earning money to support their family and education. Furthermore, educational funding for parents and caregivers needs to be increased. Funding of childcare for students has been neglected in federal, state and local services. Students with children or those caring for siblings are at times unable to attend classes and their academic performance suffers. Increasing childcare services and funding to cover such services would be an important step in increasing persistence for low-income students.

\section{Prioritize Faculty and Adopt "Caring Pedagogy"}

An important finding of this study is the role of faculty in academic persistence of low-income students. Faculty is named by students as one of the most important supports in their success. Faculty members who are approachable, available, flexible and caring make students feel safe and cared for on campus. They become they face of the campus for students. Funding of educational dollars needs to be focused on supporting faculty and classroom learning, as they are the primary relationships that mediate success for students and in particular, low-income students. Previous research has identified the predictive factor increased contact with faculty has on student success, but this body of research has focused on student behaviors that elicit these outcomes rather than faculty behaviors (Astin 1993; Kuh, Kinzie, Schuh and Whitt 2005). For low-income, first 
generation students, faculty initiative and caring is essential for success (Schreiner, Noel, Anderson and Cantwell 2011).

In order for faculty to engage in a "caring pedagogy," faculty need to feel supported and have the time to dedicate to students. Institutions can increase student success by focusing their efforts and funding on supporting faculty in adopting a caring pedagogy and other pedagogies that centralize the student learning experience. Support services for underrepresented groups should still be prioritized, but the classroom experience and interactions with faculty prove to be essential for student success. Faculty members that have adopted a caring pedagogy could serve as mentors for other faculty members to further implement this culture and pedagogical approach.

Furthermore, it is important to emphasize that students in this study sought out mentors and services that were congruent with both their racial-ethnic background and gender. Students seek out those professionals they can identify with and connect with their experience. These professionals not only become forms of support in helping students mediate the challenges they face as low-income and marginalized students, but they serve as role models that shift students' idea of what is possible. Female instructors are role models for working-class female students seeking to become independent. Male instructors and staff members are role models for working -class male students attempting to redefine their masculinity. Latino/a professionals help Latino/a students feel connected and reframe what it means to be Latino/a in the face of overwhelming odds. They validate students' cultural identity and form a support group on campus for students. 
In each of these cases, students rely on those mentors and role models that match their own identities. At Small Town Community College, like many other colleges, faculty of color are underrepresented. Faculty diversity has increased slowly over time and there is still a deficit of faculty of color on campuses (Weinberg 2008). In 2013, only $4.1 \%$ of all full-time faculty members were Latino/a whereas the Latino/a student population is just over $12 \%$. White faculty members are overrepresented at institutions and comprise nearly $80 \%$ of all full-time faculty. Forty-four percent of faculty members are male and 35\% are female (NCES 2013; Weinberg 2008). Considering that students seek out culturally congruent mentors and advisors, it is imperative that colleges and universities increase the number of full-time faculty of color, both male and female. This is important not only to offer students a diverse experience, but is also important to increase student success for underrepresented groups (Hurtado and Carter 1997). Involve Community and Family in College Pathways

Another insight from this study is how the home community and family continue to influence student persistence beyond high school. All but two students in this study lived at home in the same community where they attended high school. Therefore, the home and community context was just as influential as the college environment. Although family presented challenges for students and constrained some choices for female, family generally supported student success. Family acted as a motivator early in students' academic careers by cultivating college aspirations and behaviors for academic success. Even though parents could not offer advice or guidance for their children during college, at times family was the only support students could depend upon. 
In traditional models of student persistence (Tinto 1987), family is treated as a deficit that negatively affects student success for underrepresented groups. Students must detach from family and integrate into the new college culture. As first generation, lowincome community college students, this may not be possible or advantageous. Students generally live at home and remain ties to their family of origin. This study suggests that lack of detachment does not negatively affect student success, but connection with family aids student in mediating some of the challenges they face in college and contributes to their motivation to persist.

Therefore, highlighting the role of family in the process of persistence is important for college to increase student success. College campuses have minimal influence on community life, but it must be acknowledged that students attending community college may not separate themselves from their community life. Students' connections to past acquaintances, previous mentors, extended family and friends are important connections that factor into successful persistence. Maintaining the positive relationships in one's community and family then becomes just as important as distancing from negative relationships. It is important that community colleges acknowledge these relationships at the community level and not just in the college environment.

TRiO programs, such as GEAR-UP and Upward Bound, have been successful in involving parents in the college planning process, which has helped students gain more access to higher education. Once students are enrolled they do not know what to expect and cannot depend upon their parents. Colleges should make more effort to involve parents and family members in the orientation process. Efforts should focus not only providing parents and family members with information on the financial aid process, 
enrollment and college bureaucracies, but should support family members understanding of what type of support their students need in order to be successful in college. Parents lack the knowledge, or cultural capital, of how college is different from high school, just as their students lack this understanding. By increasing parents' understanding, colleges can invest in preventative measures to ensure students have safety nets at home as well as at college.

Increased understanding of the educational system does not trump the strongly embedded gender expectations within the family that continue to negatively effect lowincome students, but additional efforts need to be made in order to address these structural constraints students face that are conditioned by their gender expectations within the family. By acknowledging the both the positive and negative influences of family, colleges can capitalize on the support families offer students, while providing support to families to help students transition to their new roles as college students.

Furthermore, numerous studies (Campell and Campell 1997; Crisp 2010; Noguera 2003; Strayhorn 2010) have identified the role of mentoring in supporting student success. Implementing a mentoring program for parents and family members may seem outside the scope of higher education, but could positively affect graduation and retention rates. As Alex, a Latina student in this study shared, without mentoring for her parents she would have never been able to attend college.

For Alex and other immigrant families, mentoring may be especially important, as understanding of the educational system may be based upon prior home country knowledge and may have limited transferability to the U.S. context. Immigrant families desire upward mobility for their children and community, but may lack understanding of 
how educational success directly influences this mobility. Providing programming and mentoring for immigrant parents is an important step to bridge the cultural wealth of Latino/a families in order to translate this wealth into the educational context. Peer parent and family mentoring programs could provide parents with a trusted source to answer questions and increase understanding of this new context. Parents training other parents would act as a support network.

Community health programs have pioneered such programs as the Promatores de Salud, a model of peer education from the Office of Minority Health (2009) ${ }^{10}$. Community Health Workers educate community members that share similar identities and serve as a more approachable and trusted resource for community members. The Promotores model has been used to increase positive health outcomes specifically for the Latino/a population in the United States, but this model could be translated and used in an educational context ${ }^{11}$. In fact, the Promotores de Salud model is currently used in Small Town Community College's service district. Experts and current health workers could provide consultation and serve as a resource in piloting this model. The same type of model could be used with White low-income parents and students, as they face similar challenges in understanding the new culture of higher education.

\section{Utilize Counter-Storytelling for Resistance}

\footnotetext{
10 "Promotores de Salud/Community Health Workers (CHWs) are volunteer community members and paid frontline public health workers who are trusted members of and/or have an unusually close understanding of the community served" (Office of Minority Health 2009).

${ }^{11}$ Padres Promotores de la educacion is a new model founded in the Santa Ana Unified School District. The model is funded in part by National Council for Community and Educational Partnerships. (http://www.edpartnerships.org/resources/padres-promotoresde-la-educación)
} 
Finally, findings from this study suggest that Community Cultural Wealth and resistant capital are particularly important in the persistence and success of Latino/a students (Yosso 2005). Counter-storytelling has its roots in Critical Race Theory and case law. It was originally used in the courtroom when a defendant of color was tried in front of a predominantly white jury. This method was used to center the case on the human face of suffering and oppression caused by racism that can be lost in a society founded on White Supremacy (Yosso 2013). In education, counter-storytelling has been used in the research process to tell those stories that challenge the dominant narrative of failure and reproduction of inequality.

Although inequality exists and should not be ignored, it is equally important that researchers retell narratives of resistance to dominant structures and success that place students' stories at the center of the research process (Solorzano and Yosso 2002). This study focused on the mechanisms that Latino/a students use to navigate the dominant structures within higher education, not through assimilation, but by adopting attitudes and behaviors of resistance. As Yosso (2005) describes, students used their culture as a resource by maintaining ties with their culture and family. They translated this wealth of knowledge and collective value in order to navigate institutional barriers within higher education and the local context (Altschul, Oyserman, and Bybee 2008; Portes and Rumbaut 2001).

Counter-storytelling can also be used within the community college context to support new students on their pathway through higher education. Peer mentoring programs have been successful in helping students navigate the system of higher education, but counter-storytelling can be useful in helping students redefine what is 
possible, not only to acquire new information. Including the counter-narratives of Latino/a students, faculty and staff in orientations, classroom lectures and advising sessions would increase the collective identity of Latino/a students on campus and support new students in redefining their own pathway of success. Although this methodology has been used primarily to support students of color, similar strategies could be used to develop the resistant capital of female students and low-income students. Developing students' sense of identity and critical consciousness can help students navigate and resist the structures that are designed to reproduce inequality within the educational system. 


\section{REFERENCES}

Adelman, Clifford. 1999. "Answers in the Tool Box. Academic Intensity, Attendance Patterns, and Bachelor's Degree Attainment."

Altschul, Inna, Daphna Oyserman, and Deborah Bybee. 2008. "Racial-Ethnic SelfSchemas and Segmented Assimilation: Identity and the Academic Achievement of Hispanic Youth.” Social Psychology Quarterly 71(3):302-320.

Astin, Alexander W. 1993. What matters in college? Four critical years revisited. JosseyBass.

Barajas, Lasley, and Pierce. 2001. "The Significance of Race and Gender in School Success Among Latinas and Latinos in College." Gender \& Society 15(6):859-878.

Bernal, Dolores Delgado. 2002. "Critical Race Theory, Latino Critical Theory, and Critical Raced-Gendered Epistemologies: Recognizing Students of Color as Holders and Creators of Knowledge.” Qualitative Inquiry 8 (1 ):105-126.

Bordes, Veronica, Jennifer K Sand, Patricia Arredondo, Sharon E Robinson Kurpius, and Andrea Dixon Rayle. 2006. "Validation of Four Measures of Social Support With Latina/o and Non-Hispanic White Undergraduates." Hispanic Journal of Behavioral Sciences 28 (1 ):65-83.

Bordes-Edgar, Veronica, Patricia Arredondo, Sharon Robinson Kurpius, and James Rund. 2011. "A Longitudinal Analysis of Latina/o Students' Academic Persistence." Journal of Hispanic Higher Education 10(4):358-368.

Bourdieu, Pierre. 1977. Outline of a Theory of Practice. Cambridge university press.

Bourdieu, Pierre. 1984. Distinction: A social critique of the judgment of taste. Harvard University Press.

Braun, Virginia, and Victoria Clarke. 2006. "Using thematic analysis in psychology." Qualitative research in psychology 3(2):77-101.

Buchmann, Claudia, and Thomas A DiPrete. 2006. "The Growing Female Advantage in College Completion: The Role of Family Background and Academic Achievement." American Sociological Review 71(4):515-541.

Buchmann, Claudia, Thomas A DiPrete, and Anne McDaniel. 2008. "Gender inequalities in education." Annu. Rev. Sociol 34:319-337. 
Cammarota, J. 2004. "The gendered and racialized pathways of Latina and Latino youth: Different struggles, different resistances in the urban context." Anthropology \& Education Quarterly 35(1):53-74.

Campa, Blanca. 2010. "Critical Resilience, Schooling Processes, and the Academic Success of Mexican Americans in a Community College." Hispanic Journal of Behavioral Sciences 32(3):429-455.

Campa, Blanca. 2013. "Pedagogies of Survival: Cultural Resources to Foster Resilience Among Mexican-American Community College Students." Community College Journal of Research and Practice 37(6):433-452.

Campbell, Toni A, and David E Campbell. 1997. "Faculty/student mentor program: Effects on academic performance and retention." Research in Higher Education 38(6):727-742.

Collier, PeterJ., and DavidL. Morgan. 2008. “'Is that paper really due today?': differences in first-generation and traditional college students' understandings of faculty expectations." Higher Education 55(4):425-446.

Collins, Patricia Hill. 2000. Black feminist thought: Knowledge, consciousness, and the politics of empowerment. Psychology Press.

Connell, Robert William. 1987. Gender and power: Society, the person and sexual politics. Stanford University Press.

Connell, R W. 1989. "Cool Guys, Swots and Wimps: the interplay of masculinity and education." Oxford Review of Education 15(3):203-291.

Crisp, Gloria. 2010. "The impact of mentoring on the success of community college students." The Review of Higher Education 34(1):39-60.

Crisp, Gloria, and Amaury Nora. 2010. "Hispanic Student Success: Factors Influencing the Persistence and Transfer Decisions of Latino Community College Students Enrolled in Developmental Education." Research in Higher Education 51(2):175194.

D’Amico, Mark M, Grant B Morgan, and Thashundray C Robertson. 2011. "Student achievement in identified workforce clusters: understanding factors that influence student success." Community College Journal of Research and Practice 35(10):773790 .

Dougherty, Kevin, and Gregory Kienzl. 2006. "It's not enough to get through the open door: Inequalities by social background in transfer from community colleges to fouryear colleges." The Teachers College Record 108(3):452-487. 
Dowd, Alicia C, and Tarek Coury. 2006. "The effect of loans on the persistence and attainment of community college students." Research in Higher Education 47(1):33-62.

Eddy, Pamela L, Ray Christie, and Michael Rao. 2006. "Factors affecting transfer of 'traditional' community college students." The Community College Enterprise 12(1):73-92.

Espinoza, R. 2010. "The good daughter dilemma: Latinas managing family and school demands.” Journal of Hispanic Higher Education 9(4):317-330.

Espinoza-Herold, Mariella. 2007. "Stepping beyond 'Sí Se Puede: Dichos' as a Cultural Resource in Mother-Daughter Interaction in a Latino Family." Anthropology \& Education Quarterly 38(3):260-277.

Feliciano, Cynthia. 2012. "The Female Educational Advantage Among Adolescent Children of Immigrants." Youth \& Society 44(3):431-449.

Feliciano, Cynthia, and Rubén G Rumbaut. 2005. "Gendered paths: Educational and occupational expectations and outcomes among adult children of immigrants." Ethnic and Racial Studies 28(6):1087-1118.

Ferrari, A M. 2002. "The impact of culture upon child rearing practices and definitions of maltreatment." Child Abuse \& Neglect 26(8):793-813.

Fry, R A, and P H Center. 2002. Latinos in higher education: Many enroll, too few graduate. Pew Hispanic Center Washington, DC.

Giroux, Henry A. 1983. "Theories of reproduction and resistance in the new sociology of education: A critical analysis." Harvard educational review 53(3):257-293.

Gloria, Alberta M, Jeanett Castellanos, Ambrocia G Lopez, and Rocio Rosales. 2005. "An Examination of Academic Nonpersistence Decisions of Latino Undergraduates." Hispanic Journal of Behavioral Sciences 27(2):202-223.

Gloria, Alberta M, Jeanett Castellanos, and Veronica Orozco. 2005. "Perceived educational barriers, cultural fit, coping responses, and psychological well-being of Latina undergraduates.” Hispanic Journal of Behavioral Sciences 27(2):161-183.

Goffman, E. 1976. Gender advertisements. Society for the Anthropology of Visual Communication.

Goldrick-Rab, Sara. 2006. "Following their every move: An investigation of social-class differences in college pathways." Sociology of Education 79(1):67-79. 
Gonzales, Leslie D. 2012. "Stories of Success: Latinas Redefining Cultural Capital." Journal of Latinos and Education 11(2): 124-138.

Guiffrida, Douglas. 2006. "Toward a cultural advancement of Tinto's theory." The Review of Higher Education 29(4): 451-472.

Hardway, C, and A J Fuligni. 2006. "Dimensions of family connectedness among adolescents with mexican, chinese, and european backgrounds." Developmental Psychology 42(6): 1246.

Harker, Richard K. 1984. "On Reproduction, Habitus and Education." British Journal of Sociology of Education 5(2):117-127.

Hondagneu-Sotelo, P. 1994. Gendered transitions: Mexican experiences of immigration. University of California Press.

Hurtado, Sylvia, and Deborah Faye Carter. 1997. "Effects of college transition and perceptions of the campus racial climate on Latino college students' sense of belonging." Sociology of Education 324-345.

Hurtado, Sylvia, and Luis Ponjuan. 2005. "Latino educational outcomes and the campus climate." Journal of Hispanic Higher Education 4(3):235-251.

Jones, Susan, and Debra Myhill. 2004. “'Troublesome boys' and 'compliant girls': Gender identity and perceptions of achievement and underachievement." British Journal of Sociology of Education 25(5):547-561.

Kuh, George D, Jillian Kinzie, John H Schuh, and Elizabeth J Whitt. 2010. Student success in college: Creating conditions that matter. John Wiley \& Sons.

Lareau, Annette. 2011. Unequal childhoods: Class, race, and family life. University of California Press.

Lee, Valerie E, and Kenneth A Frank. 1990. "Students' Characteristics that Facilitate the Transfer from Two-Year to Four-Year Colleges." Sociology of Education 63(3):178-193.

Legewie, Joscha, and Thomas A DiPrete. 2012. "School Context and the Gender Gap in Educational Achievement." American Sociological Review 77 (3 ):463-485.

Levine, Arthur, and Jana Nidiffer. 1996. Beating the Odds: How the Poor Get to College. The Jossey Bass Higher and Adult Education Series. ERIC.

Lorber, Judith. 1994. Paradoxes of gender. Yale University Press. 
Lucal, Betsy. 2008. "Building Boxes and Policing Boundaries: (De)Constructing Intersexuality, Transgender and Bisexuality." Sociology Compass 2(2):519-536.

MacLeod, Jay. 1995. Ain't no makin'it: Aspirations and attainment in a low-income neighborhood. Westview Press Boulder, CO.

Mamiseishvili, Ketevan. 2010. "Effects of Employment on Persistence of Low-Income, First-Generation College Students." College Student Affairs Journal 29(1):65-74.

Marin, G. 1993. "Influence of acculturation on familialism and self-identification among Hispanics." Ethnic identity: Formation and transmission among Hispanics and other minorities 181-196.

Marshall, Catherine, and Gretchen B Rossman. 2010. Designing qualitative research. Sage Publications, Incorporated.

Movimiento Estudiantile Chican@ de Aztlán. 2013. "About Us." Retrieved April 14, 2014 (http://www.nationalmecha.org/about.html).

Muñoz, Susana María, and Marta María Maldonado. 2011. "Counterstories of college persistence by undocumented Mexicana students: navigating race, class, gender, and legal status." International Journal of Qualitative Studies in Education 25(3):293315.

National Center for Educational Statistics (NCES). 2010. "Integrated Postsecondary Data System (IPED)." Retrieved March 20, 2014 (http://nces.ed.gov/ipeds/deltacostproject/).

National Council for Community and Educational Partnerships. 2013. "Padres Promotores de la Educación." Retrieved April 14, 2014 (http://www.edpartnerships.org/resources/padres-promotores-de-la-educación).

Noguera, Pedro A. 2003. "The trouble with Black boys: The role and influence of environmental and cultural factors on the academic performance of African American males." Urban Education 38(4):431-459.

O'Connor, Noga. 2009. "Hispanic origin, socio-economic status, and community college enrollment." The Journal of Higher Education 80(2):121-145.

Ogbu, John U. 1978. Minority education and caste: The American system in crosscultural perspective. Academic Press New York.

Office of Minority Health. 2009. "Definition of Promotores de Salud." Retrieved April 14,2014 (http://minorityhealth.hhs.gov/templates/content.aspx?lvl=2\&lvlid=207\&ID=8930). 
Ojeda, L, R L Navarro, and A Morales. 2011. "The role of la familia on Mexican American men's college persistence intentions." Psychology of Men \& Masculinity 12(3):216.

Paulsen, Michael B, and Edward P St John. 2002. "Social class and college costs: Examining the financial nexus between college choice and persistence." The Journal of Higher Education 73(2):189-236.

Porchea JeffRobbins, StevePhelps, Richard P., Sameano F.Allen. 2010. "Predictors of Long-Term Enrollment and Degree Outcomes for Community College Students: Integrating Academic, Psychosocial, Socio-demographic, and Situational Factors." Journal of Higher Education 81(6):680-708.

Portes, A, and R G Rumbaut. 2001. Legacies: The story of the immigrant second generation. University of California Press.

Renold, Emma. 2004. “'Other' boys: negotiating non-hegemonic masculinities in the primary school." Gender and Education 16(2):247-265.

Riegle-Crumb, Catherine. 2010. "More Girls Go to College: Exploring the Social and Academic Factors Behind the Female Postsecondary Advantage Among Hispanic and White Students." Research in Higher Education 51(6):573-593.

Sabogal, Fabio, Gerardo Marín, Regina Otero-Sabogal, Barbara Vanoss Marín, and Eliseo J Perez-Stable. 1987. "Hispanic Familism and Acculturation: What Changes and What Doesn't?” Hispanic Journal of Behavioral Sciences 9(4):397-412.

Saenz, Victor B, and Luis Ponjuan. 2009. "The Vanishing Latino Male in Higher Education." Journal of Hispanic Higher Education 8(1):54-89.

Schreiner, Laurie A, Patrice Noel, and Linda Cantwell. 2011. "The impact of faculty and staff on high-risk college student persistence." Journal of College Student Development 52(3):321-338.

Sheffield, M L. 2011. "Stories of Success: First Generation Mexican-American College Graduates."

Skeggs, Beverley. 1997. Formations of Class \& Gender: becoming respectable. Sage.

Skeggs, Beverley. 2004. "Context and background: Pierre Bourdieu's analysis of class, gender and sexuality." The Sociological Review 52(s2):19-33.

Snyder, Thomas D, Sally A Dillow, and Charlene M Hoffman. 2008. "Digest of Education Statistics, 2007. NCES 2008-022.” National Center for Education Statistics. 
Solorzano, Daniel G, and Dolores Delgado Bernal. 2001. "Examining Transformational Resistance Through a Critical Race and Latcrit Theory Framework: Chicana and Chicano Students in an Urban Context ." Urban Education 36 (3):308-342.

Solórzano, Daniel G, and Tara J Yosso. 2002. "Critical Race Methodology: CounterStorytelling as an Analytical Framework for Education Research." Qualitative Inquiry 8 (1):23-44.

Sólorzano, Daniel G, Octavio Villalpando, and Leticia Oseguera. 2005. "Educational Inequities and Latina/o Undergraduate Students in the United States: A Critical Race Analysis of Their Educational Progress." Journal of Hispanic Higher Education 4 (3 ):272-294.

Stevens, E P, and A Pescatello. 1973. Marianismo: The other face of machismo in Latin America. University of Pittsburgh Press.

Strayhorn, Terrell L. 2010. "When Race and Gender Collide: Social and Cultural Capital's Influence on the Academic Achievement of African American and Latino Males." The Review of Higher Education 33(3):307-332.

Suárez-Orozco, C, and M Suárez-Orozco. 1995. Transformations: Immigration, family life, and achievement motivation among Latino adolescents. Stanford University Press.

Thompson, J.B. 1991. Editor's introduction. In Language and symbolic power, ed. P. Bourdieu, 1-31. Cambridge: Polity.

Thompson, Lynn A, and Lisa Kelly-Vance. 2001. "The impact of mentoring on academic achievement of at-risk youth." Children and Youth Services Review 23(3):227-242.

Tinto, Vincent. 1987. Leaving college: Rethinking the causes and cures of student attrition. ERIC.

U.S. Census. 2010. "Interactive Population Map." Retrieved March 10, 2014 http://www.census.gov/2010census/popmap/.

U.S. Department of Education, Office of Post-Secondary Education. 2011. "Definition of Hispanic-Serving Institutions." Retrieved February 5, 2014 (http://www2.ed.gov/programs/idueshsi/definition.html).

U.S. Department of Education, Office of Post-Secondary Education. 2014. "Federal TRiO Programs-Home Page." Retrieved March 10, 2014 (http://www2.ed.gov/about/offices/list/ope/trio/index.html). 
Valenzuela, A. 1999. Subtractive schooling: US-Mexican youth and the politics of caring. Suny Press.

Valenzuela, A, and S M Dornbusch. 1994. "Familism and social capital in the academic achievement of Mexican origin and Anglo adolescents." Social Science Quarterly.

Villalpando, O. 2004. "Practical considerations of critical race theory and Latino critical theory for Latino college students." New Directions for Student Services 2004(105):41-50.

Walpole, MaryBeth. 2003. "Socioeconomic status and college: How SES affects college experiences and outcomes." The review of higher education 27(1):45-73.

Weinberg, Sharon L. 2008. "Monitoring faculty diversity: The need for a more granular approach.” The Journal of Higher Education 79(4):365-387.

West, Candace, and Don H Zimmerman. 1987. "Doing Gender." Gender and Society $1(2): 125-151$.

Willis, Paul E. 1977. Learning to labor: How working class kids get working class jobs. Columbia University Press.

Yosso, Tara J. 2005. "Whose culture has capital? A critical race theory discussion of community cultural wealth." Race Ethnicity and Education 8(1):69-91.

Yosso, Tara J. 2013. Critical race counterstories along the Chicana/Chicano educational pipeline. Routledge. 


\section{APPENDIX A \\ Interview Protocol: STCC Persistence Research}

\section{Introduction}

Thank students for time.

Go over consent form and ask permission to audio record.

Give them a short explanation of study.

Ask them if they'd like to choose their own

pseudonym:

\section{Opening}

How long have you been a student at STCC?

Why did you come to STCC?

\section{Mechanisms of Persistence}

Students are given cards reflecting the categories in the left-hand column.

Let's talk about how what helps you be successful as a college student. Here are some things that other students have said help them be successful in college. Go ahead and take a moment to think about which ones fit for you and which one(s) you'd like to talk about first.

Once students have chosen their cards, proceed with questions that correspond to the categories. *Make notes of those NOT chosen by student and what order student chooses to discuss them in.

\begin{tabular}{|l|l|}
\hline Question & Category \\
\hline $\begin{array}{l}\text { How does your family help you be successful? } \\
\text { How do you think your parents view your education? } \\
\quad+\text { Do you talk about your educational goals with them? }\end{array}$ & Family: supportive (+) \\
\hline $\begin{array}{l}\text { How do friends help you be successful? } \\
\text { Can you describe the relationships you have with friends? } \\
\text { Can you describe the support they provide you? } \\
\text { +how did you form these relationships? }\end{array}$ & $\begin{array}{l}\text { Social Support: } \\
\text { supportive }(+) \\
\text { (friends) }\end{array}$ \\
\hline $\begin{array}{l}\text { How do classmates help you be successful? } \\
\text { Can you describe the relationship you have with classmates? } \\
\text { Can you describe the support they provide you? }\end{array}$ & $\begin{array}{l}\text { Social Support: } \\
\text { supportive }(+)\end{array}$ \\
\hline
\end{tabular}




\begin{tabular}{|c|c|}
\hline +how did you form these relationships? & \\
\hline $\begin{array}{l}\text { How do faculty help you be successful? } \\
\text { Can you describe the relationship you have with faculty? } \\
\text { Can you describe the support they provide you? } \\
\text { +how did you form these relationships? }\end{array}$ & $\begin{array}{l}\text { Social Support: } \\
\text { supportive }(+) \\
\text { faculty }\end{array}$ \\
\hline $\begin{array}{l}\text { How do mentors help you be successful? } \\
\text { Can you describe the relationship you have with mentors? } \\
\text { Can you describe the support they provide you? } \\
\text { +how did you form these relationships? }\end{array}$ & $\begin{array}{l}\text { Social Support: } \\
\text { supportive }(+) \\
\text { Non-faculty mentors }\end{array}$ \\
\hline $\begin{array}{l}\text { How do you think working while attending school helps you be } \\
\text { successful? } \\
\text { How do you successfully balance work and school? }\end{array}$ & Work: supportive $(+)$ \\
\hline $\begin{array}{l}\text { What type of program do you use or participate in? } \\
\text { How do you think your involvement in this program helps you } \\
\text { be successful? } \\
\text { What specifically about this program helps you? }\end{array}$ & $\begin{array}{l}\text { Involvement: } \\
\text { supportive }(+) \\
\text { Academic support } \\
\text { programs }\end{array}$ \\
\hline $\begin{array}{l}\text { What type of program do you use or participate in? } \\
\text { How do you think your involvement in this program helps you } \\
\text { be successful? } \\
\text { What specifically about this program helps you? }\end{array}$ & $\begin{array}{l}\text { Involvement: } \\
\text { supportive }(+) \\
\text { Mentoring }\end{array}$ \\
\hline $\begin{array}{l}\text { What type of club/organization do you use or participate in? } \\
\text { How do you think your involvement in this club/organization } \\
\text { helps you be successful? } \\
\text { What specifically about this club/organization helps you? }\end{array}$ & $\begin{array}{l}\text { Involvement: } \\
\text { supportive }(+) \\
\text { On-Campus } \\
\text { Clubs/Organizations }\end{array}$ \\
\hline $\begin{array}{l}\text { What type of organization do you use or participate in? } \\
\text { How do you think your involvement in this organization helps } \\
\text { you be successful? }\end{array}$ & $\begin{array}{l}\text { Involvement: } \\
\text { supportive }(+) \\
\text { Off-campus } \\
\text { organizations }\end{array}$ \\
\hline
\end{tabular}




\begin{tabular}{|l|l|}
\hline What specifically about this organization helps you? & \\
\hline $\begin{array}{l}\text { What about BBCC campus helps you be successful? } \\
\text { How do you feel when you're on campus? }\end{array}$ & $\begin{array}{l}\text { Campus Context: } \\
\text { supportive }(+)\end{array}$ \\
\hline $\begin{array}{l}\text { How did your high school experience help in college? } \\
\text { +Did you feel prepared?*only probe if chosen as top ranking }\end{array}$ & $\begin{array}{l}\text { High School } \\
\text { Preparation: }(+)\end{array}$ \\
\hline $\begin{array}{l}\text { What were your expectations for college? } \\
\text { +Did you always think you would go to college?*only probe if } \\
\text { this is top ranking } \\
\text { +Where did you think you would go to college? } \\
\text { +What did your parents expect you would do? } \\
\text { How do you think this has helped you be successful? }\end{array}$ & $\begin{array}{l}\text { College Expectations } \\
(+)\end{array}$ \\
\hline
\end{tabular}

\section{Barriers to Persistence}

Students are given cards reflecting the categories in the left-hand column.

Thank you for sharing with me what has helped you be successful. Many students say that they've had to overcome some challenges or barriers to be successful. Here are some things that others have talked about, do any of these fit for you? Take some time and think about which ones you'd like to talk about.

Once students have chosen their cards, proceed with questions that correspond to the categories. *Make notes of those NOT chosen by student and what order student chooses to discuss them in.

\begin{tabular}{|l|l|}
\hline Question & Category \\
\hline $\begin{array}{l}\text { Tell me about some of your challenges with family. } \\
\text { How hav this affected your success? } \\
\text { +Are you living at home with your family right now? }\end{array}$ & Family: challenges (-) \\
\hline $\begin{array}{l}\text { How did friends make it more challenging for you to be } \\
\text { successful? } \\
\text { +Do you still keep in contact with these people? }\end{array}$ & $\begin{array}{l}\text { Social Support: } \\
\text { challenges (-) } \\
\text { Friends }\end{array}$ \\
\hline How did classmates make it more challenging for you to be & \begin{tabular}{l} 
Social Support: \\
\hline
\end{tabular}
\end{tabular}




\begin{tabular}{|c|c|}
\hline $\begin{array}{l}\text { successful? } \\
\text { +Do you still keep in contact with these people? }\end{array}$ & $\begin{array}{l}\text { challenges (-) } \\
\text { Classmates }\end{array}$ \\
\hline $\begin{array}{l}\text { How did faculty make it more challenging for you to be } \\
\text { successful? } \\
\text { +Do you still keep in contact with these people? }\end{array}$ & $\begin{array}{l}\text { Social Support: } \\
\text { challenges (-) } \\
\text { Faculty }\end{array}$ \\
\hline $\begin{array}{l}\text { How did non-faculty mentors make it more challenging for you } \\
\text { to be successful? } \\
\text { +Do you still keep in contact with these people? }\end{array}$ & $\begin{array}{l}\text { Social Support: } \\
\text { challenges (-) } \\
\text { Non-faculty mentors }\end{array}$ \\
\hline $\begin{array}{l}\text { How has working made it more challenging for you to be } \\
\text { successful? } \\
\text { How have you tried balancing work and school? * only if they } \\
\text { didn't answer in previous section } \\
\text { Why are you working? } \\
\text { Would you say you identify more as being a worker or being a } \\
\text { student? Or some of both? }\end{array}$ & Work: challenge (-) \\
\hline $\begin{array}{l}\text { What types of groups are you involved in? } \\
\text { How has your involvement made it more challenging to be } \\
\text { successful? } \\
\text { +Why? }\end{array}$ & $\begin{array}{l}\text { Involvement: } \\
\text { challenges (-) } \\
\text { On-campus } \\
\text { clubs/organizations }\end{array}$ \\
\hline $\begin{array}{l}\text { What types of groups are you involved in? } \\
\text { How has your involvement made it more challenging to be } \\
\text { successful? } \\
\text { +Why? }\end{array}$ & $\begin{array}{l}\text { Involvement: } \\
\text { challenges (-) } \\
\text { Off-campus } \\
\text { organizations }\end{array}$ \\
\hline $\begin{array}{l}\text { What about the campus has made it more challenging for you to } \\
\text { be successful? } \\
\text { How do you feel when you're on campus? } \\
\text { +How do you think this affects your success? }\end{array}$ & $\begin{array}{l}\text { Campus Context: } \\
\text { challenges (-) }\end{array}$ \\
\hline
\end{tabular}




\begin{tabular}{|l|l|}
\hline $\begin{array}{l}\text { How did your high school experience make it more difficult for } \\
\text { you to be successful? }\end{array}$ & $\begin{array}{l}\text { High School } \\
\text { Preparation (-) }\end{array}$ \\
\hline $\begin{array}{l}\text { How did your college expectations make it more difficult for you } \\
\text { to be successful? }\end{array}$ & $\begin{array}{l}\text { College Expectations } \\
(-)\end{array}$ \\
\hline
\end{tabular}

\section{Identity}

Thank you for sharing some of the challenges you've faced. Everyone is very different, for some students it matter a lot that where they go to school fits who they are. For others, it doesn't really matter at all. And others fit somewhere in between. So, think about who you are.

How does Small Town fit who you are? Has it been good? Could it have been better?

+That is interesting...tell me more about

What you described sound similar to some experiences of others. Here are some examples of what you've described, and some others that may or may not fit. (Give chance to look at cards and write any others on blank cards that are missing). Which one(s) would you like to talk about first?

* Students are given cards reflecting different identities. Allow students to choose as many as they see fit, but focus on the theoretical categories of interest. (race, gender, ethnicity).

\begin{tabular}{|l|l|}
\hline Question & Identity Category \\
\hline As a male/female... what pressures or challenges have you faced & $\begin{array}{l}\text { Male/Female } \\
\text { (Gender) }\end{array}$ \\
+at school & \\
+ in your community & \\
+ tell me a story about... & \\
Being a male/female, how do you think this has helped you be \\
more successful in school? & \\
\hline As a Latino/a (etc.)...what pressures or challenges have you & $\begin{array}{l}\text { Latina/o, Chicano/a, } \\
\text { Hispanic, Mexican, }\end{array}$ \\
\hline
\end{tabular}




\begin{tabular}{|c|c|}
\hline $\begin{array}{l}\text { faced at school? } \\
\text { +in your community? } \\
\text { +tell me a story about... } \\
\text { As a Latino/a (etc.)...how do you think cultural values } \\
\text { influenced your experience as a college student? }\end{array}$ & $\begin{array}{l}\text { Mexican-American } \\
\text { (Ethnicity) }\end{array}$ \\
\hline $\begin{array}{l}\text { Being bicultural... how have you balanced two cultures? } \\
\text { What are some of the challenges you face? } \\
\text { How have you been successful? }\end{array}$ & Bicultural (Ethnicity) \\
\hline $\begin{array}{l}\text { As a white (etc.) person... what pressures have you faced at } \\
\text { school? } \\
\text { +in your community } \\
\text { How would you say your cultural values influenced your } \\
\text { experience as a college student? }\end{array}$ & $\begin{array}{l}\text { White, Anglo, } \\
\text { European American } \\
\text { (Race) }\end{array}$ \\
\hline $\begin{array}{l}\text { As a _ (sister, brother, mother, father)...what challenges } \\
\text { have you faced balancing school and family needs or duties? } \\
\text { How have you balanced this successfully?*if not answered } \\
\text { previously } \\
\text { +what hasn't worked? } \\
\text { +what would make it easier? }\end{array}$ & $\begin{array}{l}\text { Family Member: } \\
\text { gender role }\end{array}$ \\
\hline
\end{tabular}

6. Knowing what you know now about successfully completing your community college degree, imagine what you would do differently if starting all over again.

+what about overcoming challenges?

7. If you could give one piece of advice to an incoming freshman at STCC, what would you say?

8. Is there anything else you would like to add? 


\title{
APPENDIX B
}

\author{
Code Book
}

100 Reason for Attending

110 Close to home

120 Low cost

130 Outreach

140 Prep for university

150 Smaller

200S Family Supportive

210S Having college expectations

211S Immigration for opportunity

212S Communicating goals

213 S Do the best you can (in vivo)

220S Providing support and encouragement

221S Providing discipline

222S Helping with academics

223S Support from sibs (siblings)

224S Advocating

225S Support from spouse

226S Providing space

230S Providing advice

231S Family familiar with college culture

232S Helping plan education

240S Helping financially

241S Finding scholarships

242S Help with babysitting

250S Motivating

251S Being a role model

252S Making family proud

253S Community/family uplift

254S Making family proud

200C Family challenge

210C Not meeting expectations

$211 \mathrm{C}$ "their degree" vs. "my degree" (in vivo)

212C Cutting ties

213C Comparing to sibs (siblings)

220C Needing to support family

221C Family lacking resources

222C Family work injury/illness

230C Gendered limitations

231C Fulfilling duties, caring for others 
232C No time for homework

233C Cultural values

240C Parents not educated

241C Feeling embarrassed of parents

242C Parents succeeded w/o degree

243C Don't understand commitment

250C Mixed messages

251C Education is important, money is tight

$252 \mathrm{C}$ Need to help family

260C Parents communicating infrequently

261C Don't praise success

262C Lack of involvement

270C Living situation

271C No place to study

272C Stress of family situations

280C Parents/family unsupportive

300S Peers supportive

310S Forming relationships

311S Friends from HS help in college

312S Being a leader, being outgoing

313S Finding smart students

314S Sharing struggles

315S Taking classes together

320S Helping academically

321S Preventing failure

322S Study groups, better studying

$323 \mathrm{~S}$ Remembering and understanding material

324S Keeping focus

325S Discussing course and faculty

330S Understanding people, personalities and groups

340S Having a support network

341S Friends like family

342S Developing identity, finding direction

343S Helping out, pushing each other

300C Peers challenge

$310 \mathrm{C}$ Being more successful

320C Bad influences at college

330C Pressure to drop out

$340 \mathrm{C}$ Working with other students

400S Mentoring supportive

410S Forming relationships

411S Seeking older people 
412S Asking questions, being proactive

413S Sharing struggles

414S Outreach

420S Advocating for students

430S Being "there" for students

440S Dealing w/ life's dragons (in vivo)

450S Developing new identity

460S Holding accountable

470S Motivating, caring about success

480S Sharing knowledge, resources, experiences

481S Scheduling/advising

482S Connecting school and home

483S Walking through expectations

490S Types of mentors

491S Community/religious mentors

492S Counselors

493S Faculty

494S Family

495S Mentors for parents

496S Peers

500S Faculty supportive

510S Wanting success for students

520S Being "there" for students

521S Providing advice, resources

522S Mentoring

523S Being flexible

524S Advocating for students

525S Answering questions

530S Forming relationships with faculty

531S Being proactive

532S Choosing instructors, taking same instructors

533S Sharing interests

534S TRiO connection

535S Knowing through outreach

536S Connection to family

540S Administrative help

500C Faculty challenge

510C Poor advising

520C Reason for dropping out

530C Not knowing expectations

531C Changing expectations

540C Negative attitudes

550C Not understanding student issues 
551C Being inflexible

552C Being distant

560C Treating students differently

561C Experiencing prejudice

562C Experiencing sexism

600C Financial issues

610C Financial aid issues

611C Maxing out aid

612C Not understanding fin. Aid process

620C Family lacking money/resources

$621 \mathrm{C}$ Needing to work hurts success

622C Pressure for scholarships

630S Using financial aid

631S Grants helpful

632S Help from scholarships

700S Work supportive

710 S Learning work ethic

720 S Wanting something different

730S Working identity: students

731S Prioritizing school

732S Flexible employer

700C Work challenge

710C Time commitment

$711 \mathrm{C}$ Overscheduling

712C Exhausting, can't focus

713C Spending time with family

$714 \mathrm{C}$ Prioritizing hard

720C Reason for working

721C School expenses

722C Transportation

723C Spending money

724C Family needs

725C Wanting experience

726C Living expenses

730C Working identity: worker

$731 \mathrm{C}$ Prioritizing work, loving job

800C Balancing work, school, family

$810 \mathrm{C}$ Choosing family and friends

$820 \mathrm{C}$ Stressful

800S Balancing work, school, family

810S Staying home 
820S Support from outside family

830S Studying on campus

840S Planning and scheduling

850 S Understanding/supportive family

860S Learning is more focused

870S Asking for flexible work schedule

900S On-Campus Clubs/Orgs/Programs supportive

910S Access to resources

920S Advising

930S De-stressing

940S Easy to access, approachable

950S Helping deal with life (mentoring)

960S Helping others, passing it on (in vivo)

970S Sharing experiences, building relationships

980S Tutoring

990S Types

991S College success skills 992S MEChA

993S Phi Theta Kappa (Honor Society)

994S Shared interests clubs 995S Student Success Center

996S Supplemental Instruction (SI)

997S TRiO

900C On Campus Clubs/Orgs/Programs challenge

910C Lack of programming for Veterans

920C Lacking knowledge of support programs

930C Needing to use sooner

1000S Campus context supportive

1010S Feeling like family, being known

1011S Feeling safe

1012S Diversity

1013S Small campus

1020S Preparation for university

1030S Having resources

1031S Library resources

1032S Career center

1033S Online classes

1034S Labs (Eng. and Math)

1040S Low cost

1050S Avoiding home

1060S Adapting to students, wanting success

1000C Campus context challenge 
1010C Excluding others

1020C Lacking support, resources

1030C Racial divide

1040C Too small, rural

1050C Commuting distance to campus

1060C Doesn't fit me (in vivo)

1100S Pre-College preparation supportive

1110S Gaining confidence

1120S Earning credit, money for college

1130S Planning for college

1140 S Mentoring

1150S Recognizing ability, pushing

1160S Types of supports

1161S Upward Bound, GEAR UP (TRiO)

1162S HS Teachers/Counselors

$1163 \mathrm{~S}$ Sports

1164S Honors classes, advanced courses

1165S MEChA

$1100 \mathrm{C}$ Pre-College preparation challenge

1110C Lacking HS academic preparation

1120C Lacking confidence

$1130 \mathrm{C}$ Not fitting in

$1140 \mathrm{C}$ Not knowing expectations/resources

1150C Too much pressure

$1160 \mathrm{C}$ Having no direction

$1170 \mathrm{C}$ Not knowing learning style

1180C Dropping out and returning

1200 Identity

1210 Being male

1211C Teachers expecting failure

1212C Expectation to work

1213C Machismo (in vivo)

1214S Changing expectations

1215S Taking initiative

1215S Having it easier

1220 Being female

$1221 \mathrm{C}$ Guys are crude (in vivo)

$1222 \mathrm{C}$ Competition among girls

1223C Fulfilling gender roles

1224C Lacking confidence

1225S Gaining confidence

1226S Breaking barriers 
1227S Becoming self-sufficient

1230 Being Latino/a, Mexican, Mex. American, Hispanic

1231C Parents lacking education

1232C Being stereotyped, experiencing racism

1233C Learning English, lacking confidence

1234C Questioning self

1235S Community uplift

1236 S Proving them wrong (in vivo)

1237S Feeling equal

1238S Connecting with others on campus

1239S Working hard, overcoming challenges

1240 Being Bicultural

1241C Mixed between two worlds (in vivo)

1242C Becoming Americanized

1243S Keeping values, using tools

1244S Being humble, coming from nothing

1245S Being accepting, open

1250 Being White, Anglo, European American

1251C Reverse discrimination at college

$1252 \mathrm{C}$ Focus on race, differences

$1253 \mathrm{C}$ Feeling excluded

1254S Individual culture, self-determination

$1255 \mathrm{~S}$ Treat everyone with respect

$1256 \mathrm{~S}$ Race not mattering, not seeing differences

1257S Valuing diversity

1260 Being a mother

1261C Struggling financially

1262C Lacking childcare, poor childcare

1263C Shifting gender roles, feeling limited

1264 S Being a role model

1270 Being a father

$1271 \mathrm{C}$ Spending time with family

1272 S Being a role model

1280 Being a sister, daughter

$1281 \mathrm{C}$ Balancing mothering/care-giving duties

1282C Loosing childhood

1283C Fighting with parents, rebelling

1284 S Being a role model

$1285 \mathrm{~S}$ Learning responsibility

1286S Finding support from sibs

1290 Being a brother, son

$1291 \mathrm{C}$ Not making everyone happy (in vivo)

1292S Sharing experiences with sibs

$1293 \mathrm{~S}$ Few expectations at home

1294S Honoring family name 
1295S Staying in contact with family

1300 Giving advice

1310 Have direction and goals, ganas

1320 Focus more on academics

1330 Get and seek help, ask questions

1340 Work less

1350 Be more involved, develop relationships

1360 Relax, have fun, don't stress

1400 Other

$1410 \mathrm{C}$ Self as challenge, lacking self-discipline

1420C Life event

$1421 \mathrm{C}$ Injury at work

1430C Home community issues

1431C Not feeling safe

1432C Doubting community members

1433C Community involvement time consuming

1440S Individual Effort, self-determined

Good Quote

Strong negative emotion

Strong positive emotion 


\section{APPENDIX C}

\section{Methodological Reflections}

I was mindful going into the interviews that students may feel awkward about discussing racism or experiences of prejudice with white people. Most knew that I had married into a Latino family, but all were careful at first when discussing race and racism. Raymond was the first to give me what I call the "right" answer to the question of whether he had faced pressures being a Mexican American. He discussed feeling privileged, that he shouldn't complain and be grateful for what he has. Maybe he really did feel this way, but his body language told me he was guarded. I knew that I had to make an effort to build trust. I paused and told him that I want him to feel comfortable sharing anything; I am not offended by anything, no judgments. After doing so, I remember his body language changed, he dropped his shoulders and shared his stories of being called racial slurs and derogatory terms. This happened with just about every participant I interviewed. They would start to say, something like..."I don't want to say anything bad about white people, but..." then I would interject encouraging them to share. They would and their body language usually changed. In one of my memos I remember reflecting upon this and wondering what impact this had, or if it did. I wonder how many students have the opportunity to share their experiences of racism or prejudice with white people. In this area I'm guessing not many. After conducting the interviews, many of the students thanked me, and shared that it felt good to get these things off their chest. At times these conversations started awkwardly, but I feel they were well worth the effort. I was saddened to hear that not much as changed in some of these communities. Unfortunately progress is slow.

One of the unexpected experiences of doing this research was the intense emotion that came across in the interviews that I conducted. I was surprised at first by students' responses. Many of the students cried or their eyes welled up when discussing how their family had helped them or how they will be the first in their family to earn a degree. The path towards earning their degree was almost a quest for dignity and fulfillment for themselves and their family. It was not just a pathway to economic mobility. Some students also shared stories with me of loss and painful past experiences, some of which will not be shared in this project per their request. As a researcher it is difficult to maintain distance while at the same time, sharing in their human experience. I wanted to let them share their stories without my interruption or interpretation. During some interviews, I wanted to stop and tell them how amazing I thought they were. It was hard to refrain from doing so. After the interviews were over I did communicate my admiration for their accomplishments and would congratulate them on their successes. Sometimes they would ask me about my experiences afterwards or having children and being a student myself. The unrecorded conversations after the interview can sometimes be just as valuable to the process of "gathering data." I think it can remind the researcher that these are "human subjects" and people's voices should come through when retelling their stories. 